NUREG/CR-6181, Rev. 1

PNNL-9020, Rev. 1

\title{
A Pilot Application of \\ Risk-Informed Methods to \\ Establish Inservice Inspection \\ Priorities for Nuclear \\ Components at Surry Unit 1 \\ Nuclear Power Station
}

Manuscript Completed: February 1997

Date Published: February 1997

Prepared by

T. V. Vo, H. K. Phan, B. F. Gore, F. A. Simonen, S. R. Doctor

Pacific Northwest National Laboratory

Richland, WA 99352

J. Muscara, NRC Project Manager

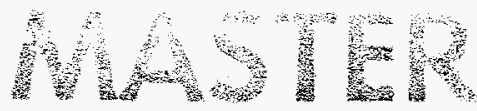

Prepared for

Division of Engineering Technology

Office of Nuclear Regulatory Research

U.S. Nuclear Regulatory Commission

Washington, DC 20555-0001

NRC Job Code B2289 


\section{DISCLAIMER}

Portions of this document may be illegible in electronic image products. Images are produced from the best available original document. 


\section{DISCLAIMER}

This report was prepared as an account of work sponsored by an agency of the United States Government. Neither the United States Government nor any agency thereof, nor any of their employees, make any warranty, express or implied, or assumes any legal liability or responsibility for the accuracy, completeness, or usefulness of any information, apparatus, product, or process disclosed, or represents that its use would not infringe privately owned rights. Reference herein to any specific commercial product, process, or service by trade name, trademark, manufacturer, or otherwise does not necessarily constitute or imply its endorsement, recommendation, or favoring by the United States Government or any agency thereof. The views and opinions of authors expressed herein do not necessarily state or reflect those of the United States Government or any agency thereof. 


\begin{abstract}
As part of the Nondestructive Evaluation Reliability Program sponsored by the U.S. Nuclear Regulatory Commission, the Pacific Northwest National Laboratory has developed risk-informed approaches for inservice inspection plans of nuclear power plants. This method uses probabilistic risk assessment (PRA) results to identify and prioritize the most risk-important components for inspection. The Surry Nuclear Power Station Unit 1 was selected for pilot application of this methodology. This report, which incorporates more recent plant-specific information and improved risk-informed methodology and tools, is Revision 1 of the earlier report (NUREG/CR-6181). The methodology discussed in the original report is no longer current and a preferred methodology is presented in this Revision. This report, NUREG/CR-6181, Rev. 1, therefore supersedes the earlier NUREG/CR-6181 published in August 1994. The specific systems addressed in this report are the auxiliary feedwater, the low-pressure injection, and the reactor coolant systems. The results provide a risk-informed ranking of components within these systems.
\end{abstract}





\section{Contents}

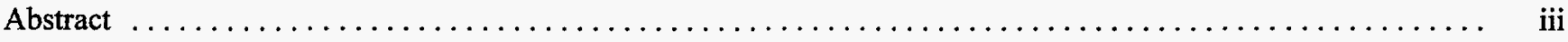

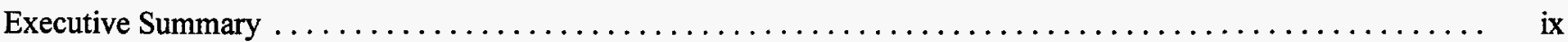

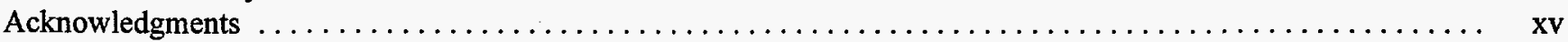

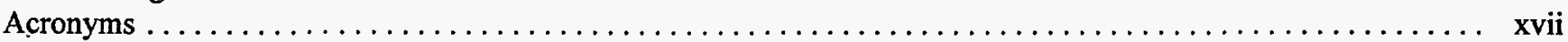

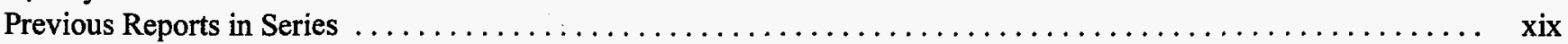

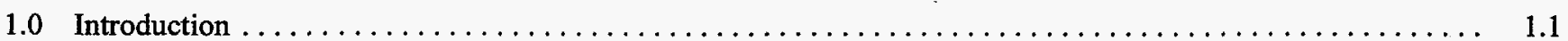

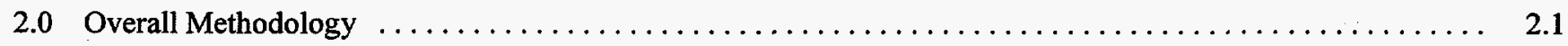

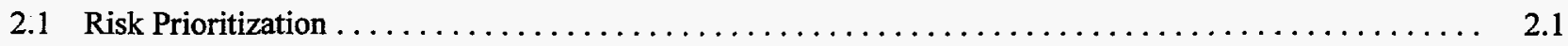

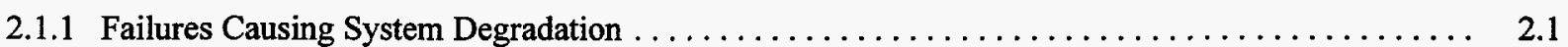

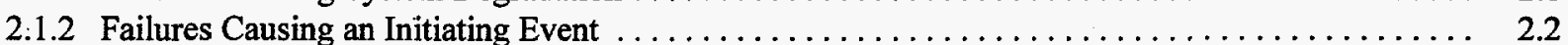

2.1.3 Failures Causing System Degradation and an Initiating Event $\ldots \ldots \ldots \ldots \ldots \ldots$

2.1.4 Pipe Segment Contribution to Core Damage Frequency $\ldots \ldots \ldots \ldots \ldots$

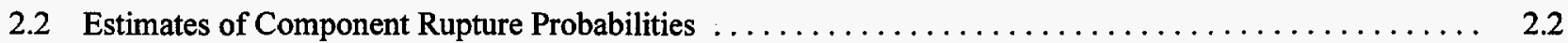

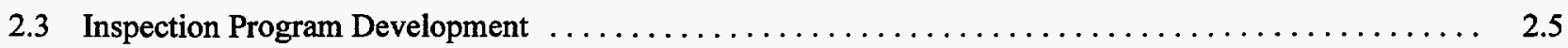

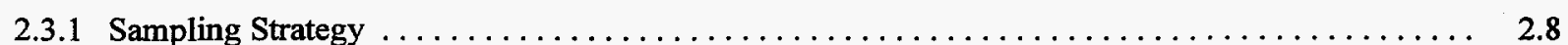

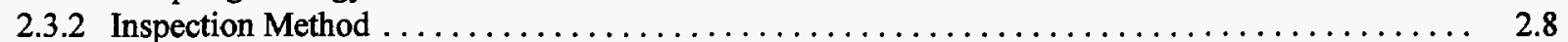

2.3.3 NDE Reliability and Performance Demonstration $\ldots \ldots \ldots \ldots \ldots \ldots \ldots$

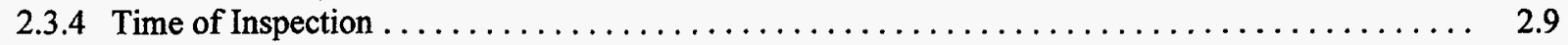

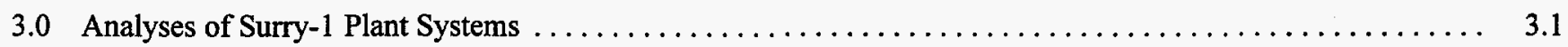

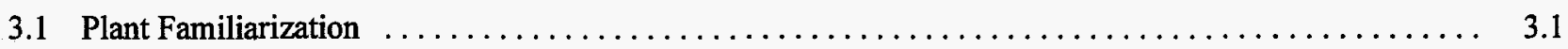

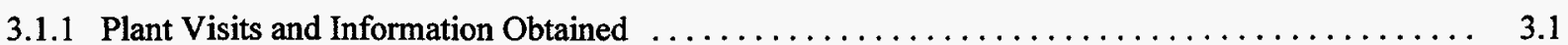

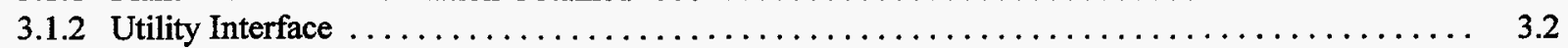

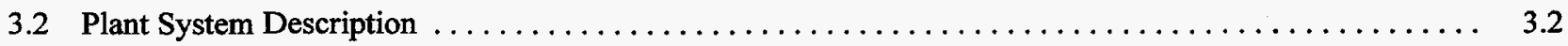

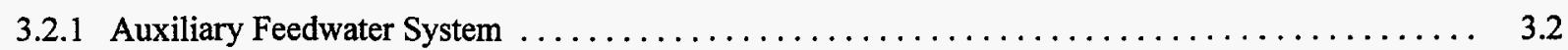

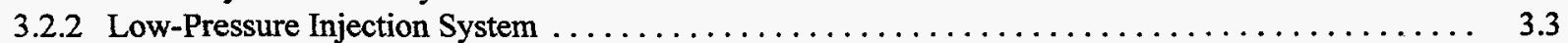

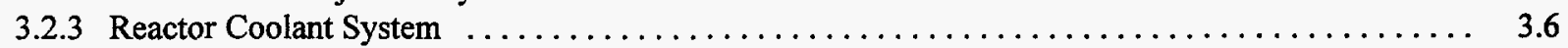

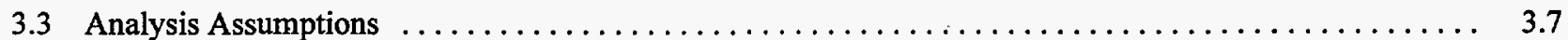

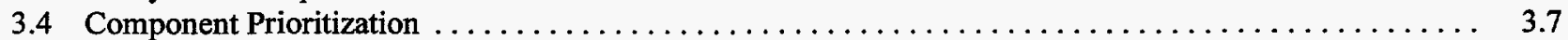

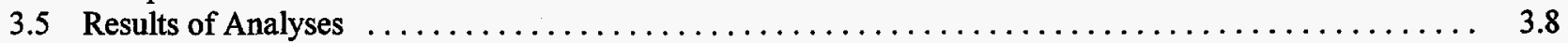

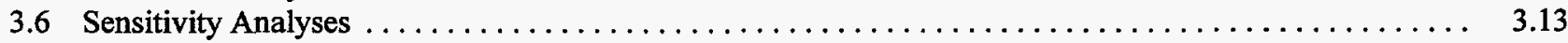

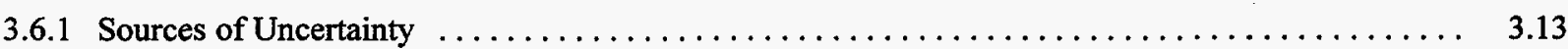

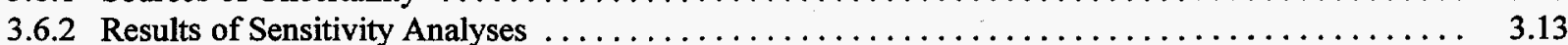


Contents

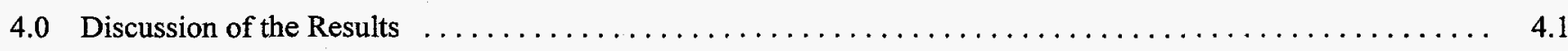

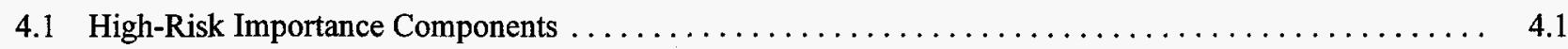

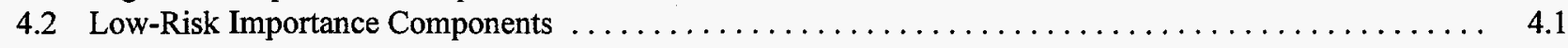

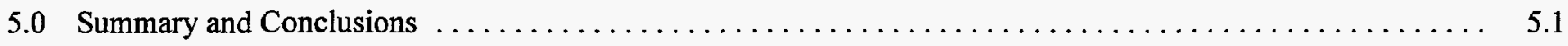

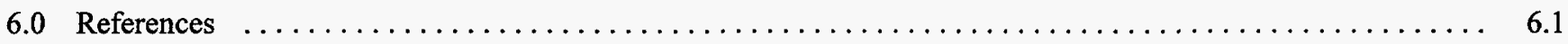

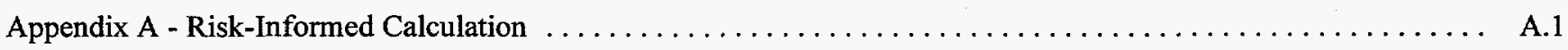

Appendix B - Review of the Risk Importance Approaches Which have been Developed by Pacific

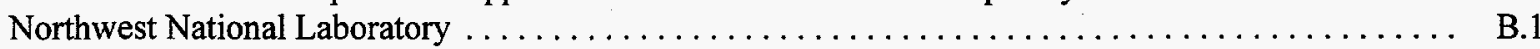




\section{Figures}

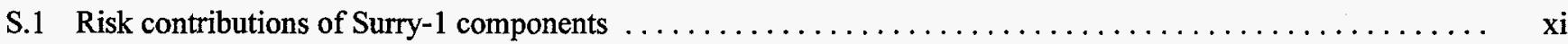

S.2 Cumulative risk contributions of Surry-1 components $\ldots \ldots \ldots \ldots \ldots \ldots \ldots \ldots \ldots \ldots \ldots \ldots \ldots \ldots \ldots \ldots$

2.1 Information provided to the participants in the expert judgment elicitation $\ldots \ldots \ldots \ldots \ldots \ldots \ldots \ldots \ldots \ldots$

2.2 Estimates of rupture probabilities for Surry- 1 auxiliary feedwater system components from expert judgment elicitation $\ldots \ldots \ldots \ldots \ldots \ldots \ldots \ldots \ldots \ldots \ldots \ldots \ldots \ldots \ldots \ldots \ldots \ldots \ldots \ldots \ldots \ldots \ldots \ldots, 2.6$

2.3 Estimates of rupture probabilities for Surry-1 low pressure injection system components from expert

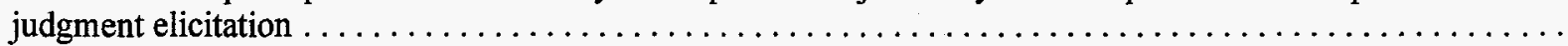

2.4 Estimates of rupture probabilities for Surry-1 reactor coolant system components from expert

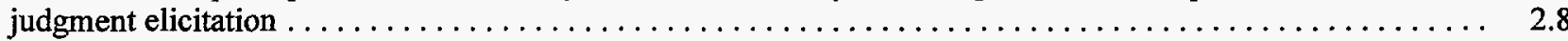

3.1 Surry-1 auxiliary feedwater system simplified schematic $\ldots \ldots \ldots \ldots \ldots \ldots \ldots \ldots \ldots \ldots \ldots \ldots \ldots \ldots \ldots$

3.2 Surry-1 low-pressure injection/recirculation system simplified schematic $\ldots \ldots \ldots \ldots \ldots \ldots \ldots \ldots \ldots \ldots . .5$

3.3 Surry-1 reactor coolant system simplified schematic $\ldots \ldots \ldots \ldots \ldots \ldots \ldots \ldots \ldots \ldots \ldots \ldots \ldots \ldots \ldots$

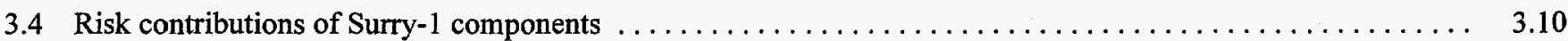

3.5 Cumulative risk contributions for Surry-1 components $\ldots \ldots \ldots \ldots \ldots \ldots \ldots \ldots \ldots \ldots \ldots \ldots \ldots \ldots \ldots \ldots \ldots$

\section{Tables}

S.1 Risk importance for components of selected systems at Surry $1 \ldots \ldots \ldots \ldots \ldots \ldots \ldots \ldots \ldots \ldots \ldots \ldots \ldots \ldots \ldots \ldots$

3.1 Component rankings based on core damage frequency for three selected systems at Surry-1 $\ldots \ldots \ldots \ldots \ldots$

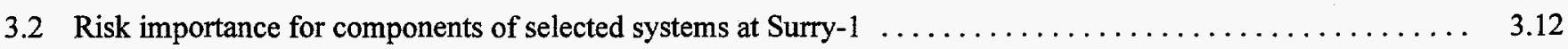

4.1 Component importance ranking compared with ASME BPVC Section XI classifications and ISI requirements for selected systems at Surry-1 



\section{Executive Summary}

As part of the Evaluation and Improvement of Nondestructive Evaluation (NDE) Reliability for Inservice Inspection of Light Water Reactors Program sponsored by the U.S. Nuclear Regulatory Commission (NRC), the Pacific Northwest National Laboratory (PNNL) has developed and applied a method using risk-informed techniques for inservice inspection (ISI) plans of nuclear power plants. As described in this report, the method uses probabilities of component failures (estimated by using an expert judgment elicitation process) and plant-specific probabilistic risk assessment (PRA) results to identify ISI priorities for components. This report is a revision of the earlier report (NUREG/CR-6181), which incorporates recent plant-specific information and improved risk-informed calculational tools. Since this report, NUREG/CR-6181, Rev. 1, provides a preferred methodology, it supersedes the earlier NUREG/CR-6181 report published in August 1994.

The Surry Nuclear Power Station Unit 1 (Surry-1) was selected for demonstrating the risk-informed methodology. The specific systems addressed in this report are the auxiliary feedwater, low-pressure injection, and the reactor coolant systems. Worksheets to guide the analyses were initially formulated using plant system drawings and other plant-specific information. The Standard Review Plan information developed by the NRC was used in determining the effects of system and component failures. To ensure that the plant models were as realistic as possible, visits at the Surry-1 plant were conducted for plant system walkdowns and discussions were held with plant operational and technical staff. Participation of Virginia Electric Power Company staff was an essential part of the pilot study.

Because of similarities in objectives, the PNNL program task related to risk-informed methodology for ISI was coordinated with the activity of the American Society of Mechanical Engineers (ASME) Research Task Force on Risk-Based Inspection Guidelines. This Task Force has made general recommendations on the application of risk-informed methods to inservice inspection and will make specific proposals to ASME for improved codes and standards. Results of PNNL studies have been made available to the ASME Research Task Force to demonstrate and validate the usefulness of the risk-based concepts.

The results of the risk-informed component prioritization (for the systems identified above) for Surry-1 are summarized in Figure S.1. Table S.1 shows the risk importance for Surry-1 components. Included in this table are the estimated rupture probabilities for the components of the systems analyzed. The estimated component rupture probabilities were based on expert judgment elicitation as described in Vo et al. $(1993,1991,1990)$. These component rupture probabilities were based on a number of assumptions including the benefits of ISI activities and the periodic testing of components.

On the basis of core damage frequency, the calculated contributions of component failures to core damage frequency range from about $1.0 \mathrm{E}-12$ to $6.0 \mathrm{E}-06$ per plant year. The cumulative risk contribution for all of the components considered was estimated to be about 1.8E-05 per plant year. Figure S.2 shows the results of cumulative risk contribution for Surry-1 components within the systems analyzed. The total estimated risk is dominated by failures of the auxiliary feedwater system components ( $60 \%$ of the total estimated risk). This risk is followed by the low-pressure injection system components (39\%), and then other various components within the reactor coolant system (1\%).

Sensitivity analyses were performed to address the changes in component rankings using the upper/lower estimates of component rupture probabilities. The results indicated no significant changes in component risk contribution rankings (as shown in Figure S.1). Sensitivity analyses were also performed to determine the core damage frequency contribution due to component failures by indirect effects (pipe whip, jet impingement effects, etc.). The results indicate that contributions from the indirect effects were negligible. 
Executive Summary

Included in the report is a comparison of the risk-informed inspection priorities from this study with the current Surry-1 plant ISI practices. ASME classifications and ISI requirements are only in partial agreement with the risk-informed rankings based on core damage frequency. The components with the greatest contribution to the core damage frequency should have the more stringent ASME inspection requirements (i.e., volumetric or both volumetric and surface examinations), but this study found only six of the twelve components contributing the most to risk (99\%) received the more stringent ASME inspection requirements, and for the other six components contributing the most to risk, only a visual examination is required.

The analysis for the Surry-1 plant could be completed by determining the risk importances of components in the remaining systems (e.g., reactor pressure vessel, high-pressure injection, service water, and balance of plant). Similar plant-specific analyses by other organizations are being performed for other pressurized-water reactors and for boiling-water reactors. Generic trends in component importances can then be established from these plant-specific evaluations. Once the components contributing the most to risk have been identified, recommended inspection programs (method, frequency, and extent) could be developed. Probabilistic structural mechanics can be applied to establish inspection strategies that will ensure that component failure probabilities are maintained at given levels. However, any complete inservice inspection program plan should also consider other additional objectives of ISI including defense-in-depth and the identification of unexpected degradation in operating plants.

The methodology and results of the present work represent a step in the development and refinement of an approach to riskinformed inservice inspection. It is therefore important to note that the present calculations were performed for demonstration purposes, and are considered to be approximate. The results should be interpreted cautiously and should not be used as a basis for actual changes to plant inservice inspection plans.

An independent and more complete Surry risk-informed ISI application is currently being performed by the NRC, ASME, and the Westinghouse Owners Group (WOG). This work utilizes detailed fracture mechanics calculations, the plant-specific IPE evaluation, and up to date plant information. When the results of this work become available, they could be used to validate this study as described in the present report. 
Executive Summary

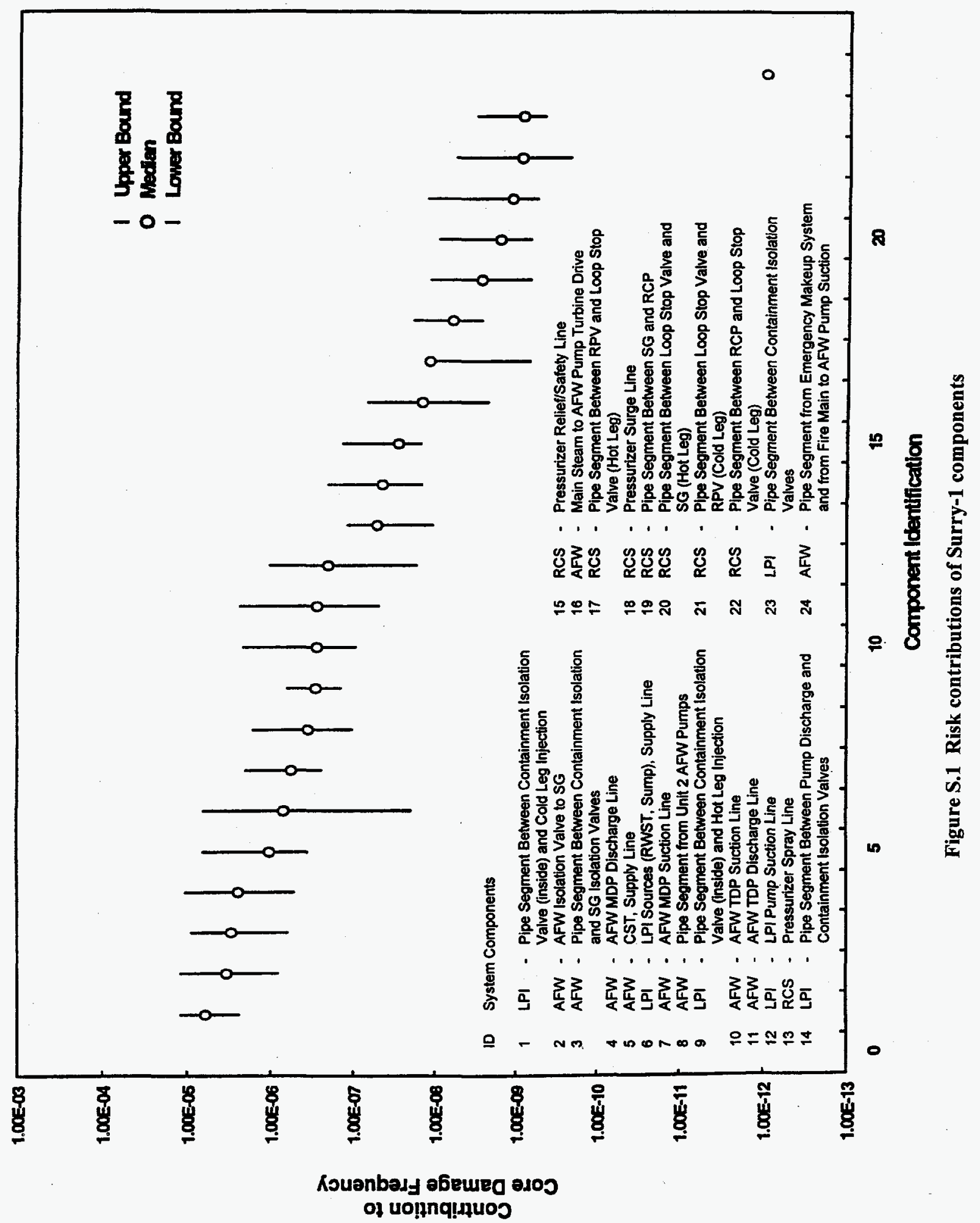




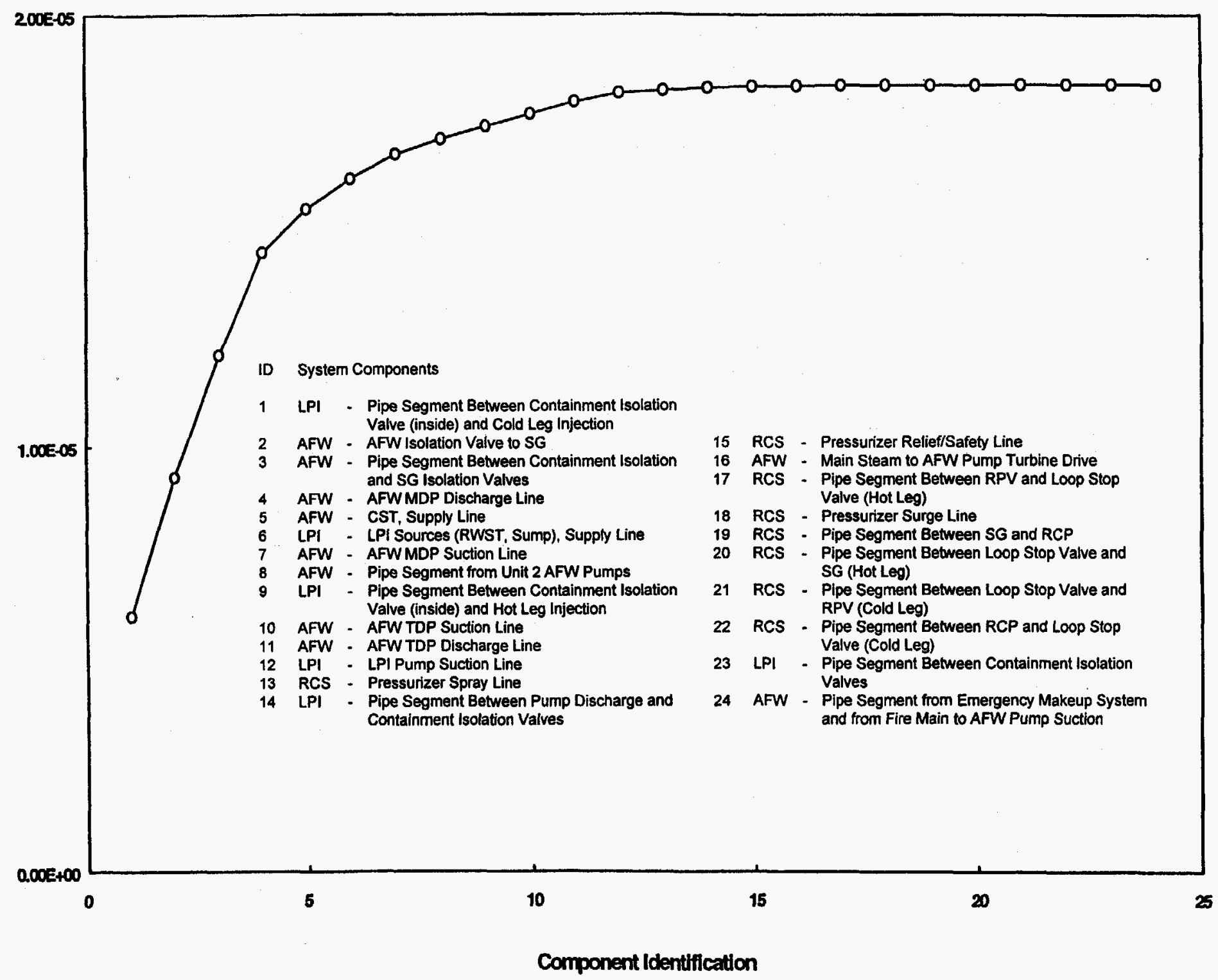

Figure S.2 Cumulative risk contributions for Surry-1 components 
Table S.1 Risk importance for components of selected systems at Surry-1 ${ }^{1}$

\begin{tabular}{|c|c|c|c|}
\hline System component $^{2}$ & Rank & $\begin{array}{l}\text { Rupture } \\
\text { frequency }\end{array}$ & $\begin{array}{c}\text { Core } \\
\text { damage } \\
\text { frequency }\end{array}$ \\
\hline $\begin{array}{l}\text { LPI - Pipe Segment Between Containment Isolation Valve (Inside) and Cold Leg } \\
\text { Injection }\end{array}$ & 1 & $2.65 \mathrm{E}-05$ & $5.96 \mathrm{E}-06$ \\
\hline AFW - AFW Isolation Valve to SG & 2 & 2.33E-04 & $3.31 \mathrm{E}-06$ \\
\hline AFW - Pipe Segment Between Containment Isolation and SG Isolation Valves & 3 & 5.27E-05 & $2.91 \mathrm{E}-06$ \\
\hline AFW - AFW MDP Discharge Line & 4 & 4.33E-05 & $2.39 \mathrm{E}-06$ \\
\hline AFW - CST, Supply Line & 5 & $1.84 \mathrm{E}-05$ & $1.01 \mathrm{E}-06$ \\
\hline LPI - LPI Sources (RWST, Sump), Supply Line & 6 & $2.34 \mathrm{E}-05$ & $6.85 \mathrm{E}-07$ \\
\hline AFW - AFW MDP Suction Line & 7 & $1.01 \mathrm{E}-05$ & $5.60 \mathrm{E}-07$ \\
\hline AFW - Pipe Segment from Unit 2 AFW Pumps & 8 & $3.00 \mathrm{E}-06$ & $3.50 \mathrm{E}-07$ \\
\hline $\begin{array}{l}\text { LPI - Pipe Segment Between Containment Isolation Valve (inside) and Hot Leg } \\
\text { Injection }\end{array}$ & 9 & 1.33E-05 & $2.84 \mathrm{E}-07$ \\
\hline AFW - AFW TDP Suction Line & 10 & $5.03 \mathrm{E}-06$ & 2.78E-07 \\
\hline AFW - AFW TDP Discharge Line & 11 & $5.00 \mathrm{E}-06$ & $2.76 \mathrm{E}-07$ \\
\hline LPI - LPI Pump Suction Line & 12 & $7.65 \mathrm{E}-06$ & 2.02E-07 \\
\hline RCS - Pressurizer Spray Line & 13 & $2.76 \mathrm{E}-05$ & 5.15E-08 \\
\hline LPI - Pipe Segment Between Pump Discharge and Containment Isolation Valves & 14 & $1.29 \mathrm{E}-05$ & $4.51 \mathrm{E}-08$ \\
\hline RCS - Pressurizer Relief/Safety Line & 15 & $8.41 \mathrm{E}-06$ & $2.86 \mathrm{E}-08$ \\
\hline AFW - Main Steam to AFW Pump Turbine Drive & 16 & $1.51 \mathrm{E}-05$ & $1.48 \mathrm{E}-08$ \\
\hline RCS - Pipe Segment Between RPV and Loop Stop Valve (Hot Leg) & 17 & $3.00 \mathrm{E}-06$ & $1.19 \mathrm{E}-08$ \\
\hline RCS - Pressurizer Surge Line & 18 & $1.60 \mathrm{E}-06$ & $6.38 \mathrm{E}-09$ \\
\hline RCS - Pipe Segment Between SG and RCP & 19 & $9.24 \mathrm{E}-07$ & $2.84 \mathrm{E}-09$ \\
\hline RCS - Pipe Segment Between Loop Stop Valve and SG (Hot Leg) & 20 & 4.35E-07 & $1.89 \mathrm{E}-09$ \\
\hline RCS - Pipe Segment Between Loop Stop Valve and RPV (Cold Leg) & 21 & $3.06 \mathrm{E}-07$ & $1.20 \mathrm{E}-09$ \\
\hline RCS - Pipe Segment Between RCP and Loop Stop Valve (Cold Leg) & 22 & $2.45 \mathrm{E}-07$ & $9.31 \mathrm{E}-10$ \\
\hline LPI - Pipe Segment Between Containment Isolation Valves & 23 & $1.83 \mathrm{E}-06$ & $9.00 \mathrm{E}-10$ \\
\hline $\begin{array}{l}\text { AFW - Pipe Segment from Emergency Makeup System and from Fire Main to AFW } \\
\text { Pump Suction }\end{array}$ & 24 & $8.06 \mathrm{E}-06$ & $<1.00 \mathrm{E}-12$ \\
\hline
\end{tabular}

${ }^{1} B$ ased on estimated median values.

${ }^{2} \mathrm{AFW}=$ Auxiliary Feedwater; LPI $=$ Low Pressure Injection; RCS $=$ Reactor Coolant System. 


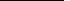




\section{Acknowledgments}

This work was supported by the U.S. Nuclear Regulatory Commission (NRC) under a Related Service Agreement with the U.S. Department of Energy under contract DE-AC06-76RLO 1830. The authors wish to acknowledge the direction and support provided by Dr. Joe Muscara, NRC Program Manager. Dr. L. R. Abramson from the NRC staff provided guidance to the elicitation process. Acknowledgments are also addressed to the many Virginia Electric Power Company staff for their participation in this work, particularly Ms. C. G. Lovett, Mr. R. K. MacManus, Mr. A. McNeill, Mr. D. Rogers, Mr. D. Sommers, and Mr. E. W. Throckmorton. The authors wish to thank Mr. Stephen Minister, PNNL summer student; Mr. Kenneth Balkey and Ms. Nancy Closky of Westinghouse Electric Corporation, and Mr. Raymond Art of ASME, CRTD, for their assistance in performing calculations and technical discussions; and Dr. William Vesely of SAIC, and Dr. Art Buslik of NRC for their contributions and review of this work. 



\section{Acronyms}

\begin{tabular}{|c|c|}
\hline AFW & Auxiliary Feedwater System \\
\hline ASME & American Society of Mechanical Engineers \\
\hline ASTM & American Society of Testing and Materials \\
\hline BPVC & Boiler and Pressure Vessel Code \\
\hline BWR & Boiling Water Reactor \\
\hline $\mathrm{CDF}$ & Core Damage Frequency \\
\hline CST & Condensate Storage Tank \\
\hline FMEA & Failure Modes and Effects Analysis \\
\hline FSAR & Final Safety Analysis Report \\
\hline IPE & Individual Plant Evaluation \\
\hline IRRAS & Integrated Reliability and Risk Analysis System \\
\hline ISI & Inservice Inspection \\
\hline IST & Inservice Testing \\
\hline LOCA & Loss of Coolant Accident \\
\hline LPI & Low-Pressure Injection System \\
\hline LPI/LPR & Low-Pressure Injection/Recirculation System \\
\hline MDP & Motor-Driven Pump \\
\hline MOV & Motor-Operated Valves \\
\hline NDE & Nondestructive Evaluation \\
\hline NRC & U.S. Nuclear Regulatory Commission \\
\hline P\&ID & Piping and Instrumentation Diagram \\
\hline PNNL & Pacific Northwest National Laboratory \\
\hline POD & Probability of Detection \\
\hline
\end{tabular}


PRA

PWR

RAW

RCP

RCS

RHR

RPV

RWST

SAIC

SG

TDP

VEPCO

VIMS

WOG
Probabilistic Risk Assessment

Pressurized Water Reactor

Risk Achievement Worth

Reactor Coolant Pump

Reactor Coolant System

Residual Heat Removal

Reactor Pressure Vessel

Reactor Water Storage Tank

Science Applications International Corporation

Steam Generator

Turbine-Driven Pump

Virginia Electric Power Company

Video Information Management System

Westinghouse Owners Group 


\section{Previous Reports in Series}

Heasler, P. G., S. R. Doctor. 1996. Piping Inspection Round Robin. NUREG/CR-5068, PNNL-10475. Pacific Northwest National Laboratory, Richland, Washington.

Vo, T. V., B. W. Smith, F. A. Simonen, B. F. Gore. 1994. Feasibility of Developing Risk-Based Rankings of Pressure Boundary Systems for Inservice Inspection. NUREG/CR-6151, PNNL-8912. Pacific Northwest Laboratory, Richland, Washington.

Vo, T. V., B. F. Gore, F. A. Simonen, S. R. Doctor. 1994. A Pilot Application of Risk-Based Methods to Establish Inservice Inspection Priorities for Nuclear Components at Surry Unit 1 Nuclear Power Station. NUREG-CR-6181, PNNL-9020. Pacific Northwest Laboratory, Richland, Washington.

Heasler, P. G., T. T. Taylor, S. R. Doctor. 1993. Statistically Based Reevaluation of PISC-II Round Robin Test Data. NUREG/CR-5410, PNNL-8577. Pacific Northwest Laboratory, Richland, Washington.

Doctor, S. R., A. A. Diaz, J. R. Friley, M. S. Greenwood, P. G. Heasler, R. J. Kurtz, F. A. Simonen, J. C. Spanner, T. V. Vo. 1993. Nondestructive Examination (NDE) Reliability for Inservice Inspection of Light Water Reactors. NUREG/CR-4469, PNNL-571 1, Vol. 16. Pacific Northwest Laboratory, Richland; Washington.

Doctor, S. R., A. A. Diaz, J. R. Friley, M. S. Good, M. S. Greenwood, P. G. Heasler, R. L. Hockey, R. J. Kurtz, F. A. Simonen, J. C. Spanner, T. T. Taylor, and T. V. Vo. 1993. Nondestructive Examination (NDE) Reliability for Inservice Inspection of Light Water Reactors. NUREG/CR-4469, PNNL-5711, Vol. 15. Pacific Northwest Laboratory, Richland, Washington.

Doctor, S. R., A. A. Diaz, J. R. Friley, M. S. Good, M. S. Greenwood, P. G. Heasler, R. L. Hockey, R. J. Kurtz, F. A. Simonen, J. C. Spanner, T. T. Taylor, and T. V. Vo. 1992. Nondestructive Examination (NDE) Reliability for Inservice Inspection of Light Water Reactors. NUREG/CR-4469, PNNL-5711, Vol. 14. Pacific Northwest Laboratory, Richland, Washington.

Green, E. R., S. R. Doctor, R. L. Hockey, and A. A. Diaz. 1992. Development of Equipment Parameter Tolerances for the Ultrasonic Inspection of Steel Components: Application to Components up to 3 Inches Thick. NUREG/CR-5817, Vol 1. Pacific Northwest Laboratory, Richland, Washington.

Doctor, S. R., M. S. Good, P. G. Heasler, R. L. Hockey, F. A. Simonen, J. C. Spanner, T. T. Taylor, and T. V. Vo. 1992. Nondestructive Examination (NDE) Reliability for Inservice Inspection of Light Water Reactors. NUREG/CR-4469, PNNL-5711, Vol. 13. Pacific Northwest Laboratory, Richland, Washington.

Doctor, S. R., M. S. Good, P. G. Heasler, R. L. Hockey, F. A. Simonen, J. C. Spanner, T. T. Taylor, and T. V. Vo. 1992. Nondestructive Examination (NDE) Reliability for Inservice Inspection of Light Water Reactors. NUREG/CR-4469, PNNL-5711, Vol. 12. Pacific Northwest Laboratory, Richland, Washington.

Doctor, S. R., M. S. Good, E. R. Green, P. G. Heasler, F. A. Simonen, J. C. Spanner, T. T. Taylor, and T. V. Vo. 1991. Nondestructive Examination (NDE) Reliability for Inservice Inspection of Light Water Reactors. NUREG/CR-4469, PNNL-5711, Vol. 11. Pacific Northwest Laboratory, Richland, Washington. 
Previous Reports

Heasler, P. G., T. T. Taylor, J. C. Spanner, S. R. Doctor, and J. D. Deffenbaugh. 1990. Ultrasonic Inspection Reliability for Intergranular Stress Corrosion Cracks: A Round Robin Study of the Effects of Personnel, Procedures, Equipment and Crack Characteristics. NUREG/CR-4908. Pacific Northwest Laboratory, Richland, Washington.

Spanner, J. C., S. R. Doctor, T. T. Taylor/PNNL and J. Muscara/NRC. 1990. Qualification Process for Ultrasonic Testing in Nuclear Inservice Inspection Applications. NUREG/CR-4882, PNNL-6179. Pacific Northwest Laboratory, Richland, Washington.

Doctor, S. R., J. D. Deffenbaugh, M. S. Good, E. R. Green, P. G. Heasler, F. A. Simonen, J. C. Spanner, T. T. Taylor, and T. V. Vo. 1990. Nondestructive Examination (NDE) Reliability for Inservice Inspection of Light Water Reactors. NUREG/CR-4469, PNNL-5711, Vol. 10. Pacific Northwest Laboratory, Richland, Washington.

Doctor, S. R., J. D. Deffenbaugh, M. S. Good, E. R. Green, P. G. Heasler, F. A. Simonen, J. C. Spanner, and T. T. Taylor. 1989. Nondestructive Examination (NDE) Reliability for Inservice Inspection of Light Water Reactors. NUREG/CR-4469, PNNL-5711, Vol. 9. Pacific Northwest Laboratory, Richland, Washington.

Doctor, S. R., J. D. Deffenbaugh, M. S. Good, E. R. Green, P. G. Heasler, F. A. Simonen, J. C. Spanner, and T. T. Taylor. 1989. Nondestructive Examination (NDE) Reliability for Inservice Inspection of Light Water Reactors. NUREG/CR-4469, PNNL-5711, Vol. 8. Pacific Northwest Laboratory, Richland, Washington.

Doctor, S. R., J. D. Deffenbaugh, M. S. Good, E. R. Green, P. G. Heasler, F. A. Simonen, J. C. Spanner, and T. T. Taylor. 1988. Nondestructive Examination (NDE) Reliability for Inservice Inspection of Light Water Reactors. NUREG/CR-4469, PNNL-5711, Vol. 7. Pacific Northwest Laboratory, Richland, Washington.

Doctor, S. R., J. D. Deffenbaugh, M. S. Good, E. R. Green, P. G. Heasler, G. A. Mart, F. A. Simonen, J. C. Spanner, T. T. Taylor, and L. G. Van Fleet. 1987. Nondestructive Examination (NDE) Reliability for Inservice Inspection of Light Water Reactors. NUREG/CR-4469, PNNL-5711, Vol. 6. Pacific Northwest Laboratory, Richland, Washington.

Doctor, S. R., D. J. Bates, J. D. Deffenbaugh, M. S. Good, P. G. Heasler, G. A. Mart, F. A. Simonen, J. C. Spanner, T. T. Taylor, and L. G. Van Fleet. 1987. Nondestructive Examination (NDE) Reliability for Inservice Inspection of Light Water Reactors. NUREG/CR-4469, PNNL-5711, Vol. 5. Pacific Northwest Laboratory, Richland, Washington.

Doctor, S. R., D. J. Bates, J. D. Deffenbaugh, M. S. Good, P. G. Heasler, G. A. Mart, F. A. Simonen, J. C. Spanner, A. S. Tabatabai, T. T. Taylor, and L. G. Van Fleet. 1987. Nondestructive Examination (NDE) Reliability for Inservice Inspection of Light Water Reactors. NUREG/CR-4469, PNNL-5711, Vol. 4. Pacific Northwest Laboratory, Richland, Washington.

Collins, H. D. and R. P. Gribble. 1986. Siamese Imaging Technique for Quasi-Vertical Type (QVT) Defects in Nuclear Reactor Piping. NUREG/CR-4472, PNNL-5717. Pacific Northwest Laboratory, Richland, Washington.

Doctor, S. R., D. J. Bates, R. L. Bickford, L. A. Charlot, J. D. Deffenbaugh, M. S. Good, P. G. Heasler, G. A. Mart, F. A. Simonen, J. C. Spanner, A. S. Tabatabai, T. T. Taylor, and L. G. Van Fleet. 1986. Nondestructive Examination (NDE) Reliability for Inservice Inspection of Light Water Reactors. NUREG/CR-4469, PNNL-5711, Vol. 3. Pacific Northwest Laboratory, Richland, Washington.

Doctor, S. R., D. J. Bates, L. A. Charlot, M. S. Good, H. R. Hartzog, P. G. Heasler, G. A. Mart, F. A. Simonen, J. C. Spanner, A. S. Tabatabai, and T. T. Taylor. 1986. Evaluation and Improvement of NDE Reliability for Inservice Inspection of Light Water Reactors. NUREG/CR-4469, PNNL-5711, Vol. 2. Pacific Northwest Laboratory, Richland, Washington. 
Doctor, S. R., D. J. Bates, L. A. Charlot, H. D. Collins, M. S. Good, H. R. Hartzog, P. G. Heasler, G. A. Mart, F. A. Simonen, J. C. Spanner, and T. T. Taylor. 1986. Integration of Nondestructive Examination (NDE) Reliability and Fracture Mechanics, Semi-Annual Report, April 1984 - September 1984. NUREG/CR-4469, PNNL-5711, Vol. 1. Pacific Northwest Laboratory, Richland, Washington.

Good, M. S. and L. G. Van Fleet. 1986. Status of Activities for Inspecting Weld Overlaid Pipe Joints.

NUREG/CR-4484, PNNL-5729. Pacific Northwest Laboratory, Richland, Washington.

Heasler, P. G., D. J. Bates, T. T. Taylor, and S. R. Doctor. 1986. Performance Demonstration Tests for Detection of Intergranular Stress Corrosion Cracking. NUREG/CR-4464, PNNL-5705, Pacific Northwest Laboratory, Richland, Washington.

Simonen, F. A. 1984. The Impact of Nondestructive Examination Unreliability on Pressure Vessel Fracture Predictions. NUREG/CR-3743, PNNL-5062. Pacific Northwest Laboratory, Richland, Washington.

Simonen, F. A. and H. H. Woo. 1984. Analyses of the Impact of Inservice Inspection Using Piping Reliability Model. NUREG/CR-3869, PNNL-5140. Pacific Northwest Laboratory, Richland, Washington.

Taylor, T. T. 1984. An Evaluation of Manual Ultrasonic Inspection of Cast Stainless Steel Piping. NUREG/CR-3753, PNNL-5070. Pacific Northwest Laboratory, Richland, Washington.

Bush, S. H. 1983. Reliability of Nondestructive Examination, Volumes I, II, and III. NUREG/CR-3110-1, -2, and -3; PNNL-4584. Pacific Northwest Laboratory, Richland, Washington.

Simonen, F. A. and C. W. Goodrich. 1983. Parametric Calculations of Fatigue Crack Growth in Piping. NUREG/CR-3059, PNNL-4537. Pacific Northwest Laboratory, Richland, Washington.

Simonen, F. A., M. E. Mayfield, T. P. Forte, and D. Jones. 1983. Crack Growth Evaluation for Small Cracks in Reactor-Coolant Piping. NUREG/CR-3176, PNNL-4642. Pacific Northwest Laboratory, Richland, Washington.

Taylor, T. T., S. L. Crawford, S. R. Doctor, and G. J. Posakony. 1983. Detection of Small-Sized Near-Surface UnderClad Cracks for Reactor Pressure Vessels. NUREG/CR-2878, PNNL-4373. Pacific Northwest Laboratory, Richland, Washington.

Busse, L. J., F. L. Becker, R. E. Bowey, S. R. Doctor, R. P. Gribble, and G. J. Posakony. 1982. Characterization Methods for Ultrasonic Test Systems. NUREG/CR-2264, PNNL-4215. Pacific Northwest Laboratory, Richland, Washington.

Morris, C. J. and F. L. Becker. 1982. State-of-Practice Review of Ultrasonic In-service Inspection of Class I System Piping in Commercial Nuclear Power Plants. NUREG/CR-2468, PNNL-4026. Pacific Northwest Laboratory, Richland, Washington.

Becker, F. L., S. R. Doctor, P. G. Heasler, C. J. Morris, S. G. Pitman, G. P. Selby, and F. A. Simonen. 1981. Integration of NDE Reliability and Fracture Mechanics, Phase I Report. NUREG/CR-1696-1, PNNL-3469. Pacific Northwest Laboratory, Richland, Washington.

Taylor, T. T. and G. P. Selby. 1981. Evaluation of ASME Section XI Reference Level Sensitivity for Initiation of Ultrasonic Inspection Examination. NUREG/CR-1957, PNNL-3692. Pacific Northwest Laboratory, Richland, Washington. 


\subsection{Introduction}

Pacific Northwest National Laboratory (PNNL) is conducting a multi-year program for the U.S. Nuclear Regulatory Commission (NRC) entitled "Evaluation and Improvement in Nondestructive Evaluation Reliability for Inservice Inspection (ISI) of Light Water Reactors." The goals of this program are to determine the reliability of current ISI for reactor systems and components, and to develop recommendations that can ensure high inspection reliability. The long-term objective is to develop technical bases for improvements to the inspection requirements of nuclear power plant components. One task of the PNNL program was to develop and evaluate risk-informed techniques for ISI plans of nuclear power plants.

Because of similarities in objectives, the PNNL program task related to risk-informed methodology for ISI was coordinated with the activity of the American Society of Mechanical Engineers (ASME) Research Task Force on Risk-Based Inspection Guidelines. The initial Task Force document (ASME 1991) has made general recommendations on the application of risk-informed methods to ISI, and forms the basis of future proposals to ASME Codes and Standards Committees for improved codes and standards. Results of PNNL studies have been made available to the ASME Research Task Force to demonstrate and validate the usefulness of the risk-informed methodology. A subsequent task force document (ASME 1992) specifically addressed nuclear power plant components. Additional documents addressing nuclear power plant components will be issued by the ASME Task Force.

To provide technical bases for improved ISI plans, a method as described in this report uses results of probabilistic risk assessments (PRAs) to estimate the consequences of component failures. The probabilities of these component failures have been estimated by using an expert judgment elicitation process (Vo et al. 1991). Using these estimates of consequences and probabilities, risk calculations can be performed to identify ISI priorities for nuclear power plant components. Once high-priority components have been identified, recommended inspection programs (method, frequency, and extent) can be developed by using probabilistic structural mechanics to identify inspection strategies that will ensure that component failure rates are maintained at given levels. However, any complete inservice inspection program plan should also consider other additional objectives of ISI inspection, including defense-in-depth and the identification of unexpected degradation in operating plants.

This report describes evaluations for the Surry Nuclear Power Station Unit 1 (Surry-1) which was selected for demonstrating the risk-informed methodology. Participation of Virginia Electric Power Company (VEPCO) staff was an essential part of the pilot study. Plant-specific information was obtained through system drawings, visits to the plant site, and discussions with plant operational staff. The specific systems selected for study were the auxiliary feedwater, reactor coolant, and the low-pressure injection systems. This report presents the results for the most riskimportant components within the three selected systems at Surry- 1 and compares the results for ISI priorities with the current ISI practices. Differences are being assessed to determine the extent of potential improvements to ISI plans provided by the new methodology.

This report is a revision of the earlier report (Vo et al. 1994) that incorporates recent plant-specific information and improved risk-informed methodology. Since this report, NUREG/CR-6181, Rev. 1, provides a preferred methodology, it supersedes the earlier NUREG/CR-6181 report published in August 1994. In the previous version, the approximate risk-informed methodology was developed for assessing component risk contributions by combining system risk importance with the contributions of components to system failures, to provide a quantitative measure of component risk importance. With lessons learned from the application of the PNNL approximate methodology and from recent research efforts being performed by the ASME Research Task Force on RiskBased ISI, an improved risk-informed methodology has evolved. This improved methodology was used for redetermining the risk importance of individual Surry-1 components, and the results of these new calculations are the subject of this report.

This revised report includes information from the earlier (NUREG/CR-6181) report that is still relevant and was used in this study to evaluate the evolved methodology. Section 2.0 of this report discusses the overall methodology for risk-informed ranking of components. Part of this discussion addresses the methods used to estimate component 
Introduction

rupture probabilities. Section 3.0 provides details of the Surry-1 pilot study. Descriptions are provided for the three systems addressed, and the assumptions made in the analyses are also included. Results of the component rankings as well as sensitivity analyses are presented. Section 4.0 provides a detailed discussion and interpretation of the results of Section 3.0. Finally, a summary and conclusions of the study are presented in Section 5.0. Appendix A of this report provides details of the risk-informed calculations for the components selected for this study. Appendix B describes a peer review and some insights of the risk-informed approach developed by PNNL. 


\subsection{Overall Methodology}

This section describes the methodology which was used to perform the risk-ranking process. This is an improved methodology that was based on lessons learned from the application of the PNNL approximate methodology and from recent research efforts of the ASME Research Task Force on Risk-Based ISI with PNNL input. The following discussion summarizes the overall methodology.

\subsection{Risk Prioritization}

For the systems selected in the study, a detailed componentlevel prioritization was performed. Simplified Piping and Instrumentation Diagram (P\&ID) drawings for each system of interest and worksheets were developed to support the analysis. The P\&ID drawings were used to identify the pipe segment boundaries. The worksheets contained information specific to a component, such as the failure probability and consequences of component rupture. The consequence type is categorized as being a component failure that causes system degradation; an initiating event; or a combination of system degradation and an initiating event. To compute the contribution to core damage frequency of a component, the plant PRA was used to find a basic event whose failure would have the same effect as a component rupture. In this analysis, the risk increase for that basic event was used to measure the contribution to core damage frequency of a component rupture. The risk increases for the basic events were calculated by setting the failure probability for the events to one, and then computing the new core damage frequency.

In order to use the plant PRA as input to the core damage frequency (CDF) calculation, the postulated consequences of the failure were identified. Then based on the identified consequences, the PRA model was manipulated to obtain the required information. The consequences considered from both direct effects and indirect effects include:

- Failures that cause an initiating event such as a LOCA or reactor trip

- Failures that disable a single component, train or system

- Failures that disable multiple components, trains or systems, and
- Failures that cause any combination of the above.

Because the consequences can vary and the correct PRA and failure probability information is necessary for the CDF calculation, the process requires different manipulations for each type of consequence. Different equations were developed to ensure the proper calculation for each type of consequence. The risk increase values are combined with the results of the component failure probability/rate to obtain core damage frequency for each component. Depending upon the type of consequence; one of the three equations (as shown below) was then used to compute the component or pressure boundary core damage frequency.

\subsubsection{Failures Causing System Degradation}

For component failures that cause only mitigating system degradation or loss, the core damage frequency for the component is determined by the following equation:

$$
\mathrm{CDF}_{\mathrm{PB}}=\mathrm{FP}_{\text {break }} * \mathrm{RAW}
$$

where $\mathrm{CDF}_{\mathrm{PB}}=$ Core damage frequency from a component failure per unit year

RAW $=$ Risk Achievement Worth

$\mathrm{FP}_{\text {break }}=$ Component failure probability given as $\lambda * \mathrm{~T} / 2$

$\lambda=$ Component failure rate

$\mathrm{T}=$ Inspection interval, assuming end-oflife, 40 yrs

To obtain the contribution to CDF, a surrogate component that is already modeled in the plant PRA is identified in which the consequence or impact on the CDF matches the postulated consequences for the component failure. The surrogate component is assumed to fail with a failure probability of 1.0 to obtain a new total plant core damage frequency. In order to determine the contribution to core damage frequency for the component only, the base total plant PRA CDF is subtracted from the new total plant CDF as shown by:

$$
\mathrm{RAW}=\mathrm{CDF}_{\mathrm{PB}=1.0}-\mathrm{CDF}_{\mathrm{BASE}}
$$

where $\mathrm{CDF}_{\mathrm{PB}=1.0}=$ New total plant $\mathrm{CDF}$ with surrogate component $=1.0$

$\mathrm{CDF}_{\mathrm{BASE}}=$ Base total plant $\mathrm{CDF}$ 


\subsubsection{Failures Causing an Initiating Event}

For piping failures that cause an initiating event only, the portion of the PRA model that is impacted is the initiating event and its frequency. For a piping segment, the core damage frequency from the piping failure is calculated by:

$$
\mathrm{CDF}_{\mathrm{PB}}=\mathrm{FR}_{\mathrm{PB}} * \mathrm{CONT}_{\mathrm{INT}}
$$

$$
\text { where } \begin{aligned}
\mathrm{CDF}_{\mathrm{PB}}= & \begin{array}{l}
\text { Core damage frequency from a } \\
\text { component failure }
\end{array} \\
\mathrm{CONT}_{\mathrm{INT}}= & \begin{array}{l}
\text { Contribution to core damage probability } \\
\text { for the initiator }
\end{array} \\
\mathrm{FR}_{\mathrm{PB}}= & \text { Component failure rate }
\end{aligned}
$$

The contribution to core damage probability is determined from existing base PRA results. The core damage frequency contribution from the initiating event postulated for the piping failure is identified along with the base PRA initiating event frequency. Dividing the CDF by the initiating event frequency yields the contribution to core damage probability as shown by:

$$
\mathrm{CONT}_{\mathrm{NNT}}=\mathrm{EVENT}_{\mathrm{CONT}} / \mathrm{IEV}_{\mathrm{freq}}
$$

where EVENT $_{\text {CONT }}=$ Base PRA core damage frequency from the initiating event $\mathrm{IEV}_{\text {freq }}=$ Initiating event frequency from base PRA

\subsubsection{Failures Causing System Degradation and an Initiating Event}

For component failures that cause an initiating event and system degradation, core damage sequences involving both events simultaneously must be evaluated. For component failures that cause an initiating event and system degradation, the following equation is applied:

$$
\mathrm{CDF}_{\mathrm{PB}}=\mathrm{FR}_{\text {break }} * \mathrm{CONT}_{\mathrm{INS}}
$$

$$
\begin{aligned}
& \text { where } \mathrm{CDF}_{\mathrm{PB}}=\text { Core Damage Frequency from a } \\
& \text { component failure } \\
& \mathrm{CONT}_{\mathrm{INS}}=\text { Contribution to core damage probability } \\
& \text { for the initiator with mitigating system } \\
& \text { component assumed to fail } \\
& \mathrm{FR}_{\text {break }}=\text { Component failure rate }
\end{aligned}
$$

The contribution to core damage probability for the initiator is determined by the following equation:

$$
\mathrm{CONT}_{\text {INS }}=\mathrm{RI} / \mathrm{IEV}_{\text {freq }}
$$

where $\mathrm{RI}=\mathrm{CDF}$ from the initiating event with segment failed

$\mathrm{IEV}_{\text {freq }}=$ Initiating event frequency

\subsubsection{Pipe Segment Contribution to Core Damage Frequency}

Each component within the scope of this study is evaluated to determine its contribution to core damage frequency due to component failure. Once this is completed, the pipe segment contribution to core damage frequency is calculated by summing across each individual component. This summation was performed for the purpose of demonstration only. The detailed calculations of component core damage frequency contributions can be found in Appendix A of this report. As shown by the equations above, estimates of component failure probabilities are required in order to perform component prioritization. These estimates are summarized in the following subsection.

\subsection{Estimates of Component Rupture Probabilities}

For each system selected (e.g., auxiliary feedwater, lowpressure injection, and reactor coolant), the per-component failure probability was estimated. Because historical failure data on low-probability events (e.g., pipe rupture) are lacking, an expert judgment elicitation was used to estimate component failure probabilities. This section summarizes the procedures and the results of PNNL's expert judgment 
elicitation. More detailed discussions are given in Vo et al. $(1993,1991,1990)$. The expert judgment elicitation used a systematic procedure, which closely followed the approaches reported in the NRC Severe Accident Risks Document (NRC 1989; Wheeler et al. 1989; Meyer et al. 1989). The specific objective of the PNNL elicitation was to develop numerical estimates for probabilities of catastrophic or disruptive failures in the selected components at Surry-1. In this demonstration study, component rupture is defined as a break or leak that is greater than make-up capability and/or that can disable the systems intended function. In his study, small leaks that may cause system degradation were not included. Figure 2.1 shows information that was used to obtain the desired estimates from the experts.
Prior to the expert judgment elicitation workshop, PNNL sent reference materials to the experts, including data sources, reports, probabilistic models, and recent PRA results. Panel members were asked to study these materials and to make initial estimates of failure probabilities.

At the meeting, a formal presentation was provided for each system addressed. Presentations covered technical descriptions, historical component failure mechanisms, elicitation statements, suggested approaches, questionnaire forms, and any materials that supported the issue descriptions. The presentations were followed by discussions. The experts provided their knowledge regarding plant design and operation, failure history, material degradation mechanisms, and methods for recomposition and aggregation of the data.

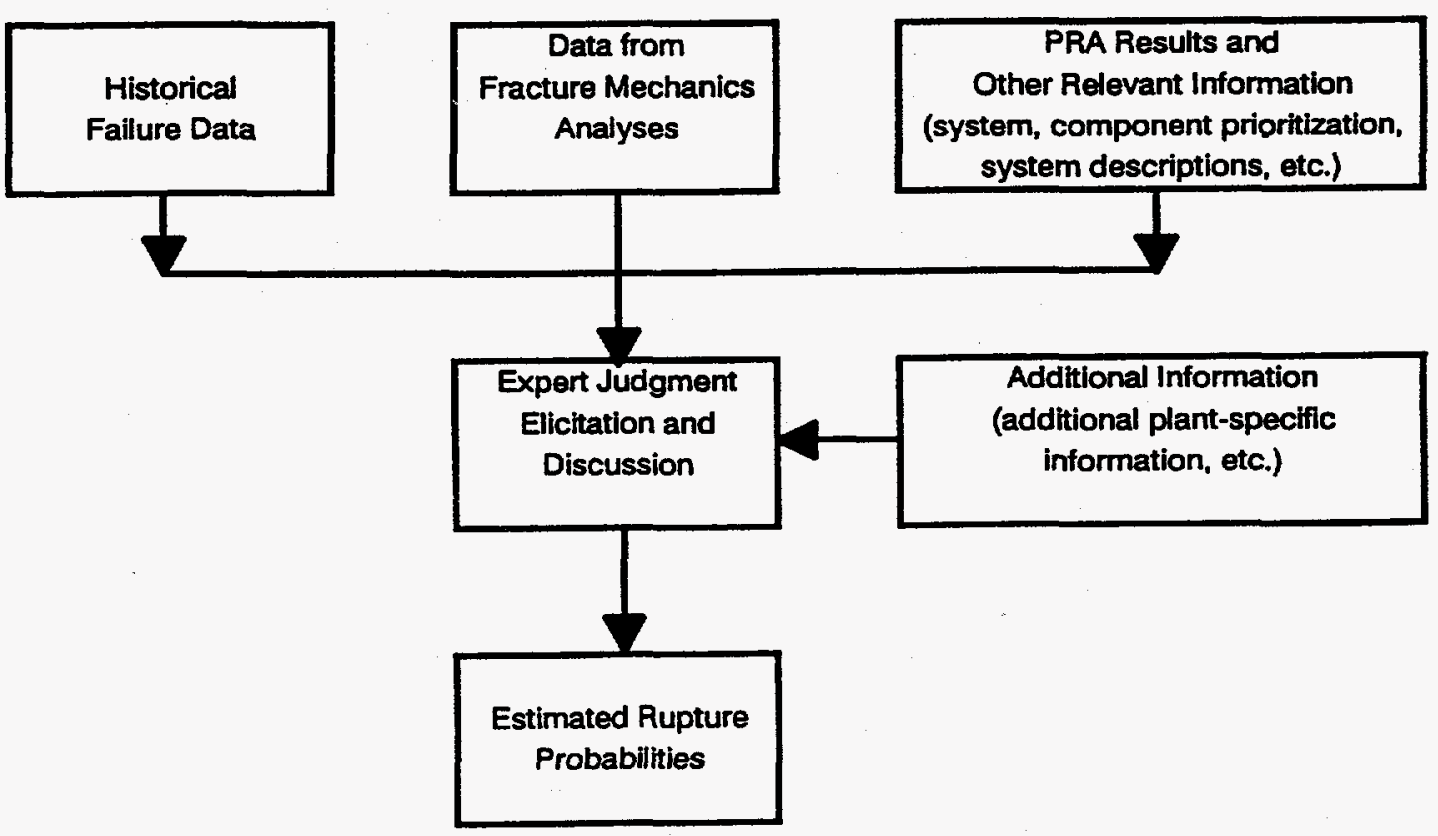

Figure 2.1 Information provided to the participants in the expert judgment elicitation 
Each expert then completed questionnaire forms that addressed location-specific rupture probabilities for the systems of interest. These responses included best estimates of probabilities and uncertainties, and the rationale for these estimates. Following the meeting, the information provided by the expert panel was recomposed and aggregated. PNNL prepared a preliminary report of the elicitation, which was then submitted to each panel member for review. This report included the initial recomposition, additional plant-specific data, and other relevant information. The experts were requested to review the report containing the compilation of expert data and the new data that had been assembled. The experts were requested to determine if this information would cause them to change their position. If it did, then they were requested to provide revised estimates of rupture probabilities. The revised information was again recomposed and aggregated to provide single composite judgments for each issue.

The appropriate failure probabilities for the risk ranking calculations should assume that no inservice inspections are performed. However, the expert judgment elicitation process was based largely on plant operating experience, which implicitly reflects any benefits derived from the ongoing inservice inspections. This issue was addressed in discussions by the expert judgment elicitation panels. The consensus was that routine inservice inspections using representative industry practices have had only relatively small impacts on the piping failure rates. For most piping segments, these inspections have been performed relatively infrequently (10 year intervals), on a small sample of welds (e.g., 7 percent), and with techniques often having marginal flaw detection capabilities. Therefore, except for piping subject to augmented inspection programs (such as for stress corrosion cracking and wall thinning due to flow assisted corrosion), it was reasonable to neglect the benefits of inservice inspections.

Discussions during the expert judgment elicitation panel meetings also addressed the role of current inservice testing (IST) programs on piping reliability. In calculations for ISI programs, it is believed to be appropriate to include the benefits of current IST programs in estimating baseline failure probabilities. On the other hand, the expert judgment elicitation panels did recognize that failures which occur during standby periods or during inservice testing should not be included as failures relevant to risk ranking calculations. Nevertheless, it is unlikely that the experts could adequately account for the relevant failures versus irrelevant failures. The failure probabilities (per demand) for standby systems were probably overestimated by the experts, and the importances of piping segments in standby systems were also likely overestimated.

The experts on the judgment elicitation panels were requested to estimate frequencies for pipe ruptures. It was clear to the experts that occurrences of cracking and small leaks were not of interest. Large leaks and small breaks sufficiently severe to disable the function of a system were of interest, even if these failures did not correspond to fracture mechanics criteria for unstable fractures or double-ended pipe breaks. It is notable that the numerical values for pipe rupture probabilities provided by the experts were greater than the typical pipe break probabilities which are calculated by probabilistic fracture mechanics codes, and correlate better with calculated values for large leak probabilities.

It has been noted that in some cases the pipe rupture frequencies estimated by the experts were approximately two orders of magnitude less than LOCA frequencies that have been used in PRAs. In part, this may be due to consideration by the experts of only structural failures of piping excluding other events that can also cause LOCAs. Another more likely explanation is that the estimates from the experts were based on their detailed knowledge of materials science, fracture mechanics, and conditions specific to the Surry-1 piping. Such knowledge is not reflected in the generic estimates of LOCA frequencies which have been used in the development of PRAs, which may tend to be bounding values. Such bounding values are often based on operating experience which is too limited to provide data on actual pipe ruptures given the low expected values for these failure probabilities.

It should also be noted that the intention of the present calculations was to use failure probabilities from the expert judgment elicitation panels to the exclusion of generic data or estimates from other sources. However, the Surry-1 PRA was applied to quantify the consequences of the failure of each given pipe segment. In this regard, the PRA implicitly addresses the reliability of other piping components, which may also be unavailable due to pipe ruptures already modeled in the PRA using failure rates inconsistent with the failure rates estimated by the expert judgment elicitation panels. In particular, when quantifying the Risk Achievement Worth (RAW) of pipe failures causing only mitigating system 
degradation or loss, the Surry-1 PRA values for LOCA frequencies are used. Because these values are two orders of magnitude higher than those estimated by the expert panels, for LOCAs caused by RCS piping failures, the potential exists for overestimation of the ISI priorities for pipe failures causing only mitigating system degradation or loss, for systems used primarily to mitigate the effects of LOCAs. This effect is mitigated by the fact that the High Pressure Injection (HPI) system is also used to mitigate steam generator tube ruptures (SGTRs) and reactor coolant pump (RCP) seal LOCAs, and the frequencies of these events are not affected by the estimates of the expert panels. Moreover, the analysis supposes that failures of some piping in the LPI system also fail the HPI system; given this supposition, the dominant contribution to the RAW, for such LPI piping, comes from SGTR sequences and RCP seal LOCA sequences. Future refinements of the risk ranking methodology should address these potential inconsistencies. The methodology should be revised as needed to address cases for which the results of the calculations are impacted by accident scenarios involving more than one pipe failure event.

Figures 2.2, 2.3, and 2.4 show the estimated failure probabilities of the AFW, LPI, and RCS components obtained from the expert judgment elicitation approach. For readability, the probabilities are presented with a $\log _{10}$ scale, with the probabilities expressed as failures per component per year.

The ranges of best estimates from the experts were summarized in a series of plots (boxes and whiskers) as shown in these figures. An individual plot displays five features of the distribution of estimated probabilities. The "whiskers" display the extreme upper and lower bound values of the distribution, while the box itself locates the $25 \%$ and $75 \%$ quartiles of the distribution. Finally, the circle within the box is the median of the distribution.

\subsection{Inspection Program Development}

The methods as described in this report can support the development of improved inservice inspection plans (what to inspect, where to inspect, when to inspect and by what method) using risk-informed approaches. In this regard, the development of a risk-informed inspection plan can be viewed as a three step process:
(1) the selection of the particular structural elements or locations that will be inspected; this selection should be made to ensure that the selected component locations include those with the higher contribution to risk.

(2) the establishment of inspection strategies for the selected locations, such that the NDE methods and inspection frequencies provide the needed probability of detection and sizing accuracy of degradation to maintain or reduce the failure probabilities.

(3) steps one and two lead to a partial ISI plan/program that needs to be supplemented with additional ISI to accommodate defense-in-depth and the additional objective of ISI to identify degradation mechanisms in various components not expected or anticipated in the original design.

The risk-ranking study described in this report focuses on the first step. However, this work was performed by PNNL for NRC as part of a larger research project with broader objectives (as described in Section 1.0) that also addresses the second and third step of the process. This work involves probabilistic fracture mechanics calculations which are being performed to estimate component failure probabilities and to quantify the benefits of alternative inspection strategies. Parametric calculations with the pc-PRAISE code have addressed crack growth by fatigue (Khaleel and Simonen 1994a, 1994b) and intergranular stress corrosion cracking of stainless steel piping (Khaleel et al. 1995).

The PNNL work is evaluating various inspection strategies to identify combinations of inspection methods (POD, sizing accuracy) and frequencies at selected locations that can be effective in maintaining or reducing the failure probabilities of passive reactor components. To accomplish this goal the inspection strategies must address the failure mechanisms of concern, and have sufficiently high probabilities of detection and sizing accuracy so that the expected damage can be detected (given various frequencies of inspection) and the components repaired before structural integrity is impacted. Considerations include acceptable approaches for determining the number of locations to be inspected (size of inspection sample) and the desired reliability and frequency of the inspections to be performed at these 
SG to first isolation valve (main feedwater portion)

SG to AFW first isolation valve

First to second isolation valve

Containment penetration to second isolation valve

From Unit 2 AFW pumps

Pipe segment between containment isolation valves AFW pump discharge headers

From Unit 2 AFW system

Motor-driven pump (MDP) discharge

Turbine discharge pump (TDP) discharge

SG to turbine drive for TDP

AFW pumps CST return lines

AFW TDP suction

TDP to CST 1

AFW MDP suction

MDP to CST1

CST1

CST1 to CST2

CST2

Emergency makeup to AFW MDPs Emergency makeup to AFW TDPs

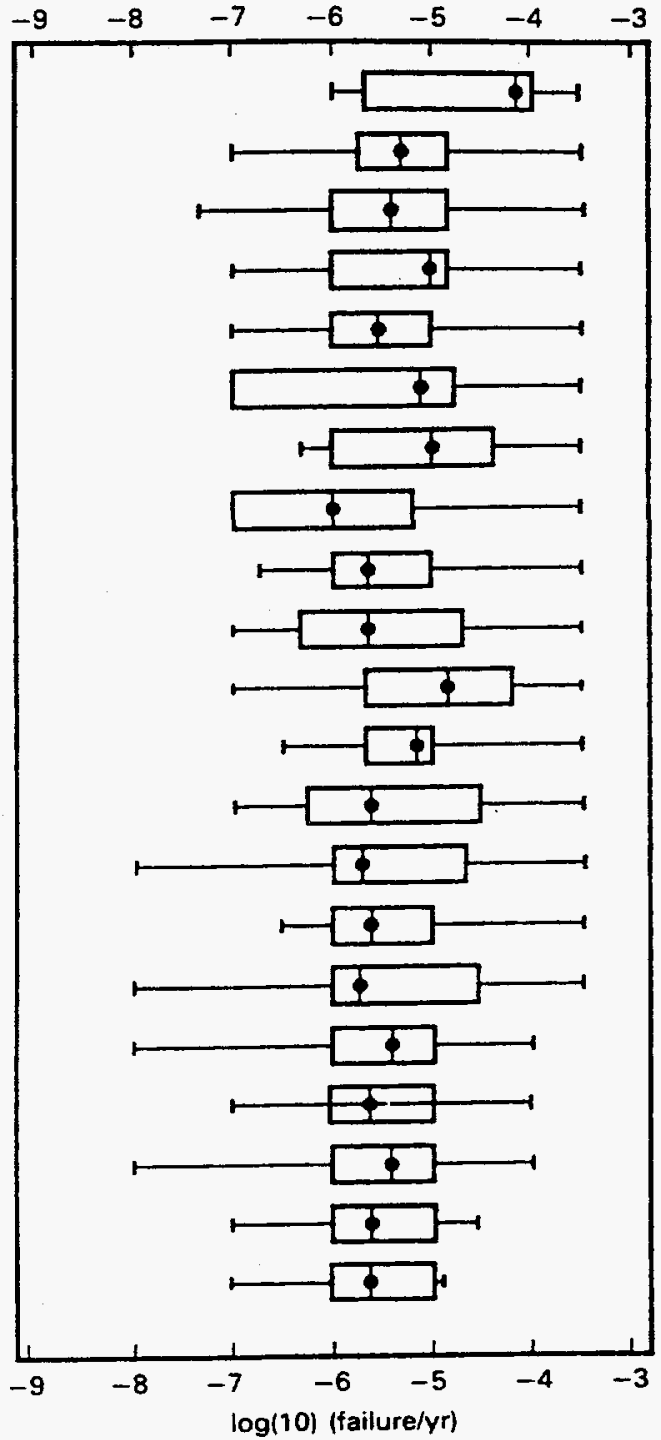

Figure 2.2 Estimates of rupture probabilities for Surry-1 auxiliary feedwater system components from expert judgment elicitation 
LPI cold-leg injection line (including first isolation valvel to RCS loop

Pipe segment between LPI isolation valves

Pipe segment from high-pressure injection (HPI) to LPI cold-leg injection LPI isolation valve to common discharge header Common discharge header to pump discharge

LPI hot-leg injection line to RCS loop

Pipe segment between LPI hot-leg isolation valves Hot-leg isolation valve to pump discharge header

Pipe segment from HPI to LPI hot-leg injection

LPI pump discharge lines

LPI pump discharge to charging system

LPI pump discharge to relief/test lines

Pump suction line

Containment sump to pump suction line

Refueling water storage tank (RWST) to pump suction

RWST

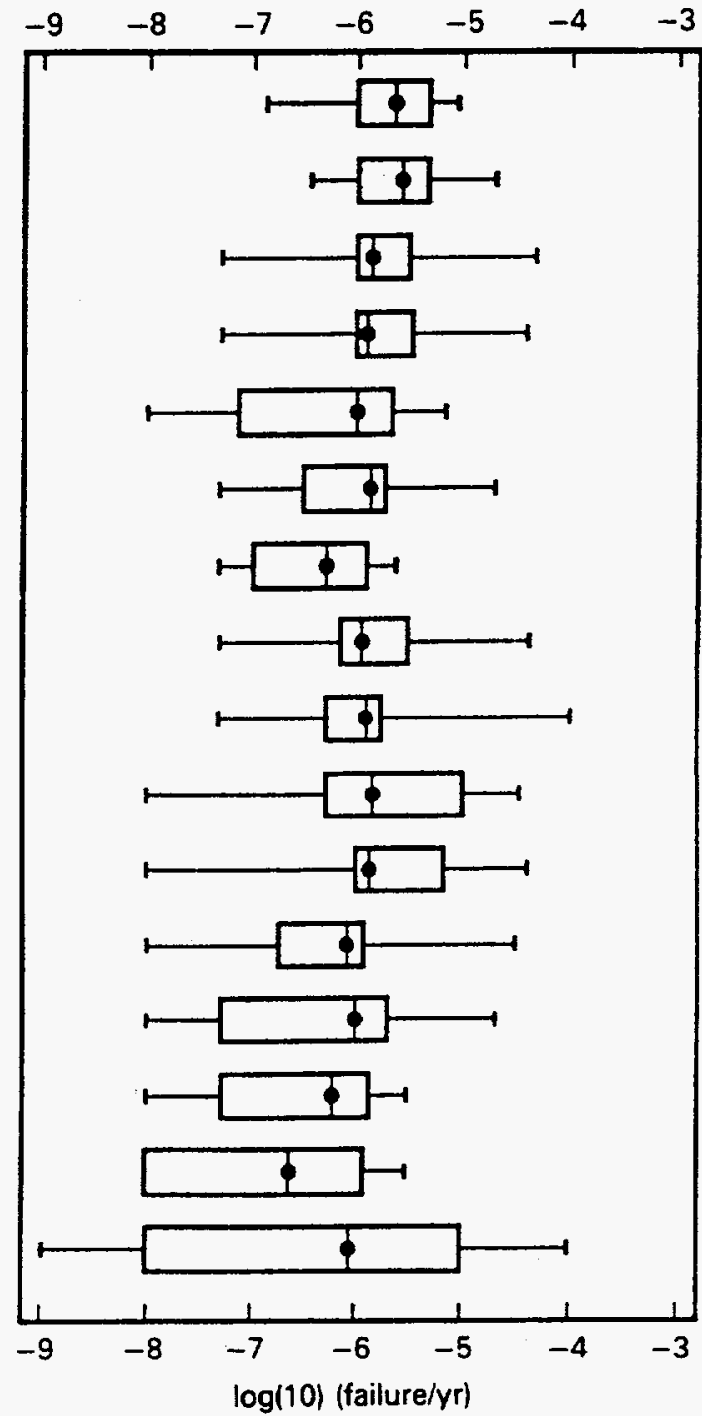

Figure 2.3 Estimates of rupture probabilities for Surry-1 low pressure injection system components from expert judgment elicitation 
Overall Methodology

RCS loop stop valve (hot leg) to vessel nozzle

Loop stop valve to SG

SG to $R C$ pump

RC pump to loop stop valve (cold leg)

Loop stop valve (cold leg) to vessel inlet nozzle

Pressurizer inlet line (from RCS loops)

Pressurizer spray line

Auxiliary spray line

Pressurizer spray common header

Pressurizer surge line

Pressurizer relief line

Pressurizer safety line

Pressurizer drain line

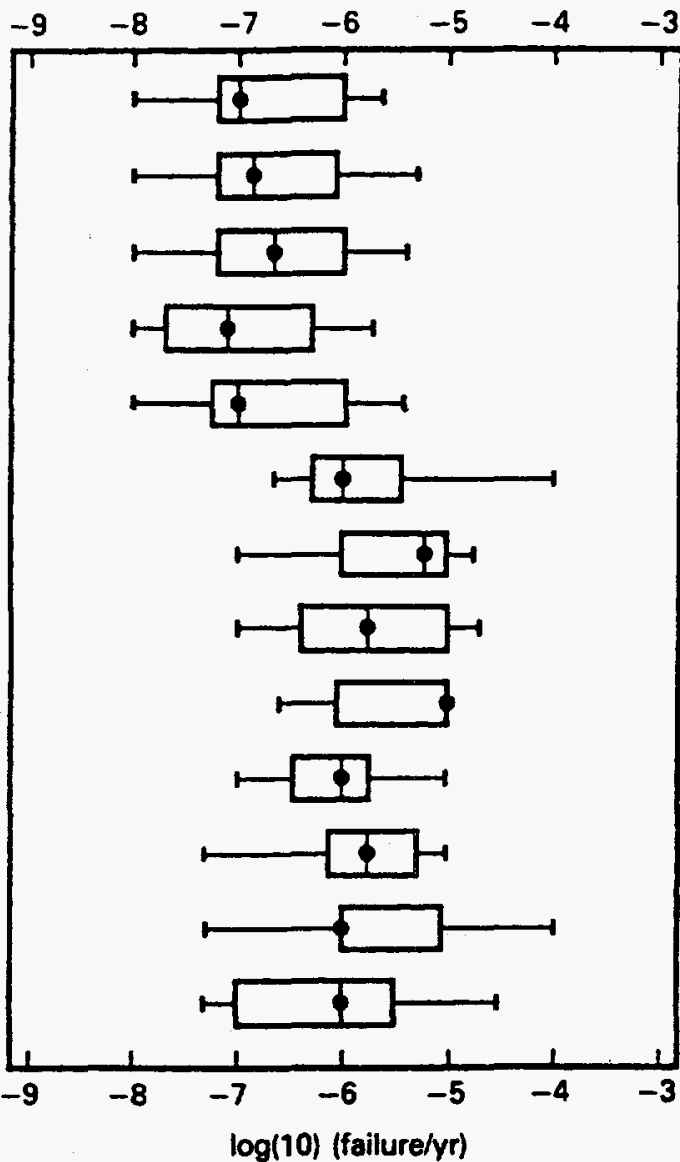

Figure 2.4 Estimates of rupture probabilities for Surry-1 reactor coolant system components from expert judgment elicitation

locations. Since several potential inspection strategies may provide the desired maintenance or reductions in failure probabilities, the final selection can be based on other important considerations including man-rem exposures to inspection personnel and cost effectiveness.

An inservice inspection strategy is defined by the following elements:

\subsubsection{Sampling Strategy}

The sampling strategy is defined by the selection of structural elements that are proposed for inclusion in the inspection program. The selection of structural elements should be guided by the calculations of risk importances and should include additional elements to address defense-in-depth for lower risk components, and to address unanticipated generic failure mechanisms that have not been detected or that have not yet occurred. The strategy should include immediate expansion of the sample when flaws are detected during an ISI through sequential sampling based on feedback from ISI findings and operating experience.

\subsubsection{Inspection Method}

Inspection methods are selected to address the degradation mechanisms, pipe sizes and materials of concern. The inspection method includes the basic technique itself (e.g., ultrasonics) along with the particular equipment and 
the procedures to be applied for detecting and sizing flaws. Candidate inspection techniques for piping include ultrasonic testing, surface examinations with dye penetrants (or magnetic particles), visual examinations, and radiography. In a larger context, monitoring methods such as leak detection, thermal transient monitoring, and acoustic emission monitoring can be used to supplement or replace nondestructive testing methods. Detailed aspects of equipment, procedures, and personnel qualifications are significant factors that govern the reliability of the inspections. The risk-informed inspection concept requires that the reliability of the inspection method be established in order to justify the selection of a particular inspection strategy. Based on materials, environments, loads, and degradation mechanisms, probabilistic fracture mechanics calculations can establish the probability of detection, the sizing accuracy, and the frequency of inspection needed to meet target goals for passive reactor component failure probabilities.

\subsubsection{NDE Reliability and Performance Demonstration}

Qualification of the NDE system (personnel, procedure and equipment) is an important element of an inspection program. Inspection systems with known reliability are needed to achieve the desired levels in failure probabilities consistent with the goals of the risk-informed inspection process. A risk-informed inspection program should justify the inspection reliability using data from performance demonstration programs.

\subsubsection{Time of Inspection}

The inservice inspection strategy must define when the inspections are to be performed. In most cases inspections are performed periodically at regular intervals such as with the 10 year interval of ASME Section XI. A riskinformed inspection program will identify the appropriate inspection intervals, such that the inspection program provides the desired maintenance or reductions in component failure probabilities. Inspection intervals must be sufficiently short so that degradation too small to be detected during one inspection does not grow to an unacceptable size before the next inspection is performed. 


\subsection{Analyses of Surry-1 Plant Systems}

This section presents the analyses of the three selected Surry-1 systems using the improved methodology detailed in Section 2. The information in Sections 3.1 through 3.3 is being repeated from the earlier NUREG/CR-6181 report since this information is needed as background and for use in the planned analyses. Following a brief discussion of plant familiarization, system descriptions, and analysis assumptions, the components of the three selected Surry-1 systems are prioritized and the results of the analysis are discussed. The section concludes with sensitivity analyses.

\subsection{Plant Familiarization}

Participation of VEPCO was an essential part of the study. Before initiating the study, a visit to VEPCO headquarters was conducted. The purpose of this first visit was to get acquainted with VEPCO personnel and to request needed data.

Prior to the initial plant visit, the PNNL project team analysts reviewed the fault trees reported in the Surry-1 PRA, the system descriptions, and the sections of the final safety analysis report (FSAR) applicable to the systems of interest. Worksheets were prepared and preliminary success criteria and dependency matrices were developed to identify specific areas where information was needed to develop an accurate model. Based on these initial activities, a letter of request was prepared and sent to plant personnel to identify the plant-specific information that was required. The following subsections provide a description of the plant visits and the information obtained during the visits.

\subsubsection{Plant Visits and Information Obtained}

A number of plant visits were required during this study. The first several plant visits were required because the very first visit occurred while the plant was in operation and thus, prevented access to all areas of the plant. Further PNNL staff required additional information following the review of information from the earlier visits, and further it was simply not possible to have everyone (both PNNL staff and plant staff) together for enough time during one visit.

The first week-long plant visit was arranged to meet with plant personnel. During this visit, project team analysts performed the system walkdowns and obtained relevant plant information. The visiting PNNL team included plant system specialists and PRA specialists. Because the plant was in operation during the initial visit, system walkdowns for some locations were not possible (e.g., inside the containment building and other high-radiation areas). Therefore, the Video Information Management System (VIMS) developed by VEPCO was also used. VIMS is a computerized system, that displays photographs of plant systems and components that have been stored in digital form on a laser disc. Following simple instructions, the plant photographs could be retrieved and viewed at any location within the plant.

For each of the systems selected for the study, a system walkdown was conducted where possible. The information obtained from the walkdowns was later used to assess the indirect effects on the systems. The walkdowns for each system included the plant engineer and one or two project team analysts. For each component (e.g., pipe segment), all the necessary information related to that component was obtained. This information was entered into the worksheets. For example, for a given pipe segment within a selected system, the component identification, including the pipe size, was identified. Numbers of welds, elbows, supports, connections, penetrations, etc., within the pipe segment in question were identified and recorded. Given a component failure, the potential targets that might be impacted by the failed components (e.g., vital electrical buses, system components nearby, etc.) were also recorded. Additionally, a video camera was used to record the conversations with the responsible engineer and views of significant locations of concern to system design and operation.

In addition to the plant system walkdowns, discussions with plant operational and technical staff were also conducted. The areas of discussion included plant and system modeling questions, collections of system design and operational information, discussions of transient sequence progressions, and the operators' responses to these events. During the first plant visit the team had discussions with the Surry-1 supervisor of system safety, the operator training coordinator, and the supervisor of the ISI. Project analysts talked with reactor operators, the shift technical advisor, and members of the maintenance and engineering staff. 
Discussions centered on gaining a clear understanding of the following items:

- the normal and emergency configurations and operations of the various systems of interest

- system dependencies

- operational problem areas identified by plant personnel that may impact the analysis

- automatic and manual actions taken in response to various emergency conditions

- availability of plant specific operational data.

The emergency procedures which addressed actions identified by the project analysts as important actions were explained to operations personnel.

During the course of the study, additional plant visits were needed. One of these visits was to obtain additional plantspecific failure mechanisms for components within the system analyzed. This information was provided to the expert judgment elicitation workshop participants for estimating component rupture probabilities. Another plant visit was conducted during the plant shutdown for refueling. This visit was to obtain additional information and to verify the information that was obtained from earlier visits (e.g., areas inside the containment building).

A complete set of the current Surry P\&ID, isometric drawings, composite drawings, and stress analysis reports were provided by the Surry-1 staff. Also, the Surry-1 staff provided copies of the Surry Emergency Procedures, Abnormal Procedures, Emergency Contingency Action Procedures, Functional Restoration Procedures, and several sections from the current revisions of the Surry-1 FSAR. The plant information was incorporated into PNNL's worksheets. For instance, the isometric and composite drawings were used to obtain additional information regarding component orientation and number of subcomponents. The Emergency Procedures were used to assess the recovery actions by the operators given a component rupture.

\subsubsection{Utility Interface}

An ongoing interface was maintained with the utility throughout the duration of the study. The project team leader was in frequent contact with Surry-1 plant personnel to ask questions and verify information. Surry-1 personnel also reviewed the results of the study when they became available.

\subsection{Plant System Description}

Surry-1 is part of a two-unit plant located on the James River near Williamsburg, Virginia. Surry-1 is a Westinghouse-designed, three-loop, pressurized-water reactor (PWR) rated at $788 \mathrm{MWe}$ capacity with a subatmospheric containment. The balance of the plant and containment building were designed and constructed by Stone and Webster Engineering Corporation. Surry-1 is operated by VEPCO. Commercial operation started in 1972.

The Surry-1 systems selected for this re-analysis study to evaluate the new methodology were the primary pressure boundary system, the front-line safety systems, and certain important support systems. These were the auxiliary feedwater (AFW), low-pressure injection (LPI), and the reactor coolant (RCS) systems. The following paragraphs summarize the descriptions for these systems. Detailed descriptions can be found in the Surry-1 FSAR.

\subsubsection{Auxiliary Feedwater System}

The AFW system provides feedwater to the steam generators for heat removal from the primary system after a reactor trip. The AFW system may also be used following a reactor shutdown, in conjunction with the condenser dump valves or atmospheric relief valves, to cool the RCS to about $300^{\circ} \mathrm{F}$ and $300 \mathrm{psig}$, at which time the residual heat removal system is brought into operation. The AFW system also provides emergency water following a secondary-side line rupture. Removal of heat in this manner prevents the reactor coolant pressure from increasing and causing release of reactor coolant through the pressurizer relief and/or safety valves. 
The AFW system is diagramed in Figure 3.1. The AFW is a multiple-train system; it consists of electric motor-driven pumps and steam turbine-driven pumps. Each pump draws suction through an independent line from the condensate storage tank. Each AFW pump discharges to parallel headers; each of these headers can provide AFW flow to any or all of the steam generators. Flow from each header to any one steam generator is through a normally open MOV and locked-open valve in series, paralleled with a line from the other header. These lines feed one line containing a check valve that joins the main feedwater line to a steam generator.

The motor-driven pumps automatically start on receipt of a safety actuation system signal, loss of main feedwater, low steam generator level in any steam generator, or loss of offsite power. The turbine-driven pumps automatically start on indication of a low steam generator level in any steam generator or undervoltage of any of the main RCS pumps.

Most of the AFW equipment is located in the auxiliary building. This building is designed to withstand the effects of earthquakes, tornadoes, floods, and other natural phenomena. Provisions are incorporated in the AFW design to allow periodic operation to demonstrate performance and structural leak-tight integrity. Leak detection is provided by visual examination and sensors in the floor drain system. The capability to isolate components or piping is provided, if required, so that the AFW system's safety function will not be compromised. Provisions are made to allow for ISI of components at the appropriate times specified in the ASME, Section XI.

\subsubsection{Low-Pressure Injection System}

The LPI consists of several independent subsystems characterized by equipment and flow path redundancy inside the missile protection boundaries. The two phases of lowpressure system operation including active low-pressure injection and recirculation mode and the passive accumulator injection. The passive accumulator system is not included in this evaluation.

The Surry-1 low-pressure injection/recirculation system (LPI/LPR) provides emergency coolant injection and recirculation following a loss-of-coolant accident (LOCA) when the RCS depressurizes below the low-pressure setpoint (about $300 \mathrm{psig}$ ). In addition to the direct recirculation of coolant during the recirculation phase once the
RCS is depressurized, the LPR discharge provides the suction source for the high-pressure recirculation system following drainage of the refueling water storage tank (RWST).

The LPI/LPR at Surry-1 is diagramed in Figure 3.2. The system consists of two $100 \%$ capacity pump trains. In the injection mode, the pump trains share a common suction header from the RWST. Each pump draws suction from the header through normally open motor-operated valves (MOVs), check valves, and locked-open manual valves. Each pump discharges through a check valve and normally open MOV in series to a common injection header. The injection header contains a locked-open MOV and branches to separate lines, one to each cold leg. Each of the lines to the cold legs contains two check valves in series to provide isolation from the high-pressure RCS.

In the recirculation mode, the pump trains draw suction from the containment sump through a parallel arrangement of suction lines to a common header. Flow from the suction header is drawn through a normally closed MOV and check valve in series. Discharge of the pump is directed to either the cold legs through the same lines used for injection or to a parallel set of headers that feed the charging pumps, depending on the RCS pressure.

In the hot-leg injection mode, system operation is identical to normal recirculation with the exception that the normally open cold-leg injection valves must be manually closed remotely, and one or more normally closed hot-leg recirculation valves must be manually opened.

The associated components, piping, structures, and power supplies of the LPI system are designed to conform with Class 1 seismic criteria. All motors, instruments, transmitters, and their associated cables located inside the containment are designed to function during and under the postulated temperature, pressure, and humidity conditions.

All LPI piping in contact with borated water is austenitic stainless steel. The piping is designed to meet the minimum requirements set forth in B31.1 Code for Pressure Piping, B36.10 and B16.19, ASTM Standards, Supplementary Standards, and Additional Quality Control Measures. The piping is supported to accommodate expansion due to temperature changes and hydraulic forces during an accident. All components of the LPI/LPR are tested periodically to demonstrate system readiness. All 

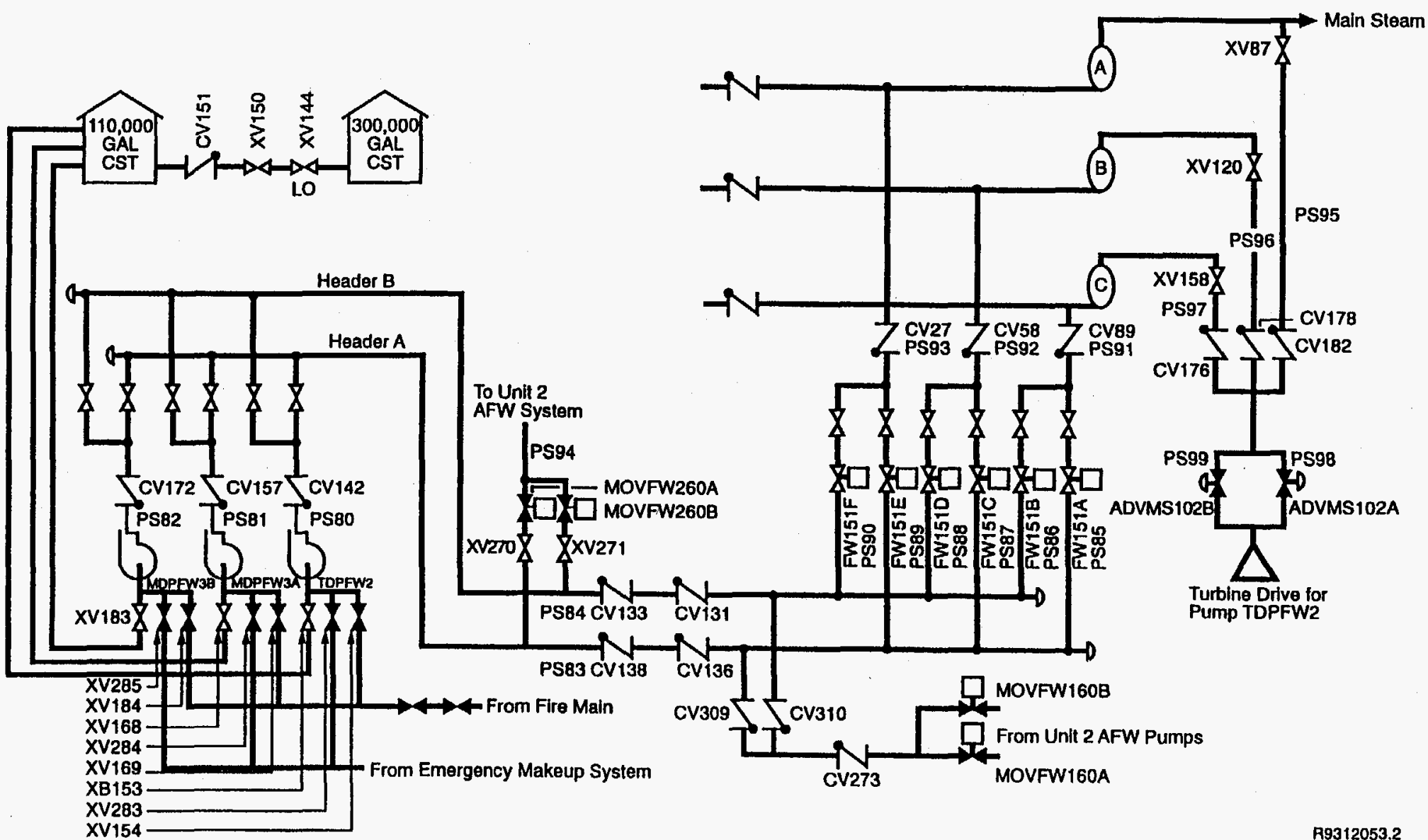

Figure 3.1 Surry-1 auxiliary feedwater system simplified schematic 


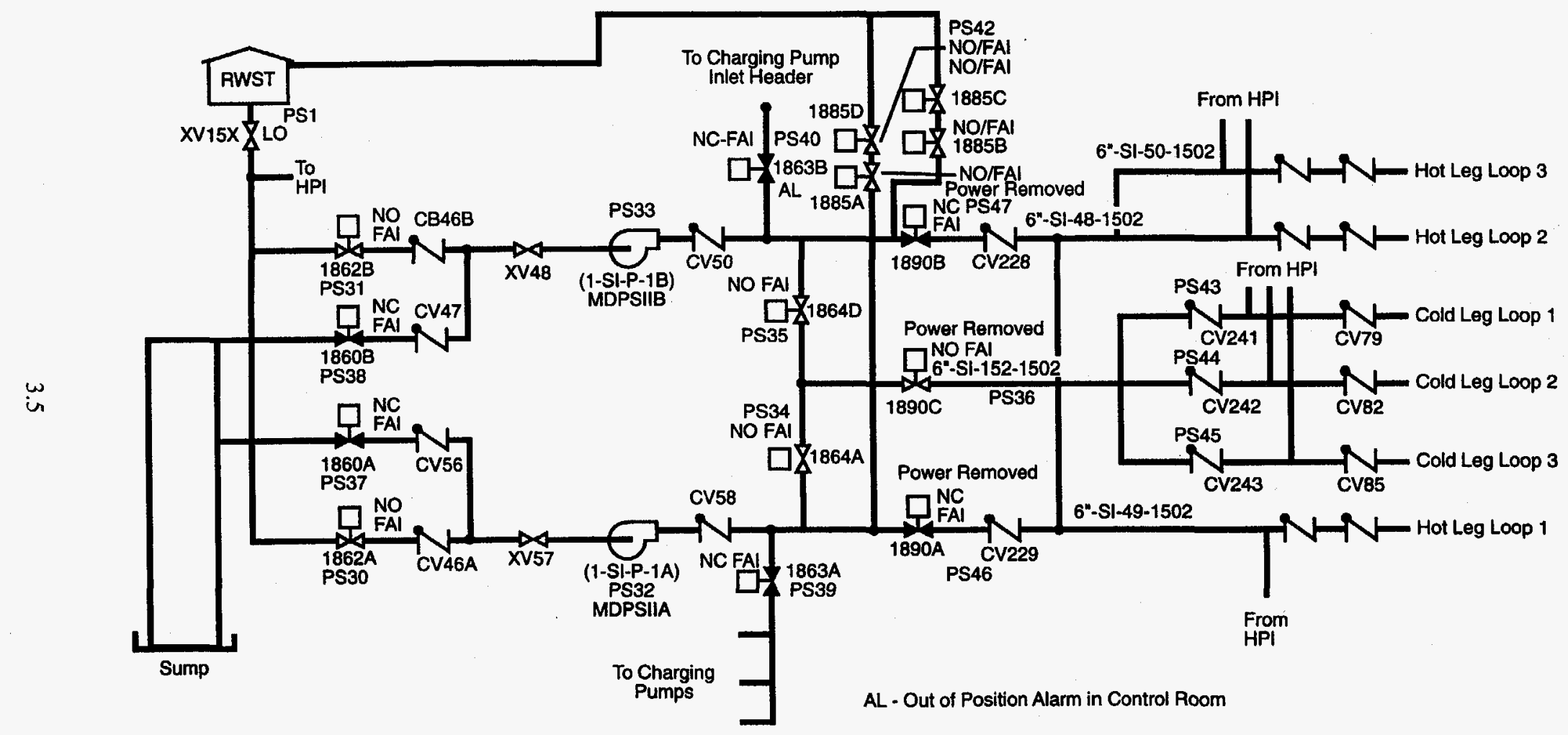

R9312053.3

Figure 3.2 Surry-1 low-pressure injection/recirculation system simplified schematic 
pressure piping butt welds containing radioactive fluid, at greater than $600^{\circ} \mathrm{F}$ and $600 \mathrm{psig}$, were radiographed. The remaining piping butt welds were randomly radiographed. Pressure-containing components are inspected for leaks from pump seals, valve packing, flanged joints, and safety valves during system testing. Frequency of testing and maintenance of the system components are specified in the ASME, Section XI.

\subsubsection{Reactor Coolant System}

The function of the RCS is to remove heat and transfer it to the secondary system. It also provides a barrier against the release of reactor coolant or radioactive materials to the containment environment. The RCS for Surry-1 is diagramed in Figure 3.3. It consists of three identical heat transfer loops (connecting parallel to the RPV), each of which includes a steam generator, reactor coolant pump, connecting piping and instrumentation for flow and temperature measurements.
The pipes through which the heated water flows from the RPV to the steam generator are called the "hot legs" and the pipes through which the cooled water flows from the steam generator and back into the RPV are called the "cold legs." The working fluid is boiled on the secondary sides of the steam generator and transported through a conventional turbine-condenser system.

The RCS also includes a pressurizer that maintains the reactor coolant at a constant pressure. The pressurizer system consists of power-operated relief valves with associated block valves, ASME code safety valves, pressurizer sprays, and electrical heaters. There is continuous control of the water and steam inventory within the pressurizer vessel. The pressurizer is connected to a coolant loop and is maintained at the saturation temperature that corresponds to the system pressure.

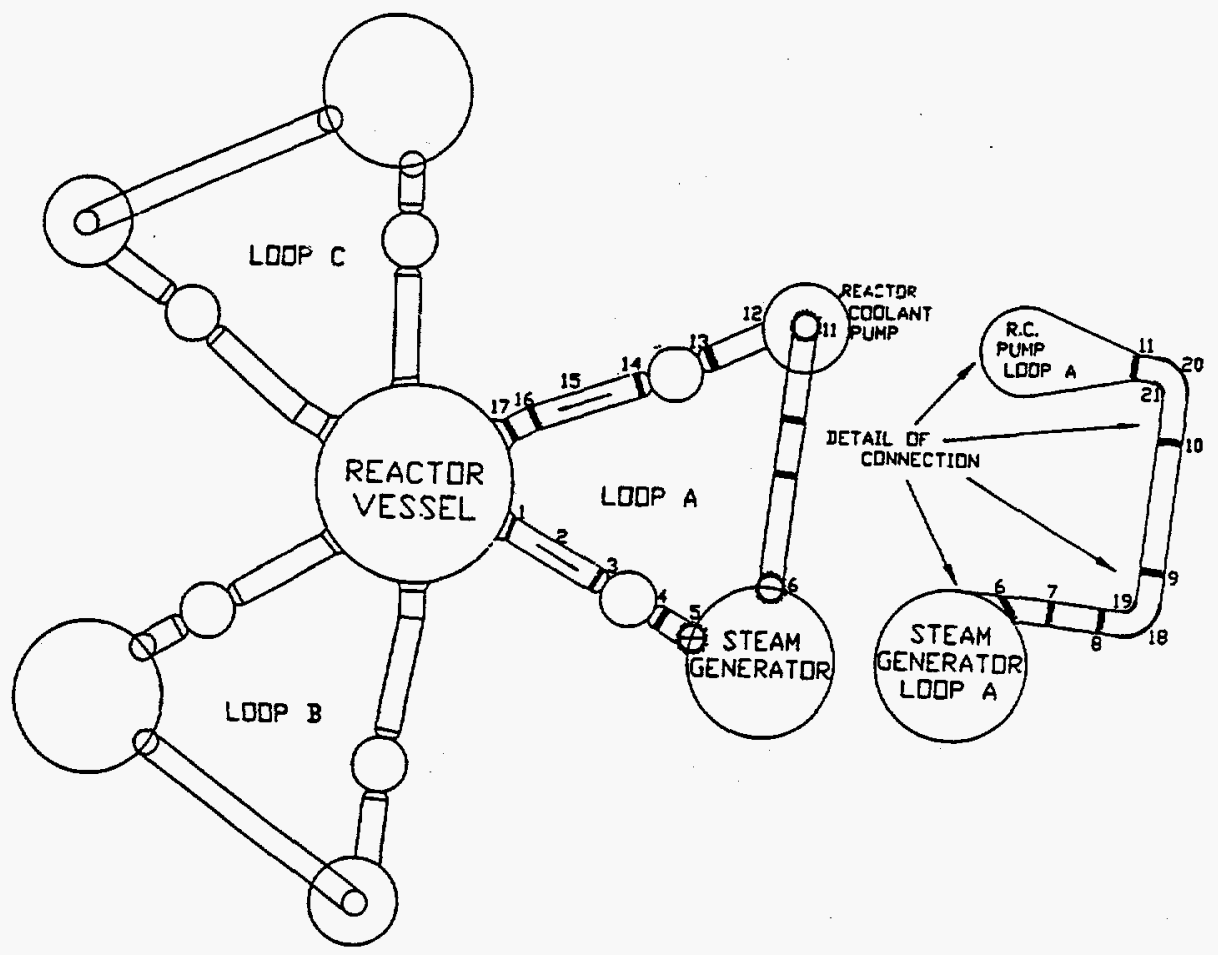

Figure 3.3 Surry-1 reactor coolant system simplified schematic 
To regulate the reactor coolant chemistry within design limits and control the pressure level, a constant letdown flow from one loop upstream of the reactor coolant pump is maintained. This flow is, in turn, controlled by the pressurizer level. Constant coolant makeup is added by charging pumps in the chemical and volume control systems. The inservice integrity of the RCS is addressed through periodic inspections performed in accordance with the requirements of ASME, Section XI.

\subsection{Analysis Assumptions}

General assumptions used for the analyses are the following:

- Core damage frequency was used as the bottom-line risk measure to prioritize plant system components.

- For the three selected systems, the discrete components (piping segments, welds, fittings, etc.) are identified for purposes of the risk-informed evaluation. For the systems analyzed, the components of interest were pipe segments. Each pipe segment included the straight lengths of pipe, pipe elbows, couplings, fittings, flanged joints, and welds. Additionally, tanks and heat exchangers, including the pressurizer, are also included as components in the analyses. The reactor pressure vessel and the accumulator systems are not included in this report.

- Generally, the risk achievement worth (RAW) results reported in NUREG/CR-4550 were used to provide the contributions to probabilities of core damage given the component failures.

- Identical components in identical trains within the same system were assumed to have the same failure consequences.

- The pipe segments are grouped on the basis of similar consequence. The grouping process was based on available information reported in NUREG/CR-4550.

- Operator actions regarding pipe rupture recovery are not considered.
- In these analyses, failures in piping of less than 1-in. diameter generally are not considered, primarily because of the enormous amount of instrumentation piping of this size. Active functions of components such as pumps and valves, which make up part of the system pressure boundary, are not considered. Steam generator tube failures have been considered in other studies and are not included in this study.

- Only breaks/ruptures that are greater than make-up capability and/or needed to disable the intended system function were considered.

- The Standard Review Plan 3.6.2, developed by the NRC (1981), was used in determining the indirect effects (e.g., pipe whip, jet forces, etc.) of component failures, when such failures effected other components in the zone of interest (e.g., vital electrical buses). Additionally, when a larger diameter pipe impacts a smaller diameter pipe of the same pipe schedule, a smaller diameter pipe is assumed to fail.

- Potential flooding due to pipe ruptures that could damage safety-related systems and equipment are not included in these analyses. Flooding should be addressed at a later date.

\subsection{Component Prioritization}

The following sources of information were used to prioritize components for inspection: 1) the component failure probabilities estimated from expert judgment elicitation (Vo et al. 1990, 1991, 1993), and 2) Surry-1 PRA (NUREG/CR-4550 Bertucio and Julius 1990). Commercially available PRA and spreadsheet programs were used for the calculations.

Worksheets were initially formulated using plant system drawings and other relevant plant-specific information. As stated in the assumptions, Standard Review Plan guidance developed by the NRC was used in determining the potential effects of system component failures on other components in the zone of interest. To ensure that plant models were as realistic as possible and reflected plant 
operational practices, visits to the Surry-1 plant were conducted for plant system walkdowns, and discussions were held with plant operational and technical staff. For locations where the walkdowns were not possible, (e.g., highradiation areas) the VIMS developed by VEPCO was used to identify the potentially impacted systems and equipment (given a failure of a component in the zone of interest).

The worksheets were devised so that the necessary information could be systematically tabulated. In the following paragraphs, the example of the AFW system is discussed. The detailed calculations are provided in Appendix A of this report.

The first step of the analysis was to identify the component locations and/or the number of subcomponents within a specified pipe segment. For example, the AFW pipe segment between the check valve XV183 (pump suction) and the condensate storage tank (CST) consists of 13 welds, 6 elbows, 5 hangers, and 1 wall penetration. The pipe segment rupture probability was estimated as $1.9 \mathrm{E}-06$ per year as shown in Appendix A.

Information from the plant PRA, system walkdowns, discussions with VEPCO staff, and the standard review plan were used to determine the failure effects. For the pipe segment above, the primary effect of a pipe segment failure was conservatively assumed to be the loss of CST which supplies all AFW pumps. The Surry-1 PRA (NUREG/CR4550 ) was then used to estimate the contribution to CDF. For instance, page E-13 in the NUREG/CR-4550 contains the RAW value for basic event AFW-TNK-VF-CST (2.8E-03).

Depending upon type of consequence; one of three equations provided in Section 2 was then used to compute the pipe segment core damage frequency. In this case, Equation 2.1 was applied and the pipe segment $\mathrm{CDF}$ was estimated as $1.5 \mathrm{E}-06 / \mathrm{yr} *(\mathrm{~T} / 2) * 2.8 \mathrm{E}-03=1.1 \mathrm{E}-07$, where $T=40$ year inspection interval.

Once this was completed, a total contribution to core damage frequency was calculated by summing across each individual pipe segment CDF. Note, grouping of the smaller pipe segments with the same consequences is for the purpose of prioritization and demonstration. For example, in the AFW system, the total CDF for pipe segment AFW-1 named "CST, Supply Line" which includes the piping between XV183 to CST and six other individual pipe runs was estimated as $1.0 \mathrm{E}-06$. This value describes the expected risk-informed implication of the segment under consideration.

\subsection{Results of Analyses}

Within the three systems analyzed, there are approximately 200 individual pipe segments. By assuming that identical components in identical trains within the same system have the same failure probabilities and consequences, this total is reduced to approximately 100 . For ranking purpose, components within the same train can be further grouped, based on major discontinuities (e.g., between pumps and major valves). This resulted in 24 major groups within the systems analyzed.

Table 3.1 shows the results of the risk-informed ranking of major components within three selected systems at Surry-1, based on the contributions of component failures to core damage frequency. Using input and data described earlier and under a PNNL contract and guidance, the ASME Research Task Force conducted the calculations using the revised methodology described in Section 2.1 of this report. Included in Table 3.1 are the estimated upper- and lowerbound values which indicate the effects of uncertainties in the estimates of component rupture probabilities. (Note that the pipe rupture probabilities used for the table are the sum of the rupture probabilities of all individual pipe segments making up the major component groupings of interest.) The rankings (as shown in the table) are based on the median values estimated from the Surry-1 PRA and PNNL evaluations of other factors such as rupture probabilities, as discussed in the preceding section. Figure 3.4 presents this information graphically for the three systems. As shown in Table 3.1, the contributions of different components to core damage frequency (based on the median values) range widely from about $1.0 \mathrm{E}-12$ to 6.0E-06 per plant year. The cumulative risk contribution from all components as shown in Figure 3.5 is about $1.8 \mathrm{E}-05$ per plant year. It is interesting to note that the risk contribution is dominated by approximately the first 12 highest-ranked components. The system level rankings obtained by summing contributions are the following: 1) AFW, 2) LPI, and 3) RCS.

Table 3.2 shows the risk importance parameters for the 24 major components identified in Table 3.1, which are ranked based on core damage frequency. 
Table 3.1 Component rankings based on core damage frequency for three selected systems at Surry-1 ${ }^{1}$

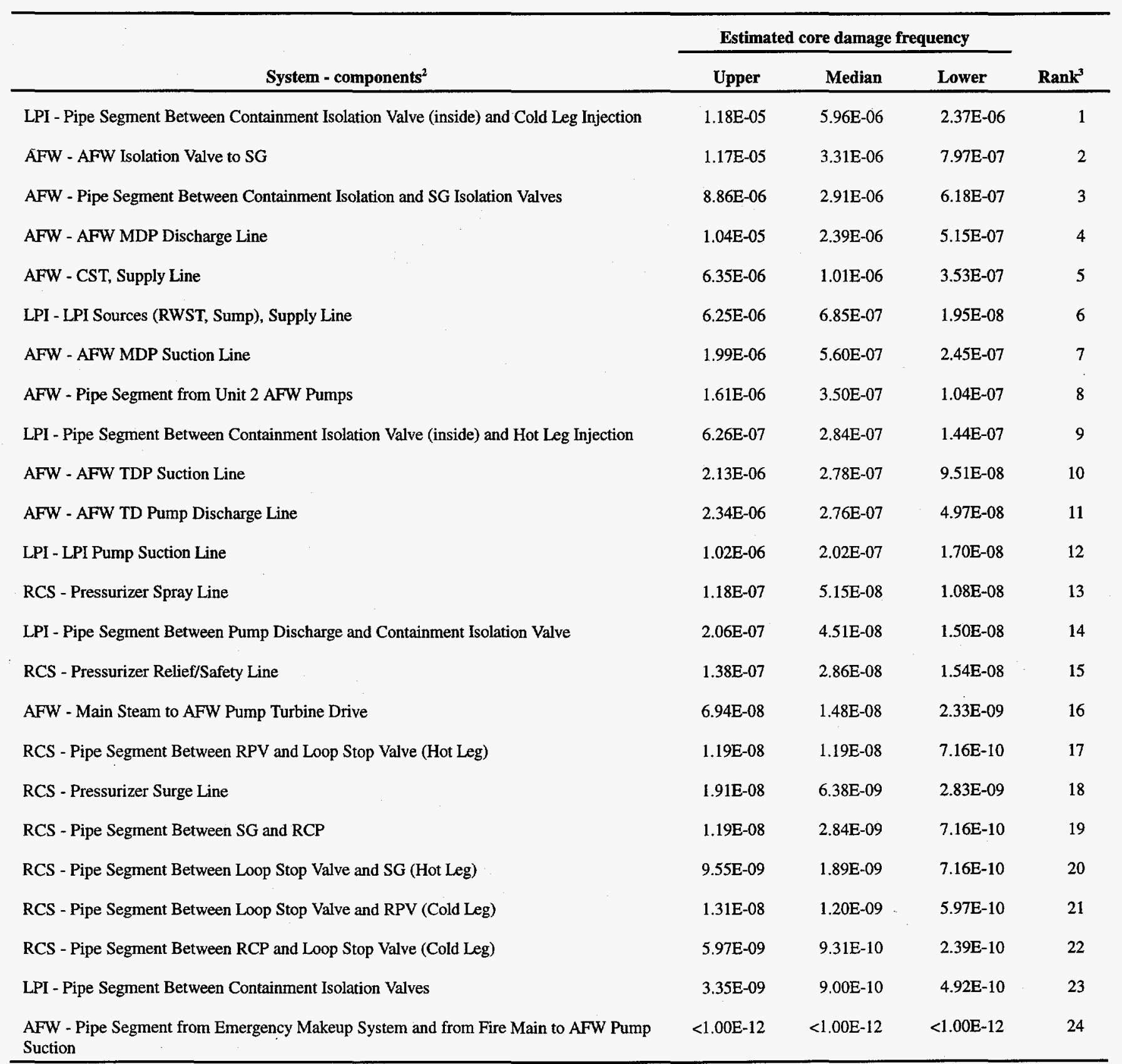

'Based on estimated median values of component rupture probabilities.

${ }^{2} \mathrm{AFW}=$ Auxiliary Feedwater; LPI = Low Pressure Injection; RCS = Reactor Coolant System.

${ }^{3}$ Rankings were based on median values. 


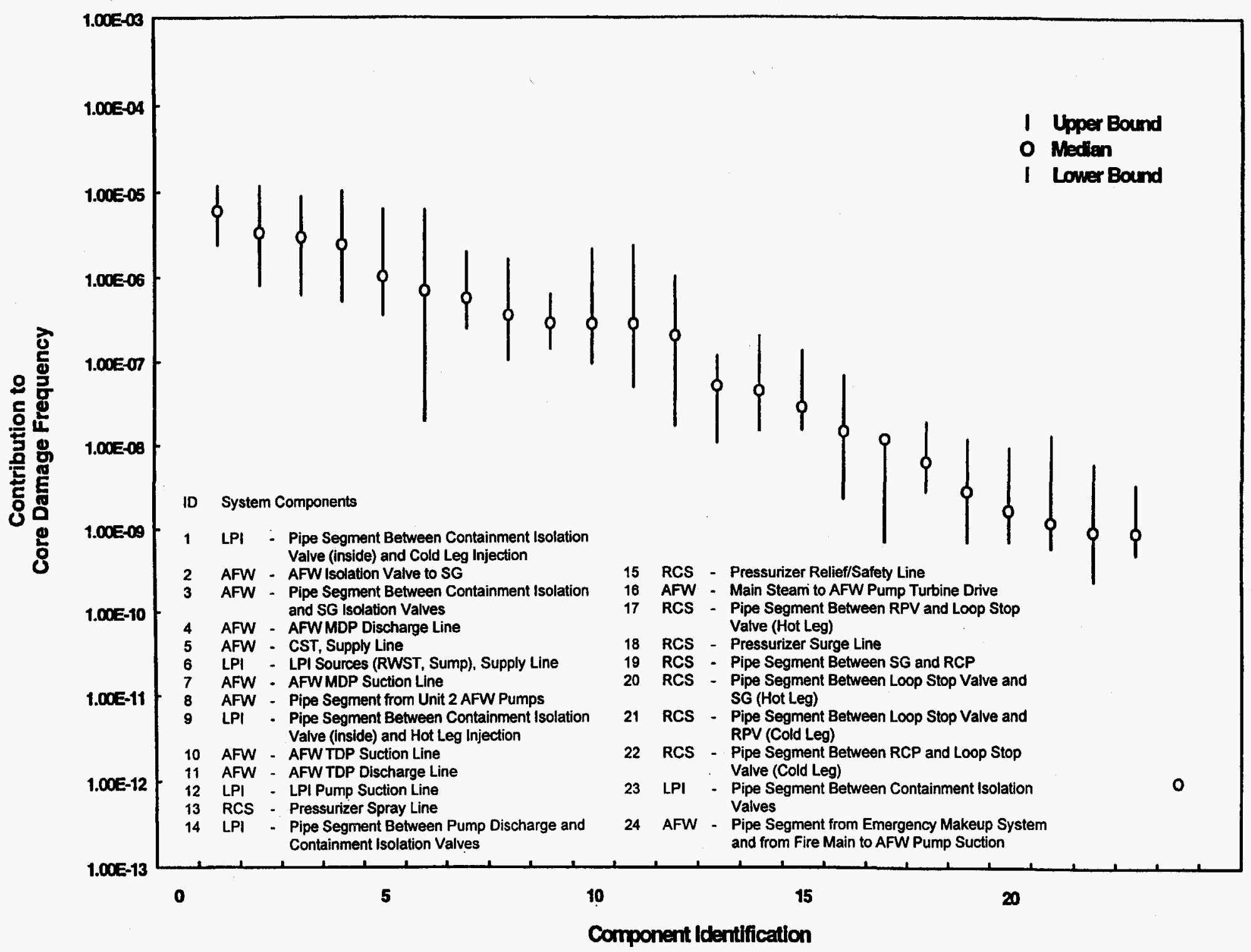

\section{Component Identlfication}

Figure 3.4 Risk contributions of Surry-1 components 


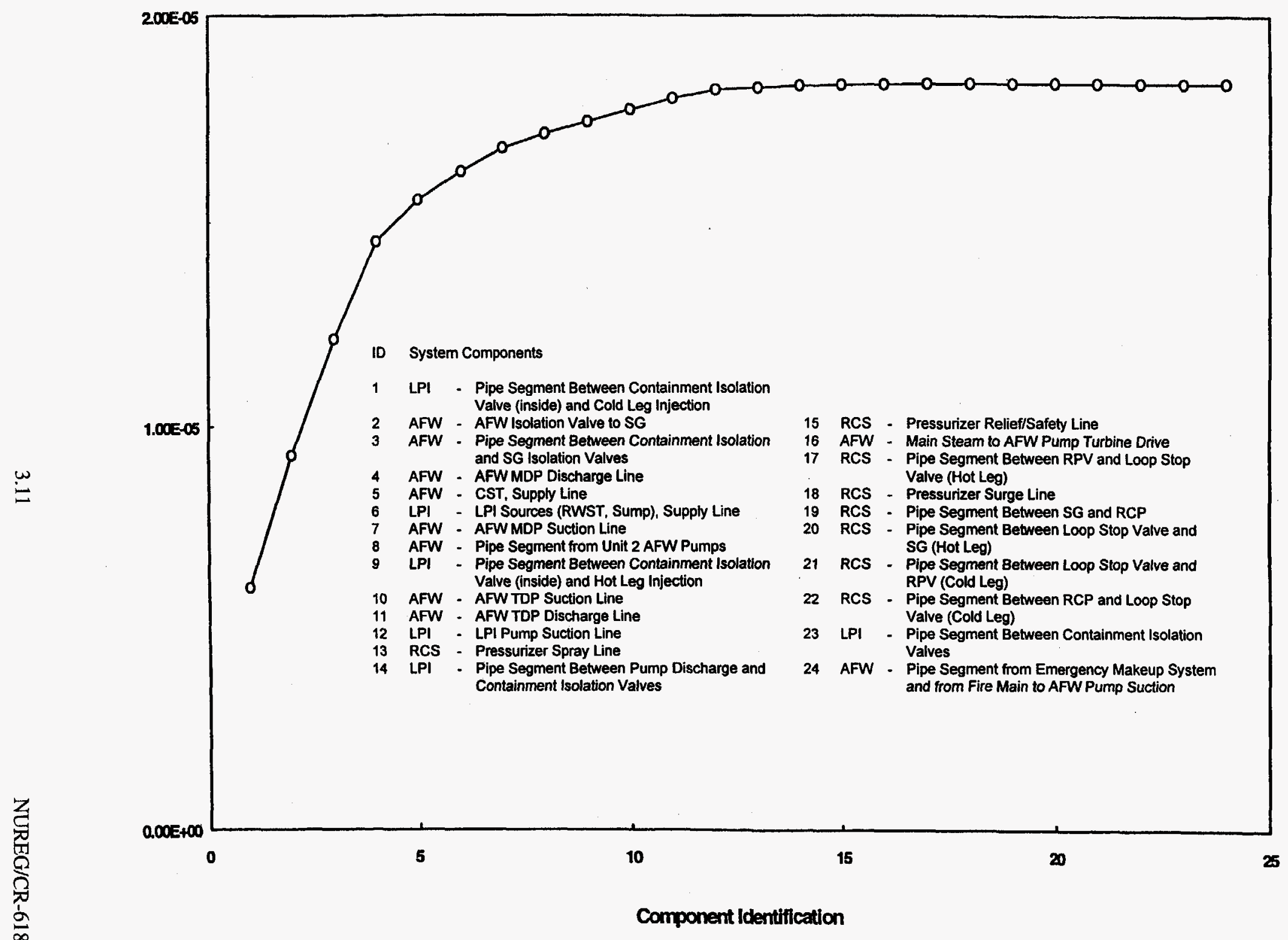

Figure 3.5 Cumulative risk contributions for Surry-1 components 
Table 3.2 Risk importance for components of selected systems at Surry-1 $1^{1}$

\begin{tabular}{|c|c|c|c|}
\hline System component ${ }^{2}$ & Rank & $\begin{array}{c}\text { Rupture } \\
\text { frequency }\end{array}$ & $\begin{array}{c}\text { Core } \\
\text { damage } \\
\text { frequency }\end{array}$ \\
\hline $\begin{array}{l}\text { LPI - Pipe Segment Between Containment Isolation Valve (Inside) and Cold Leg } \\
\text { Injection }\end{array}$ & 1 & $2.65 \mathrm{E}-05$ & $5.96 \mathrm{E}-06$ \\
\hline AFW - AFW Isolation Valve to SG & 2 & $2.33 \mathrm{E}-04$ & 3.31E-06 \\
\hline AFW - Pipe Segment Between Containment Isolation and SG Isolation Valves & 3 & $5.27 \mathrm{E}-05$ & 2.91E-06 \\
\hline AFW - AFW MDP Discharge Line & 4 & 4.33E-05 & 2.39E-06 \\
\hline AFW - CST, Supply Line & 5 & $1.84 \mathrm{E}-05$ & 1.01E-06 \\
\hline LPI - LPI Sources (RWST, Sump), Supply Line & 6 & 2.34E-05 & 6.85E-07 \\
\hline AFW - AFW MDP Suction Line & 7 & $1.01 \mathrm{E}-05$ & $5.60 \mathrm{E}-07$ \\
\hline AFW - Pipe Segment from Unit 2 AFW Pumps & 8 & $3.00 \mathrm{E}-06$ & $3.50 \mathrm{E}-07$ \\
\hline $\begin{array}{l}\text { LPI - Pipe Segment Between Containment Isolation Valve (inside) and Hot Leg } \\
\text { Injection }\end{array}$ & 9 & $1.33 \mathrm{E}-05$ & $2.84 \mathrm{E}-07$ \\
\hline AFW - AFW TDP Suction Line & 10 & 5.03E-06 & $2.78 \mathrm{E}-07$ \\
\hline AFW - AFW TDP Discharge Line & 11 & $5.00 \mathrm{E}-06$ & $2.76 \mathrm{E}-07$ \\
\hline LPI - LPI Pump Suction Line & 12 & 7.65E-06 & 2.02E-07 \\
\hline RCS - Pressurizer Spray Line & 13 & $2.76 \mathrm{E}-05$ & $5.15 \mathrm{E}-08$ \\
\hline LPI - Pipe Segment Between Pump Discharge and Containment Isolation Valves & 14 & $1.29 \mathrm{E}-05$ & 4.51E-08 \\
\hline RCS - Pressurizer Relief/Safety Line & 15 & $8.41 \mathrm{E}-06$ & $2.86 \mathrm{E}-08$ \\
\hline AFW - Main Steam to AFW Pump Turbine Drive & 16 & $1.51 \mathrm{E}-05$ & $1.48 \mathrm{E}-08$ \\
\hline RCS - Pipe Segment Between RPV and Loop Stop Valve (Hot Leg) & 17 & $3.00 \mathrm{E}-06$ & $1.19 \mathrm{E}-08$ \\
\hline RCS - Pressurizer Surge Line & 18 & $1.60 \mathrm{E}-06$ & $6.38 \mathrm{E}-09$ \\
\hline RCS - Pipe Segment Between SG and RCP & 19 & $9.24 \mathrm{E}-07$ & $2.84 \mathrm{E}-09$ \\
\hline RCS - Pipe Segment Between Loop Stop Valve and SG (Hot Leg) & 20 & 4.35E-07 & $1.89 \mathrm{E}-09$ \\
\hline RCS - Pipe Segment Between Loop Stop Valve and RPV (Cold Leg) & 21 & $3.06 \mathrm{E}-07$ & $1.20 \mathrm{E}-09$ \\
\hline RCS - Pipe Segment Between RCP and Loop Stop Valve (Cold Leg) & 22 & $2.45 \mathrm{E}-07$ & $9.31 \mathrm{E}-10$ \\
\hline LPI - Pipe Segment Between Containment Isolation Valves & 23 & $1.83 \mathrm{E}-06$ & $9.00 \mathrm{E}-10$ \\
\hline $\begin{array}{l}\text { AFW - Pipe Segment from Emergency Makeup System and from Fire Main to AFW } \\
\text { Pump Suction }\end{array}$ & 24 & $8.06 \mathrm{E}-06$ & $<1.00 \mathrm{E}-12$ \\
\hline
\end{tabular}

${ }^{3}$ Based on estimated median values.

${ }^{2} \mathrm{AFW}=$ Auxiliary Feedwater LPI $=$ Low Pressure Injection; RCS = Reactor Coolant System. 


\subsection{Sensitivity Analyses}

There are various sources of uncertainty in the numerical results of this study. This section describes specific sources of uncertainty and provides the results of sensitivity analyses.

\subsubsection{Sources of Uncertainty}

Two basic types of uncertainties addressed in this study were parameter value uncertainty and modeling uncertainty. Parameter value uncertainties were evaluated for component rupture probabilities. Modeling uncertainty was evaluated for the treatment of the indirect effects of the component failures.

The uncertainties in the component rupture probabilities have been addressed in Vo et al. 1990. For example, the population quartile was chosen to describe uncertainty in the estimates of component rupture probabilities (see Figure 2.2). The uncertainties in CDF estimation, component unavailabilities, initiating event frequencies, and cutset element unavailabilities and their associated modeling were not addressed in this study. Consideration of functional dependencies and common-cause effects on systems were based on the results evaluated by the selected PRAs.

There are many variables involved in calculating the indirect effects given a pipe break (e.g., location of pipe break, orientation of the equipment, direction of whipping pipe, number of hangers and/or supports, impact location, angle of impacts, etc.). Guidance provided in the Standard Review Plan 3.6.2 and information obtained through discussions with VEPCO staff during system walkdowns were used to assess the indirect effects. The assessments of the indirect effects using Standard Review Plan 3.6.2 are likely to be conservative. A sensitivity evaluation was performed by excluding the potential indirect effects of component failures from the model (e.g., pipe whip or jet impingement effects) and recalculating the overall core damage frequency.

\subsubsection{Results of Sensitivity Analyses}

Sensitivity analyses were performed on issues that could potentially have significant impacts on component rankings. The sensitivity analyses addressed the changes in component rankings by using upper- and lower-estimated values of component rupture probabilities as reported in Vo et al. (1990). As shown previously in Table 3.1, although variation exists in the numerical results, most components have relatively the same ranking, as compared to the ranking based on the median values. The largest variations in component ranking were the LPI supply lines and sources, pipe segments extending from isolation valves to the steam generator, LPI pump suction line, and pump suction and discharge lines of the AFW system. Pipe segments between the RCS loop stop valves and the RPV have moderate variations in ranking.

Sensitivity analyses were performed to address contributions to core damage from indirect effects of component failures. The preliminary results show that contributions of the indirect effects to the overall core damage frequency are negligible (less than $2 \%$ ). The pipe segment identified to have greatest potential failure effects on the other systems nearby was the pipe segment between LPI pump discharge line and the containment isolation valve. Rupture of this line could disable the charging pump inlet header.

Although analyses regarding potential flooding within the plant due to pipe ruptures were not part of this study, a complete study should include flooding. This is an important issue and should be addressed. Component risk prioritization for the entire reactor system should be completed and the main steam and main feedwater lines should be included in the evaluation. 


\subsection{Discussion of the Results}

This section discusses the results presented in Section 3.0. The discussions are based on the estimated median parameter values. As noted in Section 3.0, risk-importances for the LPI-accumulator system are not included in the discussion.

The rankings of Table 3.1 were developed on the basis of core damage frequency. In this discussion we will identify the factors that govern these rankings, beginning with the highest ranked segment and ending with the lowest ranked segment.

The pipe segments in the current study were defined for convenience such as group runs of pipe with similar consequences of failure. The definitions were also based in part to correspond with information as reported in NUREG/CR-4550. As a result, there were some large differences between the segments in terms of the total length of pipe and the numbers of welds and fittings within each segment. This has the potential to distort the rankings, because a segment can have a high failure probability by virtue of the large number of welds and fittings within the segment. Future refinements of the ranking process should work to minimize distortions of the ranking process by seeking an appropriate balance between the accuracy of the ranking calculations and the computational effort needed to perform calculations.

For discussion purposes in this section, we refer to "highrisk importance components" as those having a core damage frequency greater than $1.00 \mathrm{E}-07$ and we refer to "low-risk importance components" as those having core damage frequencies less than $1.00 \mathrm{E}-08$.

\subsection{High-Risk Importance Components}

Pipe segments of the LPI system extending from the inside containment isolation valves to the RCS cold- and hot-leg injection headers were identified to be high risk-important components. The high rankings are due to the relatively high stresses, potential for overpressurization of these lines, and the important functions of these lines in providing coolant to he RCS following a large LOCA. The LPI supply lines and water sources (e.g., refueling water storage tank and containment sump) and the pump suction lines were also important but had somewhat lower rankings due to relatively lower estimated rupture frequencies and/or RAW values of these components.

The high-risk importance was also identified for components located within the AFW system. A high-risk importance is associated with the pipe segments between containment isolation valves and steam generators, and motor- and turbine-driven pump discharge lines of the AFW system. The importance of these lines is due to a combination of high stress and high conditional core damage resulting from a line rupture. Failures of the pipe segment extending from the AFW isolation valves to the steam generators would result in steam generator blowdown through the break (similar to a main steam line break) and a loss of secondary cooling. Relatively high rankings were calculated for the pipe segments of the AFW system supply lines and sources (e.g., condensate storage tank), the motor-driven and turbine-driven pump suction lines, and pipe segment from Unit $2 \mathrm{AFW}$ pumps. Although these pipe segments have relatively low pressure, failure of these pipe segments could disable the entire AFW system, and thus contribute significantly to core damage. The importance of the Unit 2 pump cross-connected line is due to its key function in providing cooling to the steam generators in the case that Unit $1 \mathrm{AFW}$ is lost. This cross-connected line is also used for mitigating other initiating events (e.g., station blackout).

\subsection{Low-Risk Importance Components}

As shown in Table 3.1, the next risk-important pipe segments are the RCS pressurizer spray line, pressurizer relief/ safety line, and the main RCS piping from the hot-leg stop valves to the pressure vessel. Failure of any of these lines results in a large LOCA. The importance of the pressurizer spray line results from a relatively high-estimated failure probability due to thermal stress and the key function of this line in controlling the desired primary system pressure. Failure of the spray line could result in LOCAs in Loops A and $\mathrm{C}$, in addition to the loss of the pressurizer function.

Low rankings were estimated for the pipe segments of the LPI system for the LPI system extending from the pump discharge lines to the containment isolation valves (pipe 
segment between pump discharge and containment isolation valves and pipe segment between containment isolation valves). The importance of these lines is due to their important safety functions in providing coolant to the RCS following an accident. Equal importance was calculated for the pipe segment of the AFW system extending from steam supply lines to the AFW pump turbine drive. The importance of this line is due to a combination of high stress and high system unavailability resulting from a line rupture.

Lower importances are noted for the RCS pressurizer surge line and the main RCS piping from the steam generators to the reactor coolant pumps (RCPs), and the pipe segments from cold- and hot-leg stop valves, and the pipe segments from the RCPs to the loop stop valves. Failures of any of these lines results in a large LOCA which cannot be isolated by the loop stop valves, as is the cases with other segments of the main RCS main piping. High estimated consequences resulting from lines being connected to the RCS loop (e.g., safety injection, RHR lines, etc.) increase the importance of these particular pipe segments within the reactor coolant loop.

The cumulative risk contribution for all components (as shown in Table 3.1) for the three system is about 1.8E-05 per plant year. Significant contributions to risk come only from failures of approximately the first 12 components $(99 \%)$. The single LPI line extending from the inside containment isolation valves to the RCS cold leg injection dominates the risk, accounting for almost $32 \%$ of the core damage frequency due to component ruptures. The AFW pipe segments extending from the AFW supply lines and sources, motor-driven pump discharge lines to the containment isolation valves, containment isolation valves to steam generator isolation valves, and isolation valve to steam generator account for another $52 \%$. The various welds in the AFW and LPI systems contribute another $15 \%$. This adds up to $99 \%$ of the total core damage frequency risk associated with component ruptures for the three systems analyzed. The system level rankings derived from the component contributions to core damage are the following: 1) AFW, 2) LPI, and 3) RCS.

Table 4.1 presents the Surry-1 plant-specific ASME classifications and required ISI examinations for each piping segments or components of Table 3.1. Table 4.1 shows that ASME classifications and ISI requirements are in partial agreement with the importance rankings based on core damage frequency. The first twelve components contribute the most risk (99\%) for the three systems studied.

However, the inspection requirements from Table 4.1 for six of these twelve components require only a visual inspection. The other six require a more stringent inspection of a volumetric or a combination of a volumetric and surface examination. Furthermore, recommendations for setting inspection requirements based solely on Table 4.1 should be made cautiously because all plant systems and components must be considered. 
Table 4.1 Component importance ranking ${ }^{1}$ compared with ASME BPVC Section XI classifications and ISI requirements for selected systems at Surry-1 ${ }^{2}$

\begin{tabular}{|c|c|c|c|c|}
\hline \multirow{2}{*}{\multicolumn{2}{|c|}{ System-component }} & \multirow[b]{2}{*}{ Rank } & \multicolumn{2}{|c|}{ ASME BPVC system } \\
\hline & & & Category & Examination \\
\hline LPI & $\begin{array}{l}\text { Pipe Segment Between Containment Isolation Valve } \\
\text { (inside) and Cold-Leg Injection }\end{array}$ & 1 & B-J, C-F-1 & Volumetric and Surface \\
\hline AFW & AFW Isolation Valve to $\mathrm{SG}$ & 2 & C-F-1 & Volumetric and Surface \\
\hline AFW & $\begin{array}{l}\text { Pipe Segment Between Containment Isolation and SG } \\
\text { Isolation Valves }\end{array}$ & 3 & $\mathrm{C}-\mathrm{F}-1$ & Volumetric and Surface \\
\hline AFW & AFW MDP Discharge Line & 4 & D-B & Visual \\
\hline AFW & CST, Supply Line & 5 & D-B & Visual \\
\hline LPI & LPI Sources (RWST, Sump), Supply Line & 6 & D-C & Visual \\
\hline AFW & AFW MDP Suction Line & 7 & D-B & Visual \\
\hline AFW & Pipe Segment from Unit 2 AFW Pumps & 8 & C-F-1 & Volumetric \\
\hline LPI & $\begin{array}{l}\text { Pipe Segment Between Containment Isolation Valve } \\
\text { (inside) and Hot-Leg Injection }\end{array}$ & 9 & B-J, C-F-1 & Volumetric and Surface \\
\hline AFW & AFW TDP Suction Line & 10 & D-B & Visual \\
\hline AFW & AFW TD Pump Discharge Line & 11 & D-B & Visual \\
\hline LPI & LPI Pump Suction Line & 12 & C-F-1 & Volumetric and Surface \\
\hline RCS & Pressurizer Spray Line & 13 & B-J & Volumetric \\
\hline LPI & $\begin{array}{l}\text { Pipe Segment Between Pump Discharge and Containment } \\
\text { Isolation Valve }\end{array}$ & 14 & C-F-1 & Volumetric and Visual \\
\hline RCS & Pressurizer Relief/Safety Line & 15 & B-J & Volumetric \\
\hline AFW & Main Steam to AFW Pump Turbine Drive & 16 & C-F-1 & Volumetric \\
\hline $\mathrm{RCS}$ & $\begin{array}{l}\text { Pipe Segment Between RPV and Loop Stop Valve (Hot } \\
\text { Leg) }\end{array}$ & 17 & B-J & Volumetric \\
\hline RCS & Pressurizer Surge Line & 18 & B-J & Volumetric \\
\hline RCS & Pipe Segment Between SG and RCP & 19 & B-J & Volumetric \\
\hline $\mathrm{RCS}$ & $\begin{array}{l}\text { Pipe Segment Between Loop Stop Valve and SG (Hot } \\
\text { Leg) }\end{array}$ & 20 & B-J & Volumetric \\
\hline RCS & $\begin{array}{l}\text { Pipe Segment Between Loop Stop Valve and RPV (Cold } \\
\text { Leg) }\end{array}$ & 21 & B-J & Volumetric \\
\hline RCS & $\begin{array}{l}\text { Pipe Segment Between RCP and Loop Stop Valve (Cold } \\
\text { Leg) }\end{array}$ & 22 & B-J & Volumetric \\
\hline LPI & Pipe Segment Between Containment Isolation Valves & 23 & $\mathrm{C}-\mathrm{F}-1$ & Volumetric and Visual \\
\hline AFW & $\begin{array}{l}\text { Pipe Segment from Emergency Makeup System and from } \\
\text { Fire Main to AFW Pump Suction }\end{array}$ & 24 & D-B & Visual \\
\hline
\end{tabular}

${ }^{1}$ Ranking based on Table 3.2.

${ }^{2}$ Based on Surry-1 plant-specific system classifications. 


\subsection{Summary and Conclusions}

As part of the work sponsored by the NRC, PNNL has been pioneering the application of risk-informed techniques that can be used for improving ISI plans for nuclear power plants. The goal of this work was to develop methodologies to improve ISI plans (what and where to inspect, and how reliably and how often to inspect) to ensure that degradation in components important to safety could be reliably detected before structural integrity would be compromised. To accomplish the first step in this activity - that is, to rank the components' importance to safety and assign commensurate probability of failure goals, to be maintained with the aid of inspection, for the various components-the use of PRAs was explored.

PNNL's work involved two risk-informed methodologies. The "approximate risk-informed methodology" was developed in the mid 1980s and applied to the Surry-1 nuclear power plant. This approximate methodology was appropriate for use with early PRAs that reported system importances and commonly reported only abbreviated lists of dominant cutsets, which typically did not include the necessary information for all components (or pipe segments) of interest. It assessed component risk contributions by combining system risk importance with the conditional probabilities of system failure, to provide an approximate quantitative measure of component risk importance (NUREG/CR-6181, 1994). This methodology utilized the reanalysis of system fault trees by simulating the failures of pressure boundary components by substituting the failure of surrogate active components modeled in the fault trees. Results from the system level and component level were combined, along with estimated values of component rupture probabilities, into an approximate methodology for determining the risk importance of individual components. At that time, requantification of the PRA was impractical because of limitations on software and data storage and handling capabilities, so that an approximate methodology was needed.

The revised risk-informed methodology eliminates the determination of system risk importances, and proceeds to directly analyze component risk importances from the cutset output of the PRA. The revised methodology utilizes lessons learned from the approximate methodology and from recent research efforts being performed by the ASME Research Task Force on Risk-Based ISI. In summary, the contribution to core damage frequency for a pipe segment (or component), and a consequence type were assigned for each pipe segment. To compute the contribution to CDF for a pipe segment, the plant PRA was reviewed to find a basic event whose failure would have the same effect as a pipe break. Likewise, from the PRA analysis, the RAW value for that basic event measures the contribution to core damage frequency given a pipe break.

It is important to note that this modification of the PNNL approximate risk-informed methodology improves the accuracy of the detailed risk rankings of individual components.

Both the "approximate" and the "revised" risk-informed methodologies have undergone a peer review by Dr. Bill Vesely of SAIC, an expert knowledgeable in riskbased applications. Dr. Vesely concluded that the approximate methodology was valid but it was difficult to apply and requires the PRA satisfy certain constraints. The revised methodology overcomes the constraints of the approximate approach. Further details of Dr. Vesely's review of the methodologies are provided in Appendix B.

This revised methodology has been applied in a pilot study to identify and prioritize the most risk-important components in three systems at the Surry-1 nuclear power plant. It should be noted that this analysis was performed for demonstration purposes. In the pilot application, the method used component failure probabilities estimated from expert judgment elicitation, relevant plant information, and the Surry-1 PRA to prioritize components.

The component rupture probabilities estimated by the expert judgment elicitation panels implicitly credited ISI activities and periodic testing of components. These component rupture probabilities may be underestimated due to inclusion of these activities, and it is recommended that fracture mechanics calculations be performed in the future to refine the estimates.

For the RCS piping, the estimations were based on plantspecific system operating conditions, stresses, consideration of aging, and the extensive base of fracture mechanics calculations for this system. The estimated values were approximately two orders of magnitude lower, as compared 
to the generic LOCA frequencies (all pipe sizes) reported in the NUREG/CR-4550. The lower probabilities are due to a combination of available plant-specific information, and the favorable operating history of PWR plants in the U.S. Because this study is based on the limited data and models, the results are approximate and subject to future refinement.

As shown in Table 3.1, contributions of component failures to core damage frequency range widely for different components from about $6.0 \mathrm{E}-06$ to $<1.0 \mathrm{E}-12$ per plant year. The cumulative risk contribution (as shown in Figure 3.5) is $1.8 \mathrm{E}-05$ per plant year. This estimated value is about $45 \%$ of the total Surry-1 PRA risk. The total estimated risk is dominated by failures of the auxiliary feedwater system components $(60 \%)$. This risk is followed by the lowpressure injection system components (39\%), and then other components within the reactor cooling system (1\%).

These results must be viewed in the light of the discussion in Section 2.2, which indicates the potential for overestimation of the importance of piping failures in standby systems. One reason for the overestimation is that IST can detect piping failures in standby systems; this can reduce the importance of ISI for standby systems. Another reason is that the LOCA frequencies from the Surry-1 PRA were used in estimating the Risk Achievement Worth of piping failures that cause only mitigating system degradation or loss, and these LOCA frequencies were two orders of magnitudes higher than those estimated by the expert panels. This introduces an overestimation of ISI priorities for standby systems used primarily to mitigate the effects of LOCAs; the overestimation is reduced in importance by the fact that injection systems are used to mitigate not only LOCAs from RCS piping failures, but also steam generator tube ruptures and reactor coolant pump seal LOCAs, and the frequencies of these events were not changed by the expert panels.

The sensitivity of component rankings to upper- and lowerbounding values of estimated rupture probabilities was established. As shown in Table 3.1, the results indicated no significant changes in component rankings. Additional sensitivity analyses addressed contributions to core damage frequency due to indirect effects of component failures. The results indicate that the overall contribution to core damage frequency from the indirect effects was negligible. Sensitivity and uncertainty analyses regarding potential flooding within the plant due to pipe ruptures were not performed. A complete study should include flooding.

Risk importances of components were qualitatively compared with the current Surry-1 plant-specific ASME classifications and required ISI examinations. The ASME classifications and ISI requirements are in partial qualitative agreement with risk-rankings based on core damage frequency. Only one-half of the components with the greatest contributions to the core damage frequency currently have the more stringent inspection requirements, while the other half only receives a visual inspection. However, final conclusions for setting inspection requirements should await further pilot studies.

In a study aimed at developing improved ISI plans, a complete analysis of the entire plant (all systems and components) is needed. The work reported here demonstrates a methodology that can be used for a complete analysis of an entire plant. This will provide a ranking of all components and their contribution to risk. The contributions to risk can be used to set probability of failure goals for the various components to be maintained with the aid of ISI. Probabilistic fracture/structural mechanics can then be used to assess various inspection strategies, that is combinations of probability of flaw detection and flaw sizing accuracy as a function of flaw size, and inspection frequencies needed to achieve the probability of failure goals. Improved ISI plans include the component sampling strategy, the inspection method, the inspection reliability, and the frequency of inspection.

The final ISI sampling plan should include components or elements from the risk studies (that includes all high-risk components), be supplemented with additional ISI to accommodate defense-in-depth, and address the additional objective of ISI to identify unanticipated degradation mechanisms that have not been detected or that have not yet occurred. 


\subsection{References}

ASME Research Task Force on Risk-Based Inspection Guidelines. 1991. Risk-Based Inspection - Development of Guidelines, Volume 1 General Document. CRTD-Vol. 20-1, American Society of Mechanical Engineers Center for Research and Technology Development.

ASME Research Task Force on Risk-Based Inspection Guidelines. 1992. Risk-Based Inspection, Volume 2Part 1: Light Water Reactor (LWR) Nuclear Power Plant Components. CRTD - Vol, 20-2, American Society of Mechanical Engineers Center for Research and Technology Development. (Also published by the U.S. Nuclear Regulatory Commission as NUREG/GR-0005, Vol. 2, Part 1, July 1993).

Bertucio, R. C., and J. A. Julius. 1990. Analysis of Core Damage Frequency: Surry, Unit I Internal Events. NUREG/CR-4550, Sandia National Laboratories, Albuquerque, New Mexico.

Khaleel, M. A., and F. A. Simonen. 1994a. "A Parametric Approach to Predicting the Effects of Fatigue on Piping Reliability," Service Experience and Reliability Improvement: Nuclear, Fossil and Petrochemical Plants, Vol. 1, ASME PVP Vol. 288, pp. 117-125, American Society of Mechanical Engineers.

Khaleel, M. A., and F. A. Simonen. 1994b. "The Effects of Initial Flaw Sizes and Inservice Inspection on Piping Reliability," Service Experience and Reliability Improvement: Nuclear, Fossil and Petrochemical Plants, Vol. 1, ASME PVP Vol. 288, pp. 95-107, American Society of Mechanical Engineers.

Khaleel, M. A., F. A. Simonen, D. O. Harris, and D. Dedhia. 1995. "The Impact of Inspection on Intergranular Stress Corrosion Cracking for Stainless Steel Piping," Risk and Safety Assessment: Where is the Balance, ASME PVP Vol. 266/SERA-Vol. 3, pp. 411-422, American Society of Mechanical Engineers.
Meyer, M. A., and J. M. Booker. 1989. Eliciting and Analyzing Expert Judgment. NUREG/CR-5424, Los Alamos National Laboratory, Los Alamos, New Mexico.

U.S. Nuclear Regulatory Commission (NRC). 1981. Standard Review Plan 3.6.2 Determination of Rupture Locations and Dynamic Effects Associated with the Postulated Rupture of Piping. NUREG-0800, Rev. 1, U.S. Nuclear Regulatory Commission, Washington, D.C.

U.S. Nuclear Regulatory Commission (NRC). 1989. Severe Accident Risks: An Assessment for Five U.S. Nuclear Power Plants. NUREG-1150, Summary Report, Second Draft For Peer Review, U.S. Nuclear Regulatory Commission, Washington, D.C.

U.S. Nuclear Regulatory Commission (NRC). 1990. Analysis of Core Damage Frequency: Surry, Unit 1 Internal Events. NUREG/CR-4550, SAND 86-2084, Vol. 3, Rev. 1, Part 1 and Part 2, Sandia National Laboratories.

Vo, T. V., B. W. Smith, F. A. Simonen, and S. R. Doctor. 1990. "Development of Generic Inservice Inspection Guidance for Pressure Boundary Systems." Nuclear Technology, Volume 92 (3), American Nuclear Society, La Grange Park, Illinois.

Vo, T. V., P. G. Heasler, S. R. Doctor, F. A. Simonen, and B. F. Gore. 1991. "Estimate of Component Rupture Probabilities. Expert Judgment Elicitation." Nuclear Technology, Volume 94 (1), American Nuclear Society, La Grange Park, Illinois.

Vo, T. V., F. A. Simonen, B. F. Gore, and J. V. Livingston. 1993. "Expert Judgment Elicitation on Component Rupture Probabilities for Five PWR Systems". PVP-Vol. 251. Reliability and Risk in Pressure Vessels and Piping. pp. 115-140, American Society of Mechanical Engineers. 
References

Vo. T. V., B. F. Gore, F. A. Simonen, S. R. Doctor. 1994. A Pilot Application of Risk-Based Methods to Establish Inservice Inspection Priorities for Nuclear Components at Surry Unit I Nuclear Power Station. NUREG/CR-6181, PNNL-9020. Pacific Northwest Laboratory, Richland, Washington.
Wheeler, T. A., S. C. Hora, W. R. Cramond, and S. D. Unwin. 1989. Analysis of Core Damage Frequency from Internal Events: Expert Judgment Elicitation. NUREG/CR-4550, Volume 2, Sandia National Laboratories, Albuquerque, New Mexico. 
Appendix A

Risk-Informed Calculation 


\section{Appendix A}

\section{Risk-Informed Calculation}

This appendix describes the component risk importance calculations for the auxiliary feedwater, low-pressure injection, and reactor coolant systems. The calculations use the revised methodology based on lessons learned from the PNNL approximate methodology and from recent research efforts performed by the ASME Research Task Force on Risk-Based ISI. The revised methodology is described in Section 2 of the main report and also in an ASME report. ${ }^{1}$

The following information was used for the component CDF analysis:

- The analysis uses pipe failure rates from Section 2 of this report.

- CDF was calculated using data and modeling from the Surry PRA (NUREG/CR-4550 1990).

This analysis was performed for components of the auxiliary feedwater, low pressure injection, and reactor coolant system. The worksheets and simplified P\&ID drawings were used for each system of interest. The P\&ID drawings were used to identify the pipe segment boundaries corresponding to those listed in Table 3.1 of the main report. Each pipe segment is composed of a set of individual components. The worksheets contain information specific to a pipe segment, such as the mean rupture probability and consequences of a pipe break in that segment. Using the methodology as described in Section 2 of the main report, core damage frequency calculations were performed for each pipe segment. Pipe segment core damage frequencies were calculated by summing the CDF for the components within the pipe segment.

To compute the contribution to CDF for a pipe segment, a consequence type was assigned to each pipe segment. The consequence type is categorized as being a component failure that causes system degradation, an initiating event, or a combination of system degradation and an initiating event. To compute the core damage frequency of a component, the Surry PRA was reviewed to find a basic event whose failure would have the same effect as a component failure. Likewise, from the PRA analysis, the RAW for that basic event measures the contribution to core damage frequency of a component failure. The Surry PRA (NUREG/CR-4550) contains RAW values for all the basic events modeled in the PRA. For example: Page E-13 contains the RAW value for basic event AFW-TNK-VF-CST (2.76E-03). The RAW for this basic event corresponds to the contribution to CDF for a pipe break that would cause the loss of all AFW. Depending upon the type of consequence; one of the three equations provided in Section 2 of the main report was then used to compute the component or pressure boundary core damage frequency.

Spreadsheets were developed to automate the core damage frequency calculations. Each row in the spreadsheet corresponds to a pipe segment. The key elements (column headings) of the spreadsheets are described as follows.

${ }^{1}$ ASME Research Task Force on Risk-Based Inspection Guidelines. Risk-Based Inspection, Volume 2 - Part 2: Light Water Reactor (LWR) Nuclear Power Plant Components. CRTD-Vol. 20-4, American Society of Mechanical Engineers Center for Research and Technology Department. To be published. 
Appendix A

- Column A identifies the pipe segment of interest.

- Columns $\mathrm{E}$ and $\mathrm{F}$ identify the pipe segment failure rate and failure consequence, respectively. This information was obtained from the FMEA worksheets.

- Column I contains the basic event in the Surry PRA whose failure would have the same consequence as a pipe break in the segment of interest.

- Column $\mathrm{J}$ contains the contribution to core damage frequency given a break in the pipe segment. This information was obtained from the PRA and was calculated in one of three ways (see the equations for $\mathrm{COND}_{\mathrm{CDF}}$ in the pipe segment $\mathrm{CDF}$ equations described in Section 2 of the main report).

- Column $\mathrm{M}$ contains the pipe segment $\mathrm{CDF}$ equation.

- Column $\mathrm{N}$ contains the core damage frequency given a pipe break for the segment of interest.

Table A.1 describes the contents of the spreadsheets in more detail, and Table A.2 summarizes the CDF results for Surry-1 AFW, LPI, and RCS pipe segments.

\section{References}

1. NUREG/CR-6181, A Pilot Application of Risk-Based Methods to Establish Inservice Inspection Priorities for Nuclear Components at Surry Unit 1 Nuclear Power Station, T. Vo, et. al, January 1994.

2. NUREG/CR-4550, Analysis of Core Damage Frequency: Surry, Unit 1 Internal Events, February 1990. 
Table A.1 Surry evaluation of pipe break core damage frequency

\begin{tabular}{|c|c|c|}
\hline ID & Column & Description \\
\hline A & Segment ID & $\begin{array}{l}\text { Corresponds to the system and component segment identification used in } \\
\text { NUREG/CR- } 6181 \text {. Listed underneath the segment ID is the CDF contribution for } \\
\text { the pipe segment. }\end{array}$ \\
\hline $\mathbf{B}$ & Description & $\begin{array}{l}\text { Corresponds to the system and component segment description in } \\
\text { NUREG/CR-6181. }\end{array}$ \\
\hline $\mathrm{C}$ & Element ID & $\begin{array}{l}\text { Corresponds to the piping segments used for the failure modes and effects } \\
\text { analysis. }\end{array}$ \\
\hline $\mathrm{D}$ & Element Description & Corresponds to the piping segment description. \\
\hline $\mathrm{E}, \mathrm{F}, \mathrm{G}$ & Rupture Probabilities & $\begin{array}{l}\text { Corresponds to the rupture probabilities assigned by the expert panel during the } \\
\text { failure modes and effects analysis. }(25 \% \text {, median, } 75 \%)\end{array}$ \\
\hline $\mathrm{H}$ & Units & Mean failure probability units; either probability or frequency. \\
\hline 1 & Consequence & $\begin{array}{l}\text { Corresponds to the consequence of a pipe break in a given segment. This } \\
\text { information corresponds to the failure effects from the FMEA. }\end{array}$ \\
\hline $\mathbf{J}$ & Type & $\begin{array}{l}\text { Corresponds to the type of failure consequence. The failure can cause either } \\
\text { system degradation, system degradation and an initiating event, or an initiating } \\
\text { event. }\end{array}$ \\
\hline $\mathrm{K}$ & Linked Basic Event & $\begin{array}{l}\text { Corresponds to the basic event in the IPE analysis used to measure the risk } \\
\text { increase in a pipe segment that would have the same failure effect as the basic } \\
\text { event. }\end{array}$ \\
\hline$L$ & Contribution to $\mathrm{CDF}$ & $\begin{array}{l}\text { Corresponds to the contribution to core damage frequency value given a pipe } \\
\text { break. }\end{array}$ \\
\hline $\mathbf{M}$ & Units & $\begin{array}{l}\text { Contribution to core damage frequency units; either probability or frequency (per } \\
\text { year). }\end{array}$ \\
\hline $\mathrm{N}$ & Inspection Interval & $\begin{array}{l}\text { Interval of pipe inspection or testing (in years) used for mean time between failure } \\
\text { calculation. }\end{array}$ \\
\hline $\mathrm{O}$ & CDF Equation & Equation used to compute the pressure boundary core damage frequency value. \\
\hline $\mathrm{P}, \mathrm{Q}, \mathrm{R}$ & $\mathrm{CDF}$ & Core damage frequency contribution for the pipe segment. ( $25 \%$, median, $75 \%$ ) \\
\hline $\mathbf{S}$ & Comments & General comments related to the pipe segment. \\
\hline
\end{tabular}


Table A.2 Surry evaluation of pipe break core damage frequency

\begin{tabular}{|c|c|c|}
\hline $\begin{array}{l}\text { System/ } \\
\text { segment }\end{array}$ & Segment ID & $\underset{\text { (median) }}{\mathrm{CDF}}$ \\
\hline LPI - 1 & Pipe segment between containment isolation valve and cold leg injection & $5.96 \mathrm{E}-06$ \\
\hline LPI - 2 & Pipe segment between containment valve and hot leg injection & $2.84 \mathrm{E}-07$ \\
\hline LPI - 3 & LPI sources (RWST, sump), supply line & $6.85 \mathrm{E}-07$ \\
\hline LPI - 4 & Pipe segment between pump discharge and containment isolation valve & 4.51E-08 \\
\hline LPI - 5 & Pipe segment between containment isolation valves & $9.00 \mathrm{E}-10$ \\
\hline LPI - 6 & LPI pump suction line & $2.02 \mathrm{E}-07$ \\
\hline AFW-1 & CST, supply line & $1.01 \mathrm{E}-06$ \\
\hline AFW-2 & Pipe segment between containment isolation and SG isolation valves & 2.91E-06 \\
\hline AFW-3 & Main steam to AFW pump turbine drive & $1.48 \mathrm{E}-08$ \\
\hline AFW-5 & AFW TD pump discharge line & $2.76 \mathrm{E}-07$ \\
\hline AFW-6 & Pipe segment from Unit $2 \mathrm{AFW}$ pumps & $3.50 \mathrm{E}-07$ \\
\hline AFW-7 & $\mathrm{AFW}$ isolation valve to $\mathrm{SG}$ & $3.31 \mathrm{E}-06$ \\
\hline AFW-8 & AFW MDP suction line & $5.60 \mathrm{E}-07$ \\
\hline AFW-9 & AFW MDP discharge line & $2.39 \mathrm{E}-06$ \\
\hline AFW-10 & AFW TDP suction line & $2.78 \mathrm{E}-07$ \\
\hline AFW-11 & $\begin{array}{l}\text { Pipe segment from emergency make-up system and from fire main to } \\
\text { AFW pump suction }\end{array}$ & $<1.00 \mathrm{E}-12$ \\
\hline RCS-1 & Pipe segment between loop stop valve and RPV (cold leg) & $1.20 \mathrm{E}-09$ \\
\hline RCS-2 & Pressurizes spray line & $5.15 \mathrm{E}-08$ \\
\hline RCS-3 & Pipe segment between RPV and loop stop valve (hot leg) & $1.19 \mathrm{E}-08$ \\
\hline RCS-4 & Pressurizer relief/safety line & $2.86 \mathrm{E}-08$ \\
\hline RCS-5 & Pressurizer surge line & $6.38 \mathrm{E}-09$ \\
\hline $\mathrm{RCS}-6$ & Pipe segment between SG and RCP & $2.84 \mathrm{E}-09$ \\
\hline RCS-7 & Pipe segment between loop stop valve and SG (hot leg) & $1.89 \mathrm{E}-09$ \\
\hline RCS-8 & Pipe segment between RCP and loop stop valve (cold leg) & $9.31 \mathrm{E}-10$ \\
\hline
\end{tabular}




\begin{tabular}{|c|c|c|c|}
\hline A & B & c & D \\
\hline SURRY AFW SYSTEM & & & \\
\hline & & ELEMENTS & ELEMENTS \\
\hline SEGMENT ID & DESCRIPTION & 10 & DESCAIPTION \\
\hline AFW-1 & CST, SUPPLY LINE & IA & XV183 TO CST1 \\
\hline & & 18 & XV168 TO CST1 \\
\hline & & $1 \mathrm{C}$ & XV153 TO CSTI \\
\hline & & 10 & CST1 To CV151 \\
\hline & & IE & CVI51 TO CST2 \\
\hline & & iF & est1 \\
\hline & & 10 & CsT2 \\
\hline & & & SuM \\
\hline & & & AVERAGE \\
\hline AFW-2 & PIPE SEGMENT BETWEEN CONTAINMENT ISOLATLON & $2 A$ & 151E TOAA \\
\hline & AND SO ISOLATION VALVES & 28 & 151F TO CV131 \\
\hline & & $2 \mathrm{c}$ & NODE 7 TO CV310 \\
\hline & & 20 & $151 C$ TO $151 \mathrm{~A}$ \\
\hline & & $2 E$ & BC4 TOC CVi36 \\
\hline & & $2 \mathrm{~F}$ & NODE 9 TO CV309 \\
\hline & & 20 & 1510 TO AS \\
\hline & & $2 \mathrm{H}$ & 1518 TO C5 \\
\hline & & 25 & CV130 TO CV138 \\
\hline & & 25 & CV131 TO CV133 \\
\hline & & & SUM \\
\hline & & & AVERAGE \\
\hline AFW-3 & MAIN STEAM TO AFW PUMP TURBINE DRIVE & $3 c$ & HS LINE TO CV182 \\
\hline & & 30 & CV182 TO TDP \\
\hline & & & sUM \\
\hline & & & AVERAGE \\
\hline AFW-S & AFW TO PUMP DISCHARGE LINE & 54 & XV140 TO CV142 \\
\hline & & 58 & XV141 TO 34 \\
\hline & & $5 c$ & CV142 TO TDP \\
\hline & & & SUM \\
\hline & & & AVERAGE \\
\hline AFW-6 & PIPE SEGMENT FROM UNIT 2 AFW PUMPS & BA & CV310 TO CV273 \\
\hline & & & SUN \\
\hline & & & AVERAGE \\
\hline AFW-7 & AFW ISOLATION VALVE TO SO & $7 \mathrm{Aa}$ & SGA TO CV10 \\
\hline & & 78 & A2 TO CV27 \\
\hline & & $7 \mathrm{c}$ & CV27 TO XV30 \\
\hline & & 70 & A3 TO XV31 \\
\hline & & $7 E$ & XV30 TO $151 E$ \\
\hline & & $7 F$ & 131 T0 $151 \mathrm{~F}$ \\
\hline & & 70 & SGB TO CV A1 \\
\hline & & 74 & B2 TO CV5B \\
\hline & & 71 & CV58 To XV61 \\
\hline & & 75 & B3 TO XV162 \\
\hline & & $7 \bar{k}$ & XV81 ro 151C \\
\hline & & $\pi$ & XVB2 TO 1510 \\
\hline & & $7 M$ & $56 C$ TO CV72 \\
\hline & & $7 \mathrm{~N}$ & C2 TO CV89 \\
\hline & & 70 & CV99 Ta XV92 \\
\hline & & 78 & C3 TO XY93 \\
\hline & & 70 & XV92 TO 151A \\
\hline & & TR & XV93 TO 1518 \\
\hline & & & sum \\
\hline & & & AVERAGE \\
\hline AFW- & AFW MDP SUCTION UNE & BA & MDP3A TO XV16B \\
\hline & & BB & MDP3B TO XV183 \\
\hline & & se & 49 TO XV169 \\
\hline & & 80 & 56 TO $\times$ V284 \\
\hline & & 8E & $52 \mathrm{TO} \times \mathrm{V} 184$ \\
\hline & & BF & $58 \mathrm{TO} \times \mathrm{V} 285$ \\
\hline & & & sum \\
\hline & & & AVERAGE \\
\hline AFW-9 & AFW MDP DISCHARGE LINE & BA & CV138 TO XV141 \\
\hline & & 98 & $13 \mathrm{TO} \times \mathrm{V} 270$ \\
\hline & & oc & 15 To XV171 \\
\hline & & 90 & $16 \mathrm{TO} \times \mathrm{XV} 456$ \\
\hline & & gE & CV133 TO XV140 \\
\hline & & gF & $25 \mathrm{TO} \times \mathrm{V} 271$ \\
\hline & & 98 & 28 TO XV170 \\
\hline & & $9 \mathrm{H}$ & 27 TOXV155 \\
\hline & & 9 & XV158 TO 38 \\
\hline & & 95 & XV155 TO CV157 \\
\hline & & 9k & CV157 TO MOP3A \\
\hline & & 92 & XV170 TO CV172 \\
\hline & & 9M & XV171 TO 41 \\
\hline & & $9 \mathrm{~N}$ & CV172 TO MDP 3B \\
\hline & & & sum \\
\hline & & & AVERAGE \\
\hline AFW-10 & AFW TOP SUCTION LINE & $10 A$ & TDP TO XV153 \\
\hline & & 108 & 46 TO XV154 \\
\hline & & $10 \mathrm{C}$ & 54 TO XV283 \\
\hline & & & sum \\
\hline & & & AVERAGE \\
\hline AFW-11 & PIPE SEGMENT BETWEEN RCP AD LOOP STOP & $11 \mathrm{~A}$ & XV154 TO XV185 \\
\hline & VALVE (COLD LEO) & $11 B$ & $X V 2 B 3$ TO XV285 \\
\hline & & $11 \mathrm{c}$ & XV169 TO 63 \\
\hline & & 1110 & $x \sqrt{284}$ TO 100 \\
\hline & & $11 E$ & XV184 TO 64 \\
\hline & & $11 \mathrm{~F}$ & 100 TO MAKEUP \\
\hline & & & SUM \\
\hline & & & AVERAGE \\
\hline & & & \\
\hline
\end{tabular}




\begin{tabular}{|c|c|c|c|c|}
\hline $\mathbf{K}$ & $L$ & $M$ & $\mathbf{N}$ & 0 \\
\hline LINKED & COND COF & & TEST & $\mathrm{CDF}$ \\
\hline BASIC EVENT & VALUE & UNITS & INTER & EQUATION \\
\hline & $x$ & & $T$ & \\
\hline AFW-TNK-VF-CST & $\begin{array}{ll}2.70 E-03 & F \\
\end{array}$ & FREQ & 4011 & $\mid\left(I^{1}(\mathrm{~T} / 2)\right]^{\mathrm{C}} \mathrm{C}$ \\
\hline AFW-TNK-VF-CST & \begin{tabular}{ll|l}
$2.78 E-03$ & $F$ \\
\end{tabular} & FREQ & $40 / 1$ & $(1+(T / 2)]^{*} \mathrm{C}$ \\
\hline AFW-TNK-VF-CST & $\begin{array}{ll}2.78 E-03 & F \\
\end{array}$ & FREQ & $\$ 11$ & $\theta(\mathrm{m} / 2))^{\mathrm{c}}$ \\
\hline AFW-TNK-VF-CST & $2.76 E-03 \mathrm{~F}$ & FREQ & $\infty 18$ & $\left(r^{*}(T / 2)\right)^{*} \mathrm{C}$ \\
\hline AFW-TNK-VF-CST & $2.76 E-03: F$ & FREQ & $40 \mid 0$ & $(\mathbf{r}(\mathrm{T} / 2))^{*} \mathrm{C}$ \\
\hline AFW-TNK-VFCST & $\begin{array}{l}2,76 E-03 / F \\
\end{array}$ & FREQ & 40 & $(r(T / 2))^{-C}$ \\
\hline AFW-TNK-VF-CST & $2.76 \mathrm{E}-03 \mathrm{~F}$ & FREQ & 40 & $\left(r^{*}(T / 2)\right)^{*} \mathrm{C}$ \\
\hline SUM & 1.93E-02 & & & sum \\
\hline AVERAGE & $2.78 E .03$ & & & AVERAGE \\
\hline AFW-TNK-VF-CST & $2.78 E-03 \quad F$ & FREQ & $\infty 0$ & $(r(T / 2))^{*} \mathrm{C}$ \\
\hline AFW-TNK-VF-CST & $2.76 E-03 \quad F$ & FREQ & $40(1$ & $(1 /(T / 2))^{*} \mathrm{C}$ \\
\hline AFW-TNK-VF-CST & 2.76E.D3 F & FREQ & 406 & $(1 /(T / 2))^{*} \mathrm{C}$ \\
\hline AFW-TNK-VF-CST & 2.76E-03 F & FREQ & 40 & $(1+(T / 2))^{n} \mathrm{C}$ \\
\hline AFW-TNK-VF-CST & $\begin{array}{ll}2.76 E-03 & F \\
\end{array}$ & FREQ & 40 & $\left(1^{*}(\mathrm{~T} / 2)\right)^{*} \mathrm{C}$ \\
\hline AFW-TNK-VF-CST & \begin{tabular}{l|l|}
$2.78 E-03$ & $F$ \\
\end{tabular} & FREO & 40 & $(1+(T / 2))^{\circ} \mathrm{C}$ \\
\hline AFW-TNK-VF-CST & \begin{tabular}{ll|l}
$2.76 E-03$ & $F$ \\
\end{tabular} & FREO & 401 & $\left(I^{*}(T / 2)\right)^{-C}$ \\
\hline AFW-TNK-VF-CST & 2.76E-03 F & FREQ & 40 & $(r(T / 2))^{\circ} \mathrm{C}$ \\
\hline AFW-TNK-YF-CST & $2.76 E-03, F$ & FREQ & 40 & $(r(T / 2))^{*} c$ \\
\hline AFW-TNK-VF-CST & $2.76 \mathrm{E}-03 \mathrm{~F}$ & FREQ & 40 & $(r(T / 2))^{\circ} \mathrm{C}$ \\
\hline süm & $2.78 E-02$ & & & sum \\
\hline AVERAGE & $2.76 \mathrm{E}-03$ & & & AVERAGE \\
\hline AFW-TDP-FS-FW2 & \begin{tabular}{l|l}
$5.87 E-06$ & $P$ \\
\end{tabular} & PROB & & $\mathrm{rc}$ \\
\hline AFW-TDPFS FW2 & $\begin{array}{ll}5.77 \mathrm{E} .05 & \mathrm{~F} \\
\end{array}$ & FREO & 40 & $\left(r^{r}(\mathrm{~T} / 2)\right)^{*} \mathrm{C}$ \\
\hline sum & $6.38 \mathrm{E}-05$ & & & SUM \\
\hline AVERAGE & 3.18E-05 & & & AVERAGE \\
\hline AFW-TNK-VF-CST & \begin{tabular}{|l|l|}
$2.76 E-03$ & $F$ \\
\end{tabular} & FREO & 40 & $(T(T / 2))+C$ \\
\hline AFW-TNK-VF-CST & $2.76 \mathrm{E}-03 \mathrm{~F}$ & FREQ & 40 & $(1(T / 2))^{\bar{C}}$ \\
\hline AFW-TNK-VF-CST & $2.76 \mathrm{E}-03 \mathrm{~F}$ & FREQ & 40 & $\left(1^{*}(\mathrm{~T} / 2)\right)^{*} \mathrm{C}$ \\
\hline suM & 8.28E-03 & & & SUM \\
\hline AVERAGE & $2.76 E-03$ & & & AVERAGE \\
\hline AFW-PSF-FC-XCONN & $5.83 E-03 \quad F$ & FREQ & 40 & $(\mathrm{I}(\mathrm{T} / 2))^{*} \mathrm{C}$ \\
\hline SUM & $5.83 \mathrm{E}-03$ & & & sum \\
\hline AVERAGE & $5.83 \mathrm{E}-03$ & & & AVERAGE \\
\hline AFW-TMK-VF-CST & 5.15E-03 $\mathrm{P}$ & PROB & & re \\
\hline AFW-TNK-VF-CST & 5.15E-03 & PROB & & $r c$ \\
\hline AFW-TNK-VF-CST & 2.76E-03 F & FREQ & 40 & $\left(r^{*}(\mathrm{~T} / 2)\right)^{*} \mathrm{C}$ \\
\hline AFW-TNK-VF-CST & $2.76 \mathrm{E}-03$ & FREQ & 40 & $(\mathrm{r}(\mathrm{T} / 2))^{* \mathrm{C}}$ \\
\hline AFW-TNK-VF-CST & $2.76 \mathrm{E}-03 \mathrm{~F}$ & FREQ & 40 & $(1+(T / 2) \times c$ \\
\hline AFW-TNK-VF-CST & $2.76 \mathrm{E}-03 \mathrm{~F}$ & FREQ & 40 & $(1+(T / 2))^{*} \mathrm{C}$ \\
\hline AFW-TNK-VF-CST & $5.15 E-03 \quad F$ & PROB & & re \\
\hline AFW-TNKAF-CST & \begin{tabular}{ll|l}
$5.45 E A 3$ & $P$
\end{tabular} & PROB & & $r c$ \\
\hline AFW-TNK-VF-CST & $2.76 E-03 \quad F$ & FREQ & 40 & $(r(T / 2))^{*} \mathrm{C}$ \\
\hline AFW-INK-VF-CST & $2.76 \mathrm{E}-03 \mathrm{~F}$ & FREQ & 40 & $(\mathrm{I}(\mathrm{T} / 2))^{\circ} \mathrm{C}$ \\
\hline AFW-TMK-VF-CST & $2.76 E-03 \mathrm{~F}$ & FREO & 40 & {$\left[\mathrm{r}(\mathrm{T} / 2)^{\circ} \mathrm{C}\right.$} \\
\hline AFW-TNK-VF-CST & $2.78 E-03 \mathrm{~F}$ & FREQ & 40 & $(1+(T / 2))^{\circ} \mathrm{C}$ \\
\hline AFW-TNK-VF-CST & 5.15E-03 & PROB & & $\mathrm{rc}$ \\
\hline AFW-TNK-VE-CST & $2.76 \mathrm{E}-03$ & FREQ & 40 & $(1+(\pi / 2))^{\circ} \mathrm{C}$ \\
\hline APW-TNK-VFF-CST & $2.76 \mathrm{E}-03 \mathrm{~F}$ & FREQ & 40 & $(\mathbf{r}(\mathrm{T} / 2))^{\mathrm{C}} \mathrm{c}$ \\
\hline AFW-TNK-VF-CST & $2.76 E-03$ & FREQ & 40 & $(1 /(T / 2))^{*} \mathrm{C}$ \\
\hline AFW-TNK-VF-CST & $2.76 E-03$ & FREQ & 40 & $(\operatorname{lr}(\pi / 2))^{4} \mathrm{C}$ \\
\hline AFW-TNK-VF-CST & $2.76 E-03$ & FREQ & 40 & $(r(T / 2))^{*} \mathrm{C}$ \\
\hline sim & $6.16 E-02$ & & & sum \\
\hline AVERAGE & $3.42 \mathrm{E}-03$ & & & AVERAGE \\
\hline AFW-TNK-VF-CST & $2.78 E-03$ & FREQ & 40 & $(1+(T / 2))^{*} \mathrm{C}$ \\
\hline AFW-TNK-VF-CST & $2.76 E-03$ & FREG & 40 & $(1(T / 2))^{n} \mathrm{C}$ \\
\hline AFW-TNK-VF-CST & $2.76 E-03$ & FREQ & 40 & $(1 /(T / 2))^{*} \mathrm{C}$ \\
\hline APW-TNK-VF-CST & $2.76 E-03$ & FREa & 40 & $\left(f^{*}\left(T^{\prime} / 2\right)\right)^{*} \mathrm{C}$ \\
\hline AFW-TNK-VF-CST & $2.76 \mathrm{E}-03$ & FREO & 40 & $(\pi(\pi / 2))^{*} \mathrm{C}$ \\
\hline AFW-TNK-VF-CST & $2.76 E-03$ & FREQ & 40 & $((r(T / 2)))^{*} \mathrm{C}$ \\
\hline sum & $1.86 E-02$ & & & sum \\
\hline AVERAGE & $2.76 E-03$ & & & AVERAGE \\
\hline AFW-TNK-VF-CST & $2.76 E-03$ & FREO & 40 & $((r / T / R))^{-C}$ \\
\hline AFW-TNK-VF-CST & $2.76 E-03$ & FREO & 40 & $\left\{\left(\left.T^{*}(T R)\right|^{*} \mathrm{C}\right.\right.$ \\
\hline AFW-TMK-VF-CST & $2.76 E-03$ & FREQ & 40 & $(n+\pi R)^{+} \mathrm{C}$ \\
\hline AFW-TNK-VF-CST & $2.76 E-03$ & FREO & 40 & $(r(\pi / R))^{+c} \mathrm{c}$ \\
\hline AFW-TNK-VF-CST & $2.76 E-03$ & FREQ & 40 & $(r(T / R))^{+c}$ \\
\hline AFW-TAK-AF-CST & $2.76 E-03$ & FREO & 40 & $(n(T / R))^{*} \mathrm{C}$ \\
\hline AFW-TNK-VF-CST & $2.76 E-03$ & FREO & 40 & $\left(T^{*}(T / 2)\right)^{n} \mathrm{C}$ \\
\hline AFW-TNK-VF-CST & $2.76 E-03$ & FREQ & 40 & $(1+(T / 2))^{*} \mathrm{C}$ \\
\hline AFW-TNK-VF-CST & $2.76 E-03$ & FREQ & 40 & $(1+(\pi / 2))^{C} \mathrm{C}$ \\
\hline AFW-TNK-VF-CST & $2.76 E-03$ & FREO & 40 & $(1+(\pi / 2))^{c} \mathrm{C}$ \\
\hline AFW-TNK-VF-CST & $2.76 E-03$ & FREQ & 40 & $(\mathrm{r}(\mathrm{T} / 2))^{\circ} \mathrm{C}$ \\
\hline AFW-TNK-VF-CST & $2.76 E-03$ & FREQ & 40 & $(r(T / 2))^{-c}$ \\
\hline AFW-TNK-VF-CST & $2.76 E-03$ & FREQ & 40 & $(\mathrm{~F}(\mathrm{~T} / \mathrm{R}))^{* \mathrm{C}}$ \\
\hline AFW-TNK-VF-CST & $2.76 E-03$ & FREQ & 40 & $(\mathrm{r}(\mathrm{T} / 2))^{*} \mathrm{C}$ \\
\hline sum & $3.86 E-02$ & & & sum \\
\hline AVERAGE & $2.76 E-03$ & & & AVERAGE \\
\hline AFW-TNK-VF-CST & $2.76 E-03$ & FREO & 40 & $(\mathrm{r}(\mathrm{T} / 2))^{\mathrm{C} C} \mathrm{C}$ \\
\hline AFW-TNK-VF-CST & 2.76E-03 & FREO & 40 & $(\mathrm{r}(\mathrm{T} / 2))^{+} \mathrm{c}$ \\
\hline AFW-TNK-VF-CST & $2.76 E-03$ & FREQ & 40 & $(1+(\pi / 2))^{*} \mathrm{C}$ \\
\hline sum & B.2BE-03 & & & sum \\
\hline AVERAGE & $2.7 B E-03$ & & & AVERAGE \\
\hline NONE & $<1.00 \mathrm{E}-12$ & - & & \\
\hline NONE & $<7.00 \mathrm{E}-12$ & E & & \\
\hline NONE & $<4.00 E-12$ & - & & \\
\hline NONE & $-1.00 E-12$ & t. & & \\
\hline NONE & $<1.00 E-12$ & $=$ & & \\
\hline NONE & $41.00 \mathrm{E}-12$ & 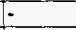 & & \\
\hline Sum & $<1.00 \mathrm{E}-12$ & & & SUM \\
\hline AVERAGE & $<1.00 E-12$ & & & AVERAGE \\
\hline
\end{tabular}




\begin{tabular}{|c|c|c|c|}
\hline A & B & C & D \\
\hline & & ELEMENTS & ELEMENTS \\
\hline SEGMENT IO & OESCFIPTION & iD & DESCRIPTION \\
\hline & & & \\
\hline LPHA & BETWEEN CIV CLEG INS & LPI-1A & RCS CL 1 TO CV79 \\
\hline $5.26 \mathrm{E}-06$ & & {$[$ LPI-1B } & CY79 TO NODE A \\
\hline & & LPI-1C & V235 TO CV241 \\
\hline & & LPI-1D & V241 TO NODE D \\
\hline & & LPI-1E & NODE 1 A TO VLV 246 \\
\hline & & LPI-1F & RCS CL 2 TO CV82 \\
\hline & & LPI-1G & VE2 TO CV236 \\
\hline & & LPI-1H & NODE 8 TO $\mathrm{CV} 242$ \\
\hline & & $L P 1 \cdot+1$ & V242 TO NODE E \\
\hline & & LPI-1J & NODE 18 TO VLV 251 \\
\hline & & LPI-1K & RCSCLITOCVBS \\
\hline & & $L P+1 L$ & V85 TOCV 237 \\
\hline & & LPI-1M & NOOE C TO CV243 \\
\hline & & LPI-TN & V243 TO MOV1890C \\
\hline & & LPY-10 & NODE 1C TO VLV 258 \\
\hline & & LPI-1P & NOOE TO TO VENT \\
\hline & & LPI-1Q & NODE 10 TO VLV 189 \\
\hline & & & sum \\
\hline & & & AVERAGE \\
\hline LPI-2 & BETWEEN CN \& HOT LEG INJ & LPI.2A & RCS HLEQ 1 TO CVOA \\
\hline 2.84E-07 & & LPI-2B & V91 To cV239 \\
\hline & $-1-1-1-1-1$ & LPI-2C & V239 TO CV229 \\
\hline & & $L P 1-20$ & NOOE 11 TO XV341 \\
\hline & - & LPI-2E & NOOE $1 \mathrm{H}$ TO VIV 254 \\
\hline & & LPI-2F & RCS HLEG 2 TO CVBS \\
\hline & . & $L P 128$ & V88 To cV 238 \\
\hline & & LPI-2H & V238 TO c c 228 \\
\hline & & LPI-2I & NODE $1 \mathrm{~K}$ TO XV339 \\
\hline & & LPI-2J & NODE 13 TO VLV 252 \\
\hline & . & LPI-2K & NODE 1 L TO $v \times v \times x \times$ \\
\hline & & LPI-2L & RCS HLEG 3 TO CV94 \\
\hline & & LPI-2M & Vo4 TO CV240 \\
\hline & & LPI-2N & CV240 TO NODE G \\
\hline & 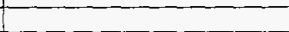 & $\angle P I-2 O$ & NOOE 1N TO V337 \\
\hline & & LPI-2P & NOOE 1 M TO HCV1 $1850 E$ \\
\hline & & LPI-2Q & NODE ITO NODE H \\
\hline & & & sum \\
\hline & & & AVERAGE \\
\hline LPI-3 & LPI SOURCES SUPPLY & $\angle P I-3 A$ & MOV1860A TO SUMP \\
\hline $6.85 E-07$ & & LPI-3B & MOVi8BoB TO SUMP \\
\hline & & LPISAC & MOV1862A TO XV15X \\
\hline & & LP1-30 & MOV1862B TO NODEU \\
\hline & & LPI-3E & NODE $V$ TO HPI ISO VLV \\
\hline & & LP(-3F & XVISX TO RWST \\
\hline & & 20130 & RWST \\
\hline & & & sum \\
\hline & & & AVERAGE \\
\hline LPIA & PMP DISGH \& CIV & LPIIAA & MOV $1890 \mathrm{C}$ TO NODEF \\
\hline $4.51 E-08$ & & LPIAB & MOV1864B TO 1864A \\
\hline & & LPIAC & NODE IF TO RVTBA5B \\
\hline & & LPI-AD & NODE 1 G TO VLV 193 \\
\hline 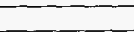 & $-{ }_{-1}$ & LPI-AE & MOV $1890 A$ TO MODE J \\
\hline & & LPIAF & MOV18B4A TO CV58 \\
\hline- & & LPI-4O & NOOE K TO MOV1863A \\
\hline & & LPI.4H & NODE AU TO RVIBASA \\
\hline 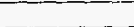 & & $|L P|-4 \mid$ & NODE IVTO VLV 191 \\
\hline & & LPIAN & NODE L TO VLV 194 \\
\hline 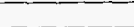 & & LPI-AK & NODE M TO VRV 195 \\
\hline & & LPI-4L & NODE 1 W TO VLV 192 \\
\hline 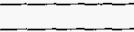 & 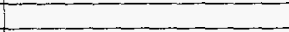 & LPI-AM & MOV18908 TO NODE N \\
\hline & & LPI-AN & MOV $1864 B$ TO CV 50 \\
\hline & & LPI-40 & NODE O TO MOV1863B \\
\hline & & LPIAP & NODE $1 \times$ TO CV 53 \\
\hline & & $L P I-4 Q$ & NODE 1 BE TO RVI845C \\
\hline & & CPIAR & NODE TY TO VLV T\&7 \\
\hline & & LPI-AS & NODE 12 TO VLV 497 \\
\hline & & LPJ-AT & NODE 1 AA TO VLV 97 \\
\hline & & LPI-AU & CV58 TO PUMP A \\
\hline & & LPIAV & CV50 TOPUMP B \\
\hline & & & sum \\
\hline & & & AVERAGE \\
\hline LPI-S & BETWEEN CIVS & LPI.5A & CV229 TO MOV1890A \\
\hline $0.00 E-10$ & & LPI-5B & CV228 TO MOV18908 \\
\hline & & LPI.SC & NODE 10 TO VLV 178 \\
\hline & & LPISOSO & NODE TR TO V V 190 \\
\hline & & LPI.5E & NOOE is TO VV 177 \\
\hline & & LPISF & NODE $1 T$ TO VVV 186 \\
\hline & & & sum \\
\hline & & & AVERAGE \\
\hline LPI-6 & LPI PUMP SUCTION LINE & LPI-GA & PUMP A TO XV57 \\
\hline $2.02 E-07$ & & LPIGB & XV57 TO CV $46 \mathrm{~A}$ \\
\hline & & LPI-BC & NODE S TO CV5B \\
\hline & & LPI-6D & PUMP В TO XV48 \\
\hline & & LPIGE & XV46 To CV46B \\
\hline & & LPI-BF & NODE TTO CV47 \\
\hline & & LPIBG & CV46A TO MOV1862A \\
\hline & & LPI-GH & VS6 ro MOV1B60A \\
\hline & & LPISI & CV468 TO MOV18628 \\
\hline & & LPI-6] & ya7 TO MOY $1860 \mathrm{~B}$ \\
\hline & & & sum \\
\hline & & & AVERAGE \\
\hline
\end{tabular}




\begin{tabular}{|c|c|c|c|}
\hline$k$ & $L$ & $M$ & N \\
\hline LINKED & COND CDF & & TEST \\
\hline BASIC EVENT & VALUE & UNITS & INTER \\
\hline & $x$ & & 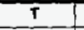 \\
\hline & $3.98 E-03 P$ & PROB & \\
\hline RWT-TNK-LF-RWST & $1.95 \mathrm{E}-02 \mathrm{~F}$ & FREQ & 8014 \\
\hline RWT-TMK-LF-FWST & $1.95 E-02$ & FREO & 4011 \\
\hline LPI-MDPFS & $2.24 E-04$ & FREQ & $40 t 0$ \\
\hline & $0.00 E+\infty 0 F$ & FREQ & 4011 \\
\hline & $3.98 E-03$ & PROA & 15 \\
\hline RWT-TNKLLF-RWST & $1.95 E-02 \mathrm{FF}$ & FREO & 401 \\
\hline RWT-TWKLIFEWST & $1.95 \mathrm{E}-02 \mathrm{FF}$ & FREQ & 211 \\
\hline LPT-MOPFAS & $2.24 E-04 F$ & FREQ & 401 \\
\hline & $0.00 E+00 \quad F$ & FRED & $40 \sqrt{1}$ \\
\hline & $3.98 \mathrm{E} .03 \mathrm{P}$ & PROB & \\
\hline RWT-TNKLLFAWST & $1.95 \mathrm{E}-02 \mathrm{~F}$ & FREQ & 4010 \\
\hline RWT-TNKLLF-RWST & $1.95 E-02 \mathrm{~F}$ & FREQ & 4011 \\
\hline LPIMDPFS & $2.24 \mathrm{E} \Omega 4 \mathrm{~F}$ & FREO & 40 (1) \\
\hline & $0.00 \mathrm{E}+\infty \mathrm{F}$ & FREO & 401 \\
\hline & $0.00 E+\infty \quad F$ & FREO & $40<$ \\
\hline- & $0.00 E+\infty 0$ & FREO & 407 \\
\hline sum & 1.30E-01 & & \\
\hline AVERAGE & 1.63E-03 & & \\
\hline LPR-CCFFO-SUMP & $3,98 E-03 / P$ & PROB & \\
\hline LPR-CCFPG SUMP & 1.55E-03 $\mathrm{F}$ & FREQ & 40 \\
\hline LPR-CCF-PG-SUMP & 1.55E-03 $\mathrm{F}$ & FREO & 40 \\
\hline LPR-GCFPGSUMP & $1.55 \mathrm{E}-03 \mathrm{~F}$ & FREQ & 40 \\
\hline & $0.00 E+00 / F$ & FREO & 40 \\
\hline LPR-CCFPG SUMP & $3.90 \mathrm{E}-03$ & PROB & 11 \\
\hline LPR-CCFPG-SUMP & $1.55 \mathrm{E}-03$ T & FREO & 40 \\
\hline LPR-CCF-PG SUMP & $1.55 E-03 / F$ & FREO & 40 \\
\hline LPR-CCFPG-SUMP & $156 E-03$ & FREQ & 40 \\
\hline & $0.00 \mathrm{E}+00 \mathrm{~F}$ & FREQ & 40 \\
\hline & $0.00 \mathrm{E}+00 \mathrm{~F}$ & FREQ & 100 \\
\hline LPR-CCF-PG SUMP & 3.98E.03 P & PROB & 1 \\
\hline LPR-CCF-PG-SUMP & 1.55E-03 & FREQ & 4010 \\
\hline LPR-CCFPG-SUMP & $1.55 \mathrm{E}-03 \mathrm{~F}$ & FAEEQ & 40 \\
\hline & $0.00 E+00$ & FREO & 401 \\
\hline & $0.00 E+90$ F & FREO & 40 \\
\hline LPRCCFPGSUMP & 1.55E.03 $\mathrm{f}$ & FREQ & 40 \\
\hline sum & 2.59E-02 & & \\
\hline AVERAGE & 1.99E-03 & & \\
\hline LPR-GCFPQ SUMP & $\begin{array}{l}1.55 E-03 \\
F\end{array}$ & FREQ & 40 \\
\hline LPR-CCF PG SUMP & $4.55 E-03 / F$ & FREO & 40 \\
\hline RWT-THKLF-AWST & $1.85 \mathrm{EA2}^{\circ} \mathrm{F}$ & FREQ & 40 \\
\hline RWT-TNKLF-FWST & $1.05 \mathrm{E}-02 / \mathrm{F}$ & FREO & 40 \\
\hline RWT-TNKLLF-AWST & $1.95 E-02$ & FREa & 40 \\
\hline RWT-TNKLLFWWST & $1.95 \mathrm{E}-02$ & FREQ & 40 \\
\hline RWT-TMKLLF-RWST & 1.95E-02 F & FREQ & 20 \\
\hline sum & $1.01 E-01$ & & \\
\hline AVERAGE & 1. $4 \mathrm{EE}-02$ & & \\
\hline LPI-MOP-FS & $2.24 E-04 / F$ & FREO & 40 \\
\hline LPIMDPFS & $2.24 E-0 . F$ & FREQ & 40 \\
\hline & $0.00 E+00$ & FREO & 40 \\
\hline & $0.00 \mathrm{E}+00 \mathrm{~F}$ & FREQ & 40 \\
\hline LPI-MDPFS & $2.24 \mathrm{E}-04 \mathrm{~F}$ & FREQ & 40 \\
\hline LPIMDPFS & $2.24 E-04$ & FREQ & 40 \\
\hline PP1-MDPFS & $2.24 E-04 F$ & FREQ & 40 \\
\hline & $0.00 \mathrm{E}+00 \mathrm{~F}$ & FREQ & 40 \\
\hline & $0.00 E+00$ & FREQ & 40 \\
\hline & $0.00 E+\infty 0$ & FREA & 40 \\
\hline & $0.00 \mathrm{E}+\infty 0 \mathrm{~F}$ & FREQ & 40 \\
\hline & $0.00 \mathrm{E}+\infty \mathrm{D}$ & FREQ & 40 \\
\hline PI-MDP-FS & $2.24 E-04$ & FREQ & 40 \\
\hline PPHDPFS & $2.20 E-04$ & FREQ & 40 \\
\hline PIADPFS & $2.24 E-0 A$ & FREQ & $\$ 0$ \\
\hline & $0.00 E+00 \mathrm{~F}$ & FREQ & 80 \\
\hline & $0.00 E+00$ & FREQ & 40. \\
\hline & $0.00 E+00$ & FREO & 40 \\
\hline & $0.00 E+\infty \quad F$ & FREQ & 40 \\
\hline & $0.00 E+00$ & FREQ & 40 \\
\hline PI-MDP-FS-SIA & $2.46 \mathrm{E}-05$ & TFREQ & 40 \\
\hline PITDPFS-SIA & $2.40 E-05$ & FPEQ & 40 \\
\hline SUM & 1.84E-03 & & \\
\hline AVERAGE & 1.67E-96 & & \\
\hline PPIMDPFS-SIA & $2.46 E-05$ & FREQ & 40 \\
\hline PI-MDP-FS-SIA & $2.46 E-05$ & FREQ & 20 \\
\hline & $0.00 \mathrm{E}+00$ & FREG & 20 \\
\hline & $0.00 E+00$ & FREQ & 40 \\
\hline & $0.00 E+00$ & FREQ & 40 \\
\hline & $0.00 E+00$ & FREQ & 40 \\
\hline$S$ & 4.92E-05 & & \\
\hline FVERAGE & $2.46 E-05$ & & \\
\hline PI-MOP FS SIA & 2.46E-05 & FREQ & 40 \\
\hline PI-MDPFS-SA & 2. $46 E-05$ & FREQ & 40 \\
\hline PI-MDPFSSIA & $2.46 E-05$ & FREQ & 40 \\
\hline PitMDPFS-SIA & $2.46 \mathrm{E}-05$ & FREQ & 40 \\
\hline PI-MDPFS-SIR & 2.46E-05 & FREQ & 40 \\
\hline Pl-MAP-FS-SIA & $2.46 E-05$ & FREQ & 4 \\
\hline WT-TNK-LF-RWST & $1.85 E-02$ & FREQ & 40 \\
\hline PR-CCF-PGSUMP & $1.55 E-03$ & FREQ & 40 \\
\hline WT-TNKLLF-RWST & $1.85 \mathrm{E}-02$ & FREQ & 6 \\
\hline PR-CGFPGSUMP & $1.55 \mathrm{E}-03$ & FREO & 10 \\
\hline$\overline{U M}$ & 4.22E-02 & & \\
\hline VERAGE & $4.22 E-03$ & & \\
\hline
\end{tabular}

Appendix A 


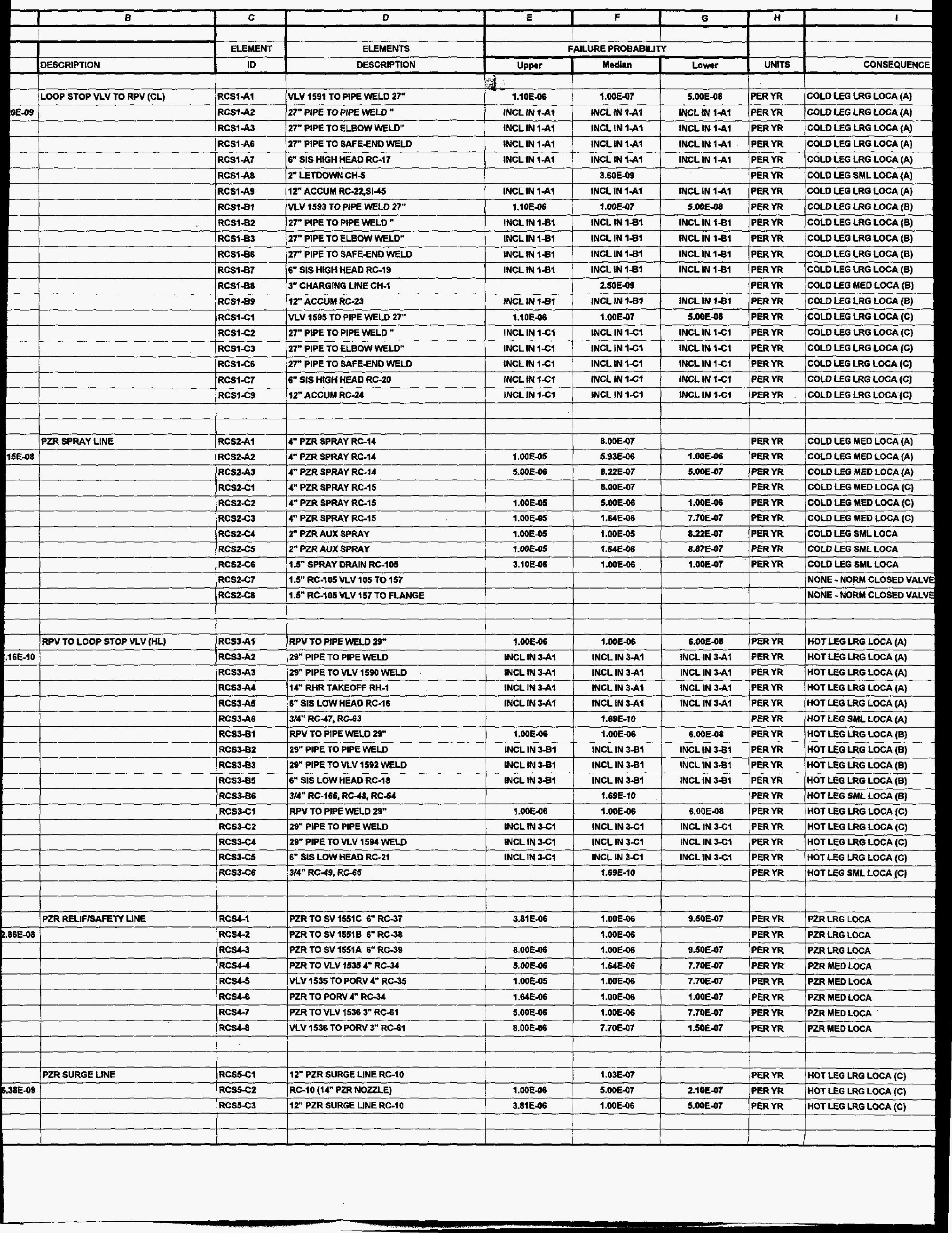


Appendix A

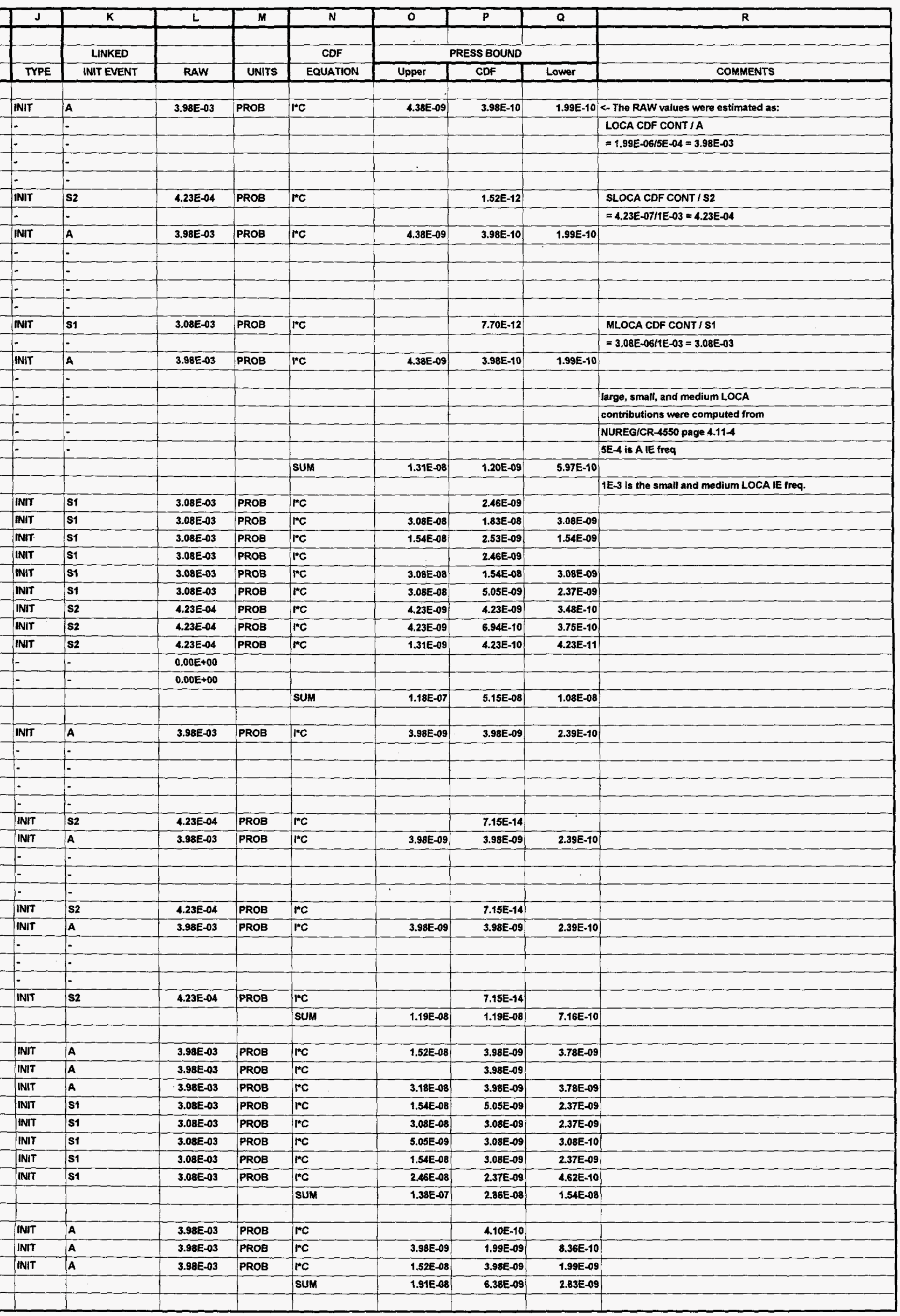




\begin{tabular}{|c|c|c|c|c|c|c|c|c|}
\hline & $B$ & $c$ & D & $\mathbf{E}$ & $\mathbf{F}$ & G & $H$ & 1 \\
\hline \multicolumn{9}{|l|}{ is } \\
\hline & & ELEMENT & ELEMENTS & \multicolumn{3}{|c|}{ FAILURE PROBABILITY } & & \\
\hline \multirow[t]{2}{*}{10} & DESCRIPTION & 10 & DESCRIPTION & Upper & Median & Lower & UNITS & CONSEQUE \\
\hline & SG TO RCP & RCS6-A1 & SG A TO ELEOW WELD 31" & $1.00 E-06$ & $2.00 E-07$ & $6.00 E-08$ & PER YR & COLD LEG LRG LOCA (A) \\
\hline \multirow[t]{37}{*}{ 2.84E-09 } & & RCS6-A2 & $31^{4}$ ELBOW TO PIPE WELD & INCL IN 6-A1 & INCL IN 6-A1 & INCL IN G-A1 & PER YR & COLO LEG LRG LOCA (A) \\
\hline & & RCS6-A3 & 31" PIPE TO ELBOW WELD & INCL IN 6-A1 & INCL IN 6-A1 & INCL IN 6-A1 & PER YR & COLO LEG LRG LOCA \\
\hline & & RCS6-A4 & 31" ELBOW TO PIPE WELD & INCL IN 6-A1 & INCL IN 6-A1 & INCL IN 6-A1 & PERYR & COLOLEG LRG LOCA \\
\hline & & RCS6AS & 31" PIPE TO ELBOW & WNCL IN G-A1 & INCL IN 6-A1 & INCL IN GAA & PERYR & COLD LEG LRG LOCA (A) \\
\hline & & RCS6-A6 & 31" ELBOW TO RCP A WELD & INCL IN 6-A1 & INCL IN 6-A1 & INCL IN G-A1 & PERYR & COLD LEG LRG LOCA \\
\hline & & RCS6-A7 & WELD 18 LONGITUDINAL & INCL IN 6-A1 & INCL IN 6-A1 & INCL IN 6-A1 & PER YR & COLD LEG LRG LOCA (A) \\
\hline & & RCS6-A8 & WELD 19 LONGITUDINAL & INCL IN 6-A1 & INCL IN 6-A1 & INCL IN 6-A1 & PER YR & COLO LEG LRG LOCA (A) \\
\hline & & RCS6-A9 & WELD 20 LONGITUDINAL & INCL IN 6-A1 & INCL IN G-A1 & INCL IN 6-A1 & PER YR & COLD LEG LRG LOCA (A) \\
\hline & & RCS6-A10 & WELO 21 LONGITUOINAL & WNCL IN G-A1 & INCL IN 6-A1 & WNCL IN 6-A1 & PER YR & COLD LEG LRG LOCA (A) \\
\hline & & RCS6-A11 & $3^{n}$ RTD RETURN RC-131 & & $4.00 E-08$ & & PER YR & COLD LEG MED LOCA (A) \\
\hline & & RCS6-A12 & 2" FILL HEADER RC-198 & & $6.80 E-08$ & & PER YR & COLD LEG SML LOCA (A) \\
\hline & & RCS6-81 & SG B TO ELBOW WELD 31" & $1.00 E-06$ & $2.00 E-07$ & $6.00 E-08$ & PER YR & COLD LEG LRG LOGA (B) \\
\hline & & RCS6-82 & 31" ELBOW TO PIPE WELD & INCL IN 6-B1 & INCL IN 6-B1 & INCL IN 6-B1 & PER YR & COLD LEG LRG LOCA (B) \\
\hline & & RCS6-83 & 31" PIPE TO ELBOW WELD & INCL IN 6-B1 & INCL IN 6-BI & INCL IN 6-BI & PERYR & COLD LEG LRG LOCA (B) \\
\hline & & RCS6-84 & 31" EL.BOW TO PIPE WELD & INCL IN 6-81 & INCL IN 6-B1 & INCL IN 6-B1 & PER YR & COLDLEG LRG LOCA (B) \\
\hline & & RCS6-85 & 31" PIPE TO ELBOW & INCL IN 6-BT & INCL IN 6-B1 & INCL IN 6-B1 & PER YR & COLD LEG LRG LOCA (B) \\
\hline & & RCS6-86 & 31" ELBOW TO RCP A WELD & INCL IN 6-B1 & INCL IN 6-B1 & INCL IN 6-B1 & PER YR & COLD LEG LRG LOCA (日) \\
\hline & & RCS6-87 & WELO 18 LONGITUDINAL & INCL IN 6-B1 & INCL IN 6-81 & INCL IN 6-BI & PER YR & COLD LEG LRG LOCA (8) \\
\hline & & RCs6-88 & WELD 19 LONGITUDINAL & INCL IN 6-B1 & INCL IN 6-B1 & INCL IN 6-81 & PER YR & COLD LEG LRG LOCA (B) \\
\hline & & RCs6-89 & WELO 20 LONGITUDINAL & INCL IN B-B1 & INCL IN 6-B1 & INCL IN 6-81 & PER YR & COLD LEG LRG LOCA (B) \\
\hline & & RCS6-810 & WELD 21 LONGITUDINAL & INCL IN 6-B1 & INCL IN G-B1 & INCL IN 6-B1 & PER YR & COLD LEG LRG LOCA (B) \\
\hline & & RCs6-811 & 3" RTD RETURN RC-116 & & $4.00 E-08$ & & PER YR & COLD LEG MEO LOCA (B) \\
\hline & & RCS6-812 & 2" FILL HEADER RC-199 & & $6.80 E-08$ & & PER YR & COLD LEG SML LOCA (B) \\
\hline & & RCS6-C1 & SG C TO ELBOW WELD 31" & $1.00 E-06$ & $2.00 E-07$ & $6.00 E-08$ & PER YR & COLD LEG LRG LOCA (C) \\
\hline & & RCS6-C2 & 31" ELBOW TO PIPE WELO & INCL IN 6-C1 & INCL IN 6-C1 & INCL IN 6-C4 & PER YR & COLOLEG LRG LOCA (C) \\
\hline & & Rcs $-\mathrm{C} 3$ & 31" PIPE TO ELBOW WELO & INCL IN 6-C1 & INCL IN 8-C1 & INCL IN 6-CI & PER YR & COLD LEG LRG LOCA (C) \\
\hline & & RCS6-C4 & 31" ELBOW TO PIPE WELD & INCL IN 6-CI & INCL ING-CI & NCL IN 6-C1 & PER YR & COLD LEG LRG LOCA (C) \\
\hline & & RCS6-C5 & 31" PIPE TO ELBOW & INCL IN 6-C1 & INCL IN 6-C1 & INCL IN 6-C1 & PER YR & COLO LEG LRG LOCA (C) \\
\hline & & RCS6.C6 & 31" ELBOW TO RCP C WELD & INCL IN 6-C1 & INCL IN 6-C1 & INCL IN 6-G1 & PER YR & COLDLEG LRG LOCA (C) \\
\hline & & RCs6-C7 & WELO 18 LONGITUDINAL. & INCL IN 6-C1 & INCL IN 6-C1 & INCL IN 6-C1 & PER YR & COLOLEG LRG LOCA (C) \\
\hline & & RCS6-C8 & WELD 19 LONGITUDINAL & INGL IN 6-C1 & INCL IN 6-CT & INCL IN 6-61 & PERYR & COLDLEG LRG LOCA (C) \\
\hline & & RCs6-C9 & WELO 20 LONGITUDINAL & INCL IN6-C1 & INCL IN G-C1 & INCL IN 6-C1 & PERYR & COLO LEG LRG LOCA (C) \\
\hline & & RCS6-C10 & WELD 21 LONGITUDINAL & INCL IN $6-C 1$ & INGL IN G-C1 & INCL IN 6-C1 & PER YR & COLOLEG LRG LOCA (C) \\
\hline & & RCS6-C11 & 3" RTD RETURN RC-147 & & $4.00 E-08$ & & PER YR & COLO LEG MED LOCA (C) \\
\hline & & RCS6-612 & 2" FILL HEADER RC-200 & & $6.80 E-08$ & & PER YR & COLD LEG SML LOCA (C) \\
\hline & & & & & & & & \\
\hline & LOOP STOP VLV TO SG (HL) & RCSTAA1 & VLV 1590 TO PIPE WELO 29" & $8.00 E-07$ & $1.41 E-07$ & $6.00 E-08$ & PER YR & HOT LEG LRG LOCA (A) \\
\hline \multirow[t]{15}{*}{$1.69 \mathrm{E}-09$} & & RCS7-A2 & 29" ELBOW TO SG A WELD & INGL IN 7 A1 & INCL IN 7AA1 & INCL IN 7A1 & PER YR & HOT LEG LRG LOGA (A) \\
\hline & & RCS7 $-A 3$ & 2" DRAIN HEADER RC-53 & & $1.50 \mathrm{E}-09$ & & PER YR & HOT LEG SML LOCA (A) \\
\hline & & RCS7-A4 & B" LOOP BYPASS RC-11 & INCL IN 7-A1 & INCL IN 7-A1 & INCL IN $7-A 1$ & PER YR & HOT LEG LRG LOCA (A) \\
\hline & & RCS7-AS & 2" RC-45 & & $3.60 E-09$ & & PER YR & HOT LEG SML LOCA (A) \\
\hline & & RCS7-B1 & VLV 1592 TO PIPE WELD 29" & $8.00 E-07$ & $1.41 E-07$ & $6.00 E-08$ & PER YR & HOT LEG LRG LOCA (B) \\
\hline & & RCs7-82 & $29^{\circ}$ ELBOW TO SG B WELD & NNCL IN 7-81 & INCL IN 7-BI & INCL IN 7-B1 & PERYR & HOT LEG LRG LOCA (B) \\
\hline & & RCS7-B3 & 2" DRAIN HEADER RC-57 & & $1.50 E-09$ & & PER YR & HOT LEG SML LOCA (B) \\
\hline & & RCS7-BA & 8" LOOP BYPASS RC-12 & INCL IN 7-B1 & INCL IN 7-B1 & INCL IN $7-B 1$ & PER YR & HOT LEG LRG LOCA (B) \\
\hline & & RCS7.C1 & VLV 1594 TO PIPE WELO 29" & $8.00 E-07$ & $1.41 E-07$ & $6.00 E-08$ & PER YR & HOT LEG LRG LOCA (C) \\
\hline & & RCS7-62 & 29" ELBOW TO SG C WELD & INCL IN 7-C1 & INCL IN 7-C1 & INCL IN 7-C1 & PER YR & HOT LEG LRG LOCA (C) \\
\hline & & RCS7-C3 & 2" DRAIN HEADER RC-58 & & $1.50 E-09$ & & PER YR & HOT LEG SML LOCA (C) \\
\hline & & RCST-CA & 8" LOOP BYPASS RC-13 & INCL IN 7-C1 & INCLINT-C1 & INCL IN 7-C1 & PER YR & HOT LEG LRG LOCA (C) \\
\hline & & RCS7-C5 & $2=R C-44$ & & $3.60 \mathrm{E}-09$ & & PER YR & HOT LEG SML LOCA (C) \\
\hline & & & & & & & & \\
\hline & RCP TO LOOP STOP VLV (CL) & RCS8-A1 & RCP A TO PIPE WELD 27 & $5.00 E-07$ & $7.75 E-08$ & $2.00 E-08$ & PER YR & COLOLEG LRG LOCA (A) \\
\hline \multirow[t]{12}{*}{$9.31 E-10$} & & RCS8-A2 & 2T" PIPE TO VLV 1591 WELO & INCL IN 8-A1 & INCL IN $8-A 1$ & INCL IN B-A1 & PER YR & COLOLEG LRG LOCA (A) \\
\hline & & $R C S 8-A 3$ & $1.5^{\prime \prime}$ RTD TAKE OFF RC-125 & & $4.00 E-09$ & & PER YR & COLOLEG SML LOCA (A) \\
\hline & & RCSB-A4 & SEAL INJECT TO RCP A & & $2.11 E-10$ & & PER YR & POTEN SEAL LOCA \\
\hline & & RCS8-81 & RCP \& TO PIPE WELD 27" & $5,00 E-07$ & $7.75 E-08$ & $2.00 E-08$ & PER YR & COLD LEG LRG LOCA (B) \\
\hline & & RCS8-B2 & 27" PIPE TO VLV 1593 WELD & INCL IN 8-B1 & INCL IN $8-B 1$ & INCL IN 8-B1 & PER YR & COLO LEG LRG LOCA (B) \\
\hline & & RCS8-B3 & 1.5" RTD TAKE OFF RC -60 & & $4.00 E-09$ & & PER YR & COLOLEG SML LOCA (B) \\
\hline & & RCs8-84 & SEAL INJECT TO RCP B & & $2.11 E-10$ & & PER YR & POTEN. SEAL LOCA \\
\hline & & $R \operatorname{Cs} 8-C 1$ & RCP C TO PIPE WELD 27" & $5.00 E-07$ & $7.75 E-08$ & $2.00 E-08$ & PER YR & COLOLEG LRG LOCA (C) \\
\hline & & $R C S 8-G 2$ & 27" PIPE TO VLV 1595 WELL & INCL IN B-C1 & NNCL IN 8-C1 & INCL IN B-C1 & PER YR & COLOLEG LRG LOCA (C) \\
\hline & & RCSB-C3 & 1.5" RTD TAKE OFF RC-141 & & $4.00 E-09$ & & PER YR & COLO LEG SML LOCA (C) \\
\hline & & RCS8-C4 & SEAL INJECT TO RCP C & & $2.11 E-10$ & & PER YR & POTEN SEAL LOCA \\
\hline & & & & & & & & \\
\hline
\end{tabular}


Appendix A

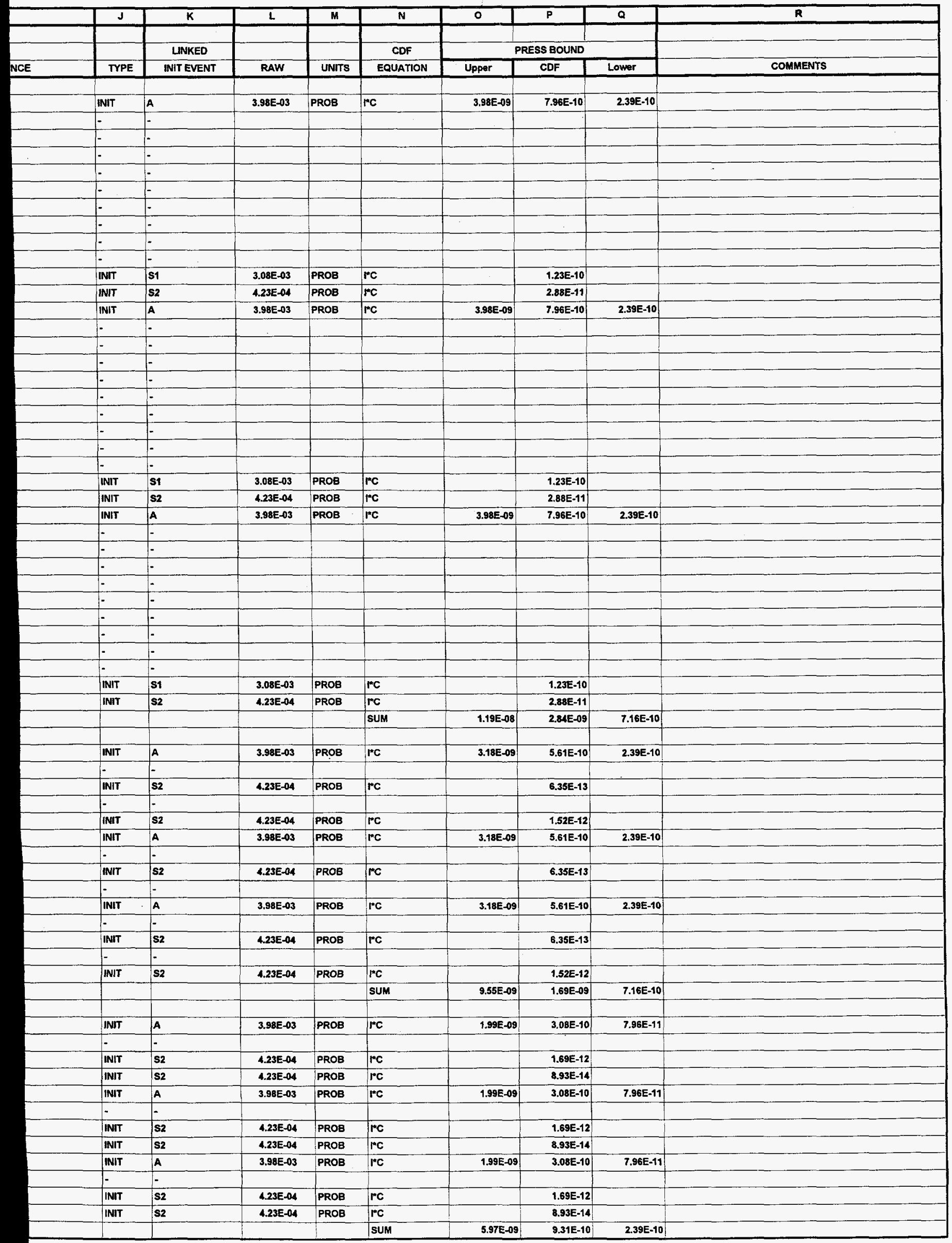




\section{Appendix B}

Review of the Risk Importance Approaches Which have been Developed by the Pacific Northwest National Laboratory 


\title{
REVIEW OF THE RISK IMPORTANCE APPROACHES WHICH HAVE BEEN DEVELOPED BY PACIFIC NORTHWEST NATIONAL LABORATORY
}

\author{
W. E. Vesely \\ November 17,1995
}

\section{SUMMARY}

On November 8-10, 1995 I traveled to Pacific Northwest National Laboratory (PNNL) to review the risk importance prioritization approaches which have been developed by PNNL for Inservice Inspection (ISI) applications. Before the meeting at PNNL, I spent one day reviewing NUREG/CR-6151 (1) and NUREG/CR-6181 (2) which describe the risk importance methodology originally applied by PNNL. At the November 9, 1995 meeting at PNNL, I also reviewed the extended risk importance methodology which has recently been developed by PNNL to respond to the reviews and comments on NUREG/CR-6151 and NUREG/CR-6181. At the full day meeting on November 9, 1995, Truong Vo, Bryan Gore, and Hahn Phan of PNNL went over additional details of PNNL's risk importance approaches which they have developed and have recently extended.

I was interested in carrying out this review because I was the originator of the risk importance methodology $(3,4,5)$ which is being applied and being extended by PNNL. I was also interested in PNNL's risk importance methodology because of its potential role in complementing the draft risk importance guidelines which I have recently helped to develop for the Office of Nuclear Reactor Regulation (NRR). Finally, since I am an advisor to the ASME on risk importance methods, I wanted to review PNNL's methodology as a basis for ASME applications.

As a summary of my review, I found that the PNNL methodology described in NUREG/CR-6151 and NUREG/CR-6181, which I will call the 6151/6181 methodology for short, is a valid methodology. However, the application of the $6151 / 6181$ methodology requires that the PRA satisfy certain constraints. The PNNL staff are aware of these constraints, but these constraints are not as clearly spelled out in the NUREG/CRs as they could be.

\footnotetext{
- Pacific Northwest National Laboratory is the recently expanded name for Pacific Northwest Laboratory in recognition of the Laboratory being formally designated a National Laboratory.
} 
Appendix B

To apply the $6151 / 6181$ methodology, the PRA has to be structured so that system importances are obtainable. If a system has different failure modes in the PRA, then the system importances for the different failure modes need to be probabilistically weighted. Alternatively, the different system importances can be bounded by the maximum system importance corresponding to a given failure mode.

If the component appears in different systems then the systems should not interact and should not appear in the same minimal cutset. When the systems do not interact then the system importances are additive as modeled in the 6151/6181 methodology. If the systems do interact, e.g. can provide the same function, then the user needs to treat the redundant systerns as a common system, i.e. must "AND" the system failures. Alternatively, the user can check if one system is a dominant contributor and use this system as the system containing the component.

The 6151/6181 methodology can thus be difficult to apply with current PRAs since the standard PRA output consists of component level information (component level minimal cutsets). System level information and system importances are not directly produced as part of the outputs. If the PRA output is not processed and restructured to satisfy the above constraints then erroneous results can be obtained from the $6151 / 6181$ methodology. This is not a problem with the methodology per se but with the application of the methodology.

The extended risk importance methodology which PNNL has recently developed uses component level information directly and does not have the constraints of the 6151/6181 methodology. Component prioritizations are not defined in terms of system importances but in terms of their direct contribution to core damage frequency or to another risk measure of interest. The component level minimal cutsets can thus be used directly, which incorporate the different possible system failure modes and system interactions. The appropriate component level failure probabilities need to be used in the formulas, however this is required for all PRA methods. Further details of my review of the 6151/6181 methodology and PNNL's extended methodology are described in the following paragraphs. 


\section{RISK IMPORTANCE METHODOLOGY IN NUREG/CR-6151 AND NUREG/CR-6181}

In NUREG/CR-6151 and NUREG/CR-6181 the importance $I_{w}$ of a given component, such as a pipe segment, in a given system is defined as

$$
\mathrm{I}_{\mathrm{w}}=\mathrm{I}_{\mathrm{B}} \cdot \mathrm{P}_{\mathrm{f}}
$$

where $I_{B}$ is the importance of the system and $P_{f}$ is the probability of failure of the component. The system importance $I_{B}$ is defined to be the increase in core damage frequency when the system is failed, which is more formally called the Birnbaum importance. The importances $I_{w}$ are used to initially identify the potentially risk important components and systems for which more detailed risk importance evaluations are then carried out.

The above formula is a conservative screening formula, as the NUREG/CRs state, which assumes that the component failure will cause system failure, i.e. that the component failure is a single failure of the system. For certain pipe segments, e.g. a single inlet supply line, this can be true. However, for other components which require additional component failures to fail the system, the imporance calculation given by Equation (1) will overstate the true component importance. However, this formula is only used to screen potentially important components for more detailed analysis. Hence, the formula is a valid screening equation.

The problem with applying the above equation is that PRAs do not generally provide the system importances $I_{B}$. Furthermore, the system importances cannot be directly obtained from the component level information, i.e. component level minimal cutsets", which do not give system contributions to core damage frequency but only the individual component contributions. The user must separate out these minimal cutsets which contain failures of components in the given system and then fail the appropriate components which cause the system failure. The minimal cutsets must then be requantified with these components set to a failed condition after eliminating logical redundancies in the minimal cutsets.

The above tasks which the user must carry out are not simple or direct. Furthermore, if different system failure modes are modeled in the PRA then the user must separate the minimal cutsets according to the different system failure modes. The highest system importance for the different system failure modes can then be used as the bounding system importance. If the

\footnotetext{
- A minimal cutset is a smallest combination of component failures resulting in core damage frequency.
} 
Appendix B

component appears in multiple systems, then the above process must be repeated for the different systems, and the highest system importance across the different systems can be used as the bounding system importance.

The detailed risk importance formula to be used after components are screened is given in NUREG/CR-6181 as

$$
\mathrm{P}_{\mathrm{cm}}=\mathrm{P}_{\mathrm{f}} * \sum_{\mathrm{i}} \mathrm{P}_{\mathrm{cm} / \mathrm{s}_{\mathrm{i}}} * \mathrm{P}_{\mathrm{s}_{\mathrm{i}}} / \mathrm{P}_{\mathrm{f}} * \mathrm{R}_{\mathrm{i}}
$$

where

$$
\begin{aligned}
& P_{c m}=\quad \begin{array}{l}
\text { the probability of core melt (core damage) resulting from } \\
\text { component failure }
\end{array} \\
& P_{f}=\quad \text { the probability of component failure } \\
& P_{c m / s}=\text { the conditional probability of core melt given system failure } \\
& P_{s_{i}} / P_{f}=\text { the conditional probability of system failure given component } \\
& R_{i}=\quad \text { failure } \\
& \text { the probability that the operator fails to recover given the system }
\end{aligned}
$$

Equation (2) gives the component failure contribution to core melt frequency in terms of the component failure contribution to system failure and the system failure contribution to the core melt frequency. When the conditional probabilities are taken to be the increases in probabilities due to the respective failures then the above formula is the standard formula for the contribution of the component failure to the core melt frequency. This can be seen from a simple example.

Let the core melt frequency $\mathrm{P}_{\mathrm{CMF}}$ be given in terms of the system failure probabilities as

$$
P_{C M F}=\Lambda P_{s_{1}} P_{s_{2}}+\Lambda P_{s_{3}} P_{s_{4}}
$$


where $\Lambda$ is the initiating event frequency and $P_{s_{i}}$ are the system failure probabilities. We only consider one initiating event but the same argument would apply to different initiating events.

Assume the particular component to be prioritized is in system $s_{1}$. Call this component $c_{1}$. Let the system failure probability $\mathrm{P}_{\mathrm{s}_{1}}$ in terms of the component failure probabilities $\mathrm{p}_{\mathrm{c}_{i}}$ be

$$
\mathrm{P}_{s_{1}}=\mathrm{p}_{\mathrm{c}_{1}} \mathrm{p}_{\mathrm{c}_{2}}+\mathrm{p}_{\mathrm{c}_{3}}
$$

where $c_{2}$ and $c_{3}$ are other components in the system. The failure probabilities are assumed to include the nonrecovery probabilities for not restoring the system failure.

The conditional probabilities required by Equation (2) are obtained by setting the respective contributor probability to 1 . The contributions containing the particular system or component are then retained to give the increase in the probability: Thus

$$
\begin{aligned}
& P_{c m / s_{1}}=\Lambda P_{s_{2}} \\
& P_{s_{1}} / P_{c_{1}}=P_{c_{2}} .
\end{aligned}
$$

Then, using Equation (2) we have

$$
\begin{aligned}
P_{c m} & =p_{c_{1}} \Lambda P_{s_{2}} p_{c_{2}} \\
& =\Lambda P_{s_{2}} p_{c_{1}} p_{c_{2}}
\end{aligned}
$$

which is the contribution to the core melt frequency from those minimal cutsets containing $c_{1}$. The standard PRA outputs would also expand $\mathrm{P}_{\mathrm{s}_{2}}$ in terms of its component failure probabilities but the same numerical result would be obtained.

If the total conditional probabilities are used without isolating the contributions (without subtracting the probability with the contributor set to zero) then the risk importance obtained

\footnotetext{
- Note this is the same as subtracting the core melt or system failure probability with the contributor probability set to zero as described in Reference 3.
} 
$\left(P_{\mathrm{cm}}\right)$ will be conservative. This conservatism will generally be small for the risk important contributors.

The problem with Equation (2) which is given by NUREG/CR-6181 is again its difficulty for application using current PRAs. Current PRAs do not express the core melt frequency (core damage frequency) in terms of system failure probabilities as in Equation (8) but only in terms of component failure probabilities. To obtain the system importances $P_{c m} / s_{i}$ the component level minimal cutsets need to be sorted to identify those minimal cutsets containing components in the given system. If the system has different failure modes then $P_{c m} / s_{i}$ needs to be determined for each system failure mode.

Equation (2) also treats different system contributions which contain the same component as being additive since the sum is over the different systems $\mathrm{s}_{\mathrm{i}}$. If the different systems interact then the systems which are redundant need to be treated as one system. In our example this means that if component $c_{1}$ appears in both system $s_{1}$ and system $s_{2}$ they need to be treated as one redundant system and $\mathrm{P}_{s_{1}} \mathrm{P}_{\mathrm{s}_{2}}$ being used as its failure probability. Of course, the appropriate component failure probabilities must also be used in the formula, which are component unavailabilities for safety standby components. Thus because system importances and system contributions are not provided in current PRAs, application of Equation (2) is not necessarily simple or direct.

\section{PNNL'S EXTENDED RISK IMPORTANCE METHODOLOGY}

PNNL'S extended risk importance methodology calculates the component risk importance, e.g. the component contribution to core melt frequency, directly. System contributions and system importances are not utilized. If $\mathrm{P}_{\mathrm{cm}}$ is the contribution of the component failure to core melt frequency as in Equation (2) then $P_{\mathrm{cm}}$ is calculated as

$$
P_{c m}=P_{c m / c} * P_{f}
$$

where

$$
\begin{aligned}
& P_{c m / c}=\text { the conditional probability of core melt given the component } \\
& \text { failure }
\end{aligned}
$$


$P_{f}=\quad$ the probability of component failure.

The nonrecovery probability for the component failure is incorporated in the conditional probability of core melt $\mathrm{P}_{\mathrm{cm} / \mathrm{c} \text {. }}$.

Equation (14) uses the component level minimal cutsets directly in determining $P_{\mathrm{cm} / \mathrm{c}}$ and no system importances are required. The equation thus uses standard methodology. If $P_{\mathrm{cm} / \mathrm{c}}$ is interpreted to be the increase in core melt frequency from the component failure then $P_{\mathrm{cm}}$ is the sum of minimal cutset contributions containing the component failure.

The component importance $P_{\mathrm{cm}}$ is calculated using Equation (14) since it allows a surrogate component to be failed for the given component when the given component, e.g. a pipe segment, is not explicitly modeled in the PRA. A failure of a surrogate component in the same train or line as the given component produces the same conditional core melt probability $P_{\text {crn/c }}$. The appropriate component failure probability $\mathrm{P}_{f}$, e.g. a pipe segment failure probability, can then be used to multiply $P_{c m / c}$ to give the minimal cutset contributions adjusted for the particular component failure probability. Equation (14) can also be appropriately applied to give the importances of components whose failure causes an initiating event as well as causing a train or line to be unavailable. 
Appendix B

\section{REFERENCES}

1. T.V. Vo, B.W. Smith, F.A. Simonen, B.F. Gore, "Feasibility of Developing Risk-Based Rankings of Pressure Boundary Systems for Inservice Inspection", NUREG/CR-6151, August 1994.

2. T. Vo, B. Gore, F. Simonen, S. Doctor, "A Pilot Application of Risk-Based Methods to Establish Inservice Inspection Priorities for Nuclear Components at Surry Unit 1 Nuclear Power Station", NUREG/CR-6181, August 1994.

3. W.E. Vesely and T.C. Davis, "Measures of Risk Importance and Their Application", NUREG/CR-3385, July 1983.

4. W.E. Vesely, T.C. Davis, N. Saltos, "Measures of the Risk Impacts of Testing and Maintenance Activities", NUREG/CR-3541, November 1983.

5. W.E. Vesely and T.C. Davis, "Evaluations and Utilizations of Risk Importances", NUREG/CR-4377, August 1985. 


\begin{tabular}{l}
$\begin{array}{l}\text { NRC FORM } 335 \\
\text { (2.89) } \\
\text { NAC.M 1102. } \\
3201.3202\end{array}$ \\
$\begin{array}{l}\text { BIBLIOG. NUCLEAR REGULATORY COMMISSION } \\
\text { (See instructions on the reverse) }\end{array}$ \\
\hline
\end{tabular}

2. TITLE AND SUBTITLE

A Pilot Application of Risk-Informed Methods to Establish Inservice Inspection Priorities for Nuclear Components at Surry Unit 1 Nuclear Power Station

5. AUTHOR(S)

T.V. Vo, H.K. Phan, B.F. Gore, F.A. Simomen, S.R. Doctor

REPORT NUMBER

(Axaigned by NRC Ada Vol. Suop., Fev. and Adondum Numbers, it iny.l

NUREG/CR-6181, Rev. 1 PNNL-9020, Rev. 1

3.

February 1997

4. FIN OR GRANT NUMBER B2289

6. TYPE OF REPORT

Technical

7. PEAIOD COVERED /NCLUsive Dares"

$10 / 89-1 / 97$

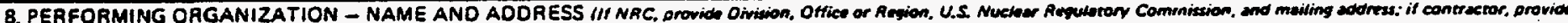
nempe end mailing edoivesel

Pacific Northwest National Laboratory

Richland, WA 99352

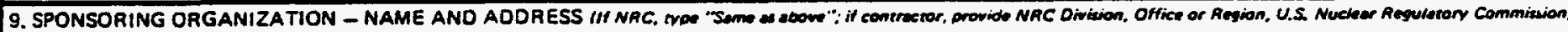
and madifing oddroces,

Division of Engineering Technology

Office of Nuclear Regulatory Research

U.S. Nuclear Regulatory Commission

Washington, DC 20555-0001

10. SUPPLEMENTARY NOTES

J. Muscara, NRC Project Manager

11. ABSTRACT 1200 mords or inst

As part of the Nondestructive Evaluation Reliability Program sponsored by the U.S. Nuclear Regulatory Commission, the Pacific Northwest National Laboratory has developed risk-informed approaches for inservice inspection plans of nuclear power plants. This method uses probabilistic risk assessment (PRA) results to identify and prioritize the most risk-important components for inspection. The Surry Nuclear Power Station Unit 1 was selected for pilot application of this methodology. This report, which incorporates more recent plant-specific information and improved risk-informed methodology and tools, is Revision 1 of the earlier report (NUREG/CR-6181). The methodology discussed in the original report is no longer current and a preferred methodology is presented in this Revision. This report, NUREG/CR-6181, Rev. 1, therefore supersedes the earlier NUREG/CR-6181 published in August 1994. The specific systems addressed in this report are the auxiliary feedwater, the low-pressure injection, and the reactor coolant systems. The results provide a risk-informed ranking of components within these systems.

nondestructive evaluation, probabilistic risk assessment, ASME Code, inservice inspection, welds, piping systems, Inspection Importance, pressure boundary systems, risk-based, Surry-1, risk-informed, risk achievement worth

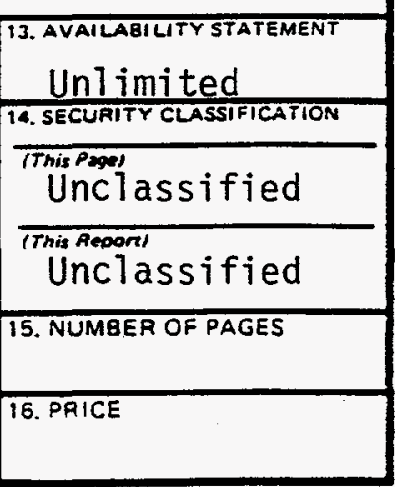

